Aus der Klinik für Neurologie

(Prof. Dr. med. M. Bähr)

im Zentrum Neurologische Medizin

der Medizinischen Fakultät der Universität Göttingen

\title{
Gesteigerte hippokampale Neurogenese nach experimenteller bakterieller Meningitis \\ mit Streptococcus pneumoniae
}

\author{
INAUGURAL - DISSERTATION \\ zur Erlangung des Doktorgrades \\ der Medizinischen Fakultät der \\ Georg-August-Universität zu Göttingen
}

\author{
vorgelegt von \\ Judith Bering \\ aus \\ Kassel
}

Göttingen 2014 
Dekan:

Prof. Dr. rer. nat. H. K. Kroemer

I. Berichterstatter: Prof. Dr. med. J. Gerber

II. Berichterstatter: PD Dr. F. Lühder

III. Berichterstatter: Prof. Dr. R. Mausberg

Tag der mündlichen Prüfung: 08.12.2014 


\section{INHALTSVERZEICHNIS}

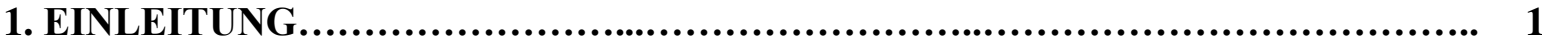

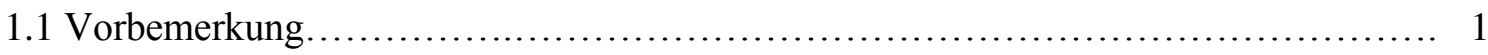

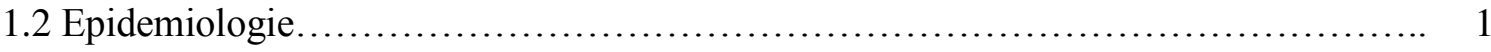

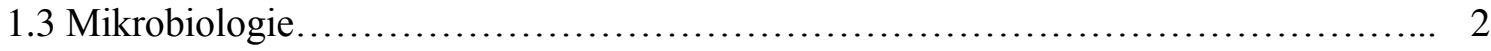

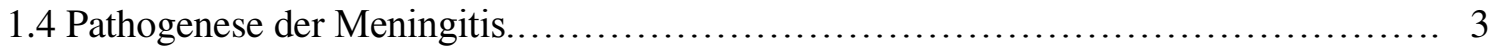

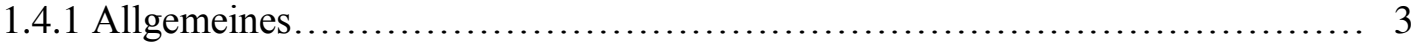

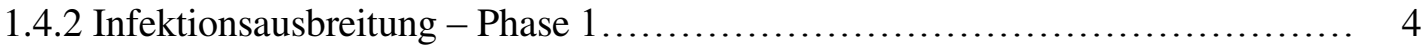

1.4.3 Matrix-Metalloproteinasen............................................ 5

1.4.4 Abwehrreaktionen des ZNS nach Erregerinvasion - Phase 2............... 6

1.4.5 Übersicht über die Pathogenese der bakteriellen Meningitis.................. 6

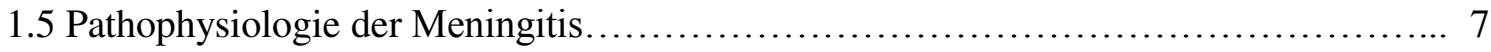

1.5.1 Allgemeines........................................................ 7

1.5.2 Erreger-spezifische Infektions-Induktion.............................. 7

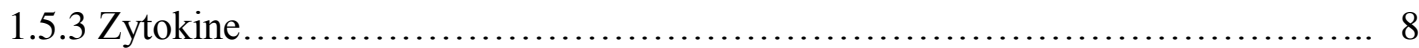

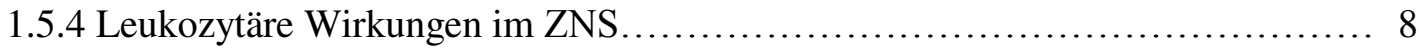

1.5.5 Zerebrale Zellschäden und Komplikationen.................................. 9

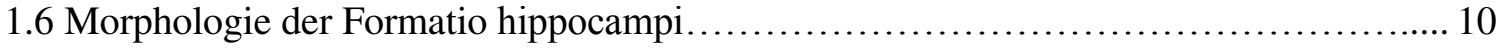

1.7 Spätschäden nach bakterieller Meningitis........................................ 12

1.7.1 Allgemeines............................................................ 12

1.7.2 Neurologische Komplikationen der bakteriellen Meningitis ................................ 14

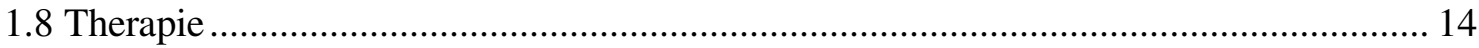

1.8.1 Antibiotische Therapie der bakteriellen Meningitis....................................... 14

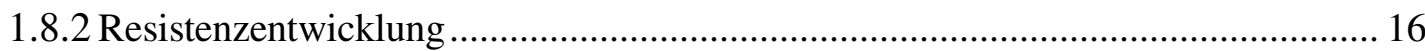

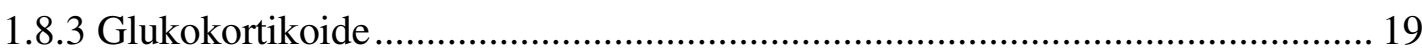

1.8.4 Antiinflammatorische Behandlung und experimentelle Therapieansätze............... 20

1.8.5 Vorgehen bei Verdacht auf bakterielle Meningitis............................................... 21

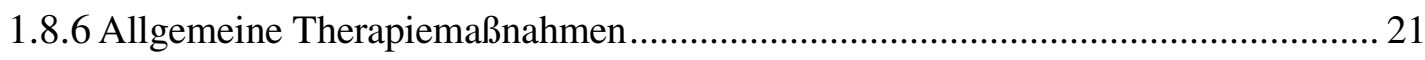

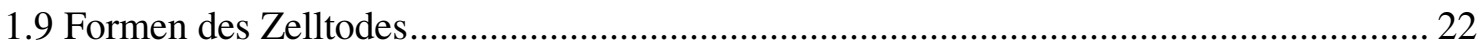

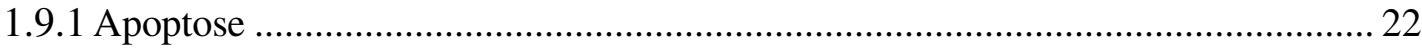

1.9.2 Nekrose

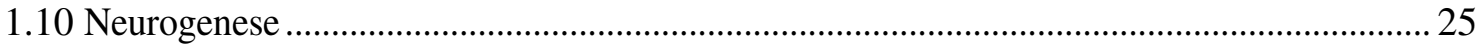

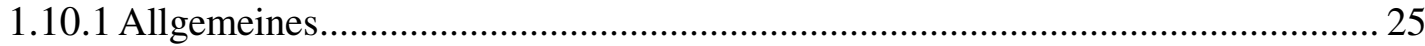

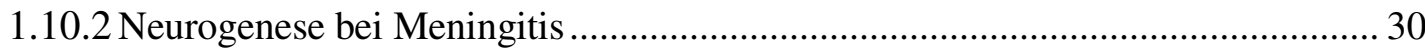

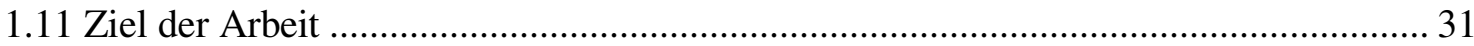




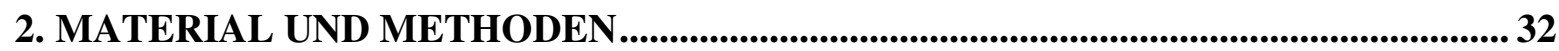

2.1 Tiermodelle

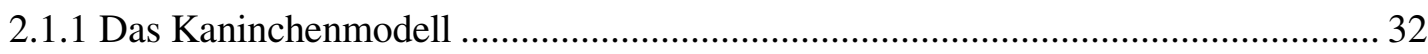

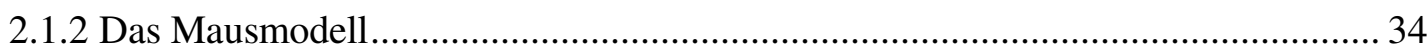

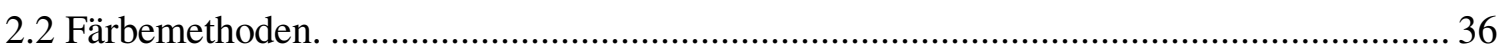

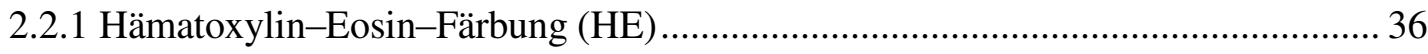

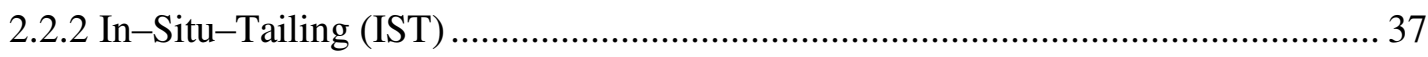

2.2.3 Anti-Bromdesoxyuridin-Färbung (Anti-BrdU) ….............................................. 39

2.3 Quantifikation der apoptotischen und BrdU-markierten Zellen ....................................... 41

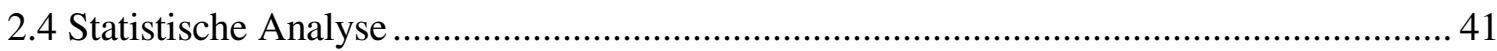

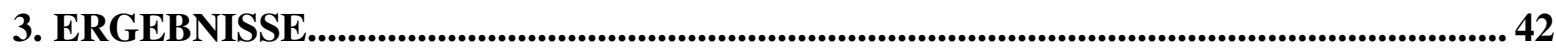

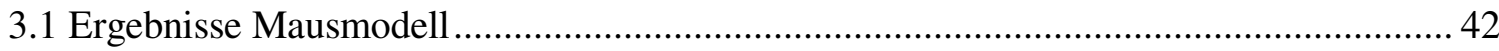

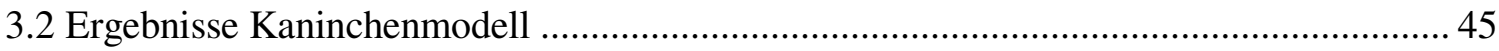

3.2.1 Entzündungsparameter im Liquor. ...................................................................... 45

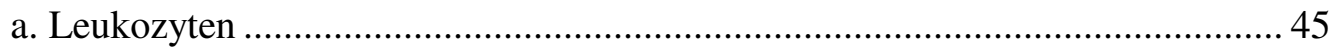

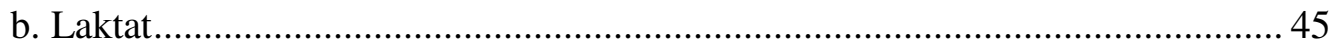

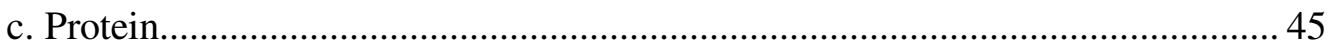

3.2.2 Apoptosen im Gyrus dentatus des Hippokampus .................................................. 46

3.2.3 Neurogenese im Gyrus dentatus des Hippokampus ............................................. 47

3.3 Tabellarische Übersicht der Laborwerte im Kaninchenmodell......................................... 48

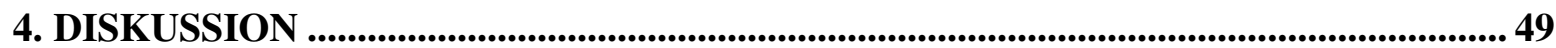

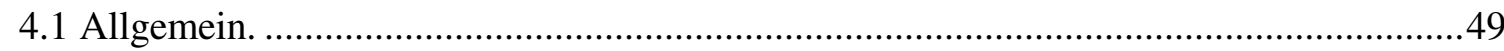

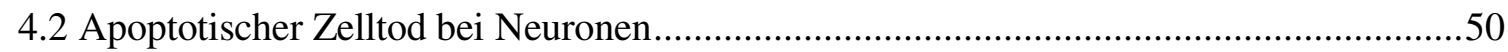

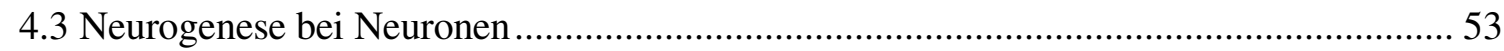

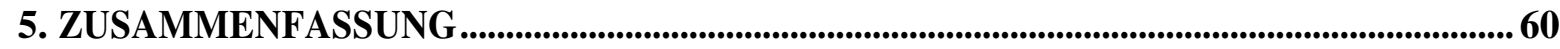

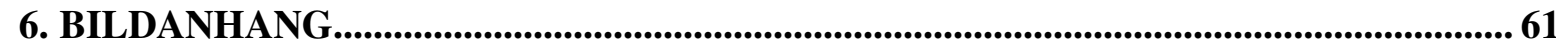

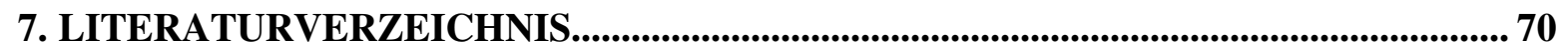




\section{ABKÜRZUNGSVERZEICHNIS}

Aqua bidest.

Aqua dest.

APAAP

ATP

BCIP

$\mathrm{Bcl}-2$

BDNF

BrdU

$\mathrm{Ca}^{2+}$

$\mathrm{CD}$

$\mathrm{CFU}$

$\mathrm{CoCl}_{2}$

$\mathrm{DAB}$

DIG-DNA

DNA

EGF

et al.

Fas/APO-1

FCS

FGF-2

FITC

$\mathrm{H}_{2} \mathrm{O}$

$\mathrm{H}_{2} \mathrm{O}_{2}$

ICE

IGF-1

IL-1

IL-6

IL-8

LPS

LTA

MAP-2

$\mathrm{Mg}^{2+}$

$\mathrm{MgCl}_{2}$ zweifach destilliertes Wasser

destilliertes Wasser

Alkalin-Phosphatase/Anti-Alkalin-Phosphatase

Adenosintriphosphat

5-Bromin-4-Chlorid-3-Indolyl-Phosphat

B-cell lymphoma-2

brain-derived neurotrophic factor

5-Brom-2-Desoxyuridin

Kalzium

cluster of differentiation

colony-forming units

Cobalt-Chlorid

3,3-Diaminobenzidin

Digoxigenin-markierte Desoxyribonucleinsäure

Desoxyribonucleinsäure

epidermal growth factor

und andere (et alii)

Fas-Rezeptor/apoptosis antigen-1 (= CD-95)

fetales Kälberserum

fibroblast growth factor 2

Fluorescein Isothiocyanat

Wasser

Wasserstoffperoxid

interleukin-1 $\beta$-converting enzyme

insulin-like growth factor

Interleukin-1

Interleukin-6

Interleukin-8

Lipopolysaccharid

lipoteichon acid, Lipoteichonsäure

microtubule associated protein-2

Magnesium

Magnesiumchlorid 


\begin{tabular}{|c|c|}
\hline MIP-1, MIP-2 & Makrophagen-inflammatorisches-Protein-1 und -2 \\
\hline MMP & Matrix-Metalloproteinasen \\
\hline $\mathrm{n}$ & Anzahl \\
\hline $\mathrm{NaCl}$ & Natriumchlorid \\
\hline $\mathrm{Na}^{+} / \mathrm{K}^{+}-\mathrm{ATPase}$ & Natrium-Kalium-Pumpe (arbeitet unter Verbrauch von ATP) \\
\hline NBT & 4-Nitroblue-Tetrazolium-Chlorid \\
\hline NGF & nerve growth factor \\
\hline NUR-77 & nuclear receptor, Steroid-Rezeptor in Thymozyten \\
\hline $\mathrm{p}$ & Signifikanzwert (probability) \\
\hline PAF & Plättchen-aktivierender-Faktor \\
\hline PBN & $\alpha$-tert-phenyl-butyl-nitron \\
\hline PBS & phosphate buffered saline \\
\hline SVZ & subventrikuläre Zone des Seitenventrikels \\
\hline TA & teichon acid, Teichonsäure \\
\hline TBS & tris buffered saline \\
\hline TNF- $\alpha$ & Tumor-Nekrose-Faktor $\alpha$ (Kachektin) \\
\hline TNFR-1 & Tumor-Nekrose-Faktor-Rezeptor-1 (= CD-120a) \\
\hline \multirow[t]{2}{*}{ TUC } & (TOAD [Turned On After Division]/Ulip/CRMP [Collapsin \\
\hline & response mediator protein]) \\
\hline u. a. & unter anderem \\
\hline wnt & wingless-type \\
\hline z. B. & zum Beispiel \\
\hline ZNS & Zentrales Nervensystem \\
\hline $\mathrm{z}-\mathrm{VAD}-\mathrm{fmk}$ & carbobenzoxy-valyl-alanyl-aspartyl-[O-methyl]- \\
\hline & fluoromethylketone, Pan-Caspase-Inhibitor \\
\hline
\end{tabular}




\section{EINLEITUNG}

\subsection{Vorbemerkung}

Mit einer Inzidenz von 2,6-6 Fällen pro $10^{5}$ Einwohner pro Jahr in den Industrieländern (geschätzt bis zu zehn Mal so hoch in den Entwicklungsländern) stellt die bakterielle Meningitis auch heute noch eine weltweit häufig vorkommende Erkrankung dar (Weisfelt et al. 2006). Trotz stetiger Fortschritte in der Diagnostik und Therapie ist sie weiterhin mit einer sehr hohen Letalität behaftet. Durch die Entwicklung der antibiotischen Therapie konnte die Letalität, die in der Ära zuvor zwischen 70 und $100 \%$ betrug, zwar drastisch gesenkt werden, sie beträgt allerdings für die bakterielle Meningitis weiterhin 5-30\% (Block und Nolden-Koch 2000, Swartz 1984). Die durch Streptococcus pneumoniae ausgelöste Meningitis endet in etwa 20\% der Fälle tödlich (Wenger et al. 1990). Die Hälfte der überlebenden Patienten trägt neurologische Spätschäden in Form von Schwindel (23\%), Müdigkeit (22\%), Gedächtnisstörungen (21\%), Gangataxie (18\%), Kopfschmerzen, Epilepsie, Paresen oder Tremor davon (Bohr et al. 1984). Bei Kindern kommt es in $10 \%$ der Fälle bei bakterieller Meningitis zu bleibenden Hörverlusten, bei den von Streptococcus pneumoniae betroffenen Kindern sogar in 31\% (Dodge et al. 1984). Einen wesentlichen Faktor für die immer noch recht dramatischen Auswirkungen stellt die zu späte Erkennung und daraus resultierend ein verzögerter Behandlungsbeginn dar (Block und Nolden-Koch 2000).

\subsection{Epidemiologie}

Risikofaktoren für das Auftreten einer bakteriellen Meningitis wurden in zahlreichen Studien untersucht. So bleibt das Alter der Patienten der wichtigste einzelne Risikofaktor, der identifiziert werden konnte. Die höchste Inzidenz aller Formen der bakteriellen Meningitis findet sich bei Kindern im Alter unter einem Jahr, sie beträgt 10-100/10 (Schlech 1992, Wenger et al. 1990). Die Inzidenzraten aller Formen der bakteriellen Meningitis, außer der Neisseria meningitidisbedingten Meningitis, zeigen einen Wiederanstieg in der dritten Dekade. Sie erreichen jedoch nie die Raten, wie sie bei Kindern unter einem Jahr zu sehen sind. Der Inzidenz-Anstieg der bakteriellen Meningitis beim älteren Patienten ( $>60$ Jahre) mag nicht nur allein altersbedingt, sondern die Folge additiver immunsuppressiver Faktoren sein. Diese prädisponieren nicht nur zu einer bakteriellen Meningitis sondern auch zu anderen invasiven bakteriellen Infektionen (Schlech 1992).

Splenektomierte Patienten haben ein deutlich erhöhtes Risiko für eine Pneumokokken-Sepsis beziehungsweise -Meningitis. Patienten, die einen Komplementfaktor-Mangel aufweisen (C5-9), sind stärker gefährdet, an einer Meningokokken-Meningitis zu erkranken. Weiterhin konnten saisonale Unterschiede im Auftreten der verschiedenen bakteriellen Meningitiden gefunden wer- 
den (Schlech 1992, Wenger et al. 1990); Hämophilus influenzae-Infektionen finden sich vermehrt im späten Herbst und frühen Frühling während Neisseria meningitidis in den Wintermonaten häufiger auftritt. Trotz der Verfügbarkeit effektiver antibiotischer Therapien, bleiben die Mortalitätsund Morbiditätsraten bei bakterieller Meningitis hoch. Die Mortalität hängt hierbei deutlich mit dem Alter der Patienten zusammen; sie ist am höchsten bei Neugeborenen und Patienten über 45 Jahren.

Streptococcus pneumoniae stellt nach wie vor den häufigsten Erreger der bakteriellen Meningitis bei Erwachsenen im Alter von über 30 Jahren dar. Die Inzidenz liegt bei ca. 1 Fall pro $10^{5}$ Einwohner, die höchste Rate findet sich im Alter von 6 Monaten (30 Fälle/10 $0^{5}$ ) und fällt dann bis zu einem Alter von 20-29 Jahren auf 1 Fall pro $10^{5}$ Einwohner ab. Außerdem findet sich hier eine höhere Mortalität als bei Infektionen mit Hämophilus influenzae oder Neisseria meningitidis (Schlech 1992).

\subsection{Mikrobiologie}

Bei der Betrachtung des Erregerspektrums der bakteriellen Meningitis lässt sich feststellen, dass eine relativ kleine Anzahl von Mikroorganismen die Auslöser der meisten Fälle von Meningitis darstellen. Die häufigsten Erreger sind Streptococcus pneumoniae, Haemophilus influenzae, Neisseria meningitidis, Escherichia coli, Listeria monocytogenes und Staphylococcus aureus. Die nachfolgende Tabelle gibt einen Überblick über die am häufigsten auftretenden Erreger bei Neugeborenen, Kindern/Jugendlichen und Erwachsenen. Außerdem erweist sich eine Erweiterung der Einteilung um Meningitis bei immundefizienten Patienten, Erreger bei chronischen Meningitiden und posttraumatische Meningitis-Erreger als sinnvoll.

Infektionen des ZNS treten in 4\% der Fälle bei immundefizienten Patienten auf. Hierbei handelt es sich jedoch mehrheitlich um Hirnabszesse oder intraventrikuläre Katheter-assoziierte Infektionen, Meningitiden finden sich seltener. Die Inzidenz der akuten Meningitis nach Schädeltrauma liegt zwischen 0,2 und 18\% (Tenney 1986). Liegt eine Eröffnung des Liquorraumes vor, erleiden 3-50\% der Patienten eine posttraumatische Meningitis (Lau und Kenna 1986, Henry und Taylor 1978), Rhinorrhoe ist deutlich häufiger mit einer Infektion assoziiert als Otorrhoe. 


\begin{tabular}{|c|c|}
\hline Patientengruppen & Erregerspektrum \\
\hline \multirow[t]{3}{*}{ Neugeborene } & Streptococcus agalacticae (Gruppe B) \\
\hline & Escherichia coli \\
\hline & Listeria monocytogenes \\
\hline \multirow[t]{3}{*}{ Kleinkinder, Kinder und Jugendliche } & $\begin{array}{l}\text { Haemophilus influenzae (Тyp B) } \\
\text { (seit den frühen 1990-ern Impfung verfügbar) }\end{array}$ \\
\hline & Neisseria meningitidis \\
\hline & Streptococcus pneumoniae \\
\hline \multirow[t]{2}{*}{ Erwachsene } & Streptococcus pneumoniae \\
\hline & Neisseria meningitidis \\
\hline \multirow[t]{3}{*}{ Immundefiziente Patienten } & Streptococcus pneumoniae \\
\hline & Haemophilus influenza \\
\hline & Listeria monocytogenes \\
\hline \multirow[t]{4}{*}{ Chronische Meningitis } & Mycobacterium tuberculosis \\
\hline & Cryptococcus neoformans \\
\hline & Histoplasma capsulatum \\
\hline & Brucella \\
\hline \multirow[t]{8}{*}{ Posttraumatisch } & Streptococcus pneumoniae \\
\hline & Haemophilus influenzae \\
\hline & Streptococcus pyogenes \\
\hline & Neisseria meningitidis \\
\hline & Staphylococcus aureus \\
\hline & Escherichia coli \\
\hline & Klebsiella pneumoniae \\
\hline & Pseudomonas aeruginosa \\
\hline
\end{tabular}

(modifiziert nach Neu 1992)

1.4 Pathogenese der Meningitis

\subsubsection{Allgemeines}

Die akute bakterielle Meningitis gehört nach wie vor zu den wichtigsten Notfällen der Neurologie. Deshalb sind eine konsequent durchgeführte Diagnostik und rechtzeitig eingeleitete Therapie maßgeblich entscheidend für den Erfolg der Behandlung. Um eine Infektion des zentralen Nervensystems (ZNS) auslösen zu können, stehen den Erregern verschiedene Eintrittspforten zur Verfügung. Sie können auf hämatogenem Weg bei bestehender Bakteriämie, per continuitatem ausgehend von benachbarten Strukturen (Ohr, Orbita, Mastoid, Nasennebenhöhlen) beziehungs- 
weise direkt infolge offener Schädel-Hirn-Verletzungen oder neurochirurgischer Eingriffe in das ZNS gelangen.

Für die klinische Praxis hat sich folgende Einteilung bewährt:

(Faktoren, die auf bakterielle Genese einer Meningitis hinweisen)

$\diamond$ ambulant erworbene Meningitis (community-acquired):

begleitende Sinusitis, Pneumonie (Patienten mit Lobärpneumonie: Risiko $>10 \%$, zusätzlich Meningitis zu entwickeln), Tonsillitis, Otitis media, vorbekannte Kollagenose, chronische Hautläsionen, Osteomyelitis, Endokarditis, meningeale Kontinuitätsunterbrechungen infolge Schädelfrakturen oder Durafisteln

$\diamond$ nosokomial erworbene Meningitis:

Operationen mit Eröffnung der Schädelkalotte, vorhandene ventrikuläre Shunt-Systeme

$\diamond$ immunsupprimierte Patienten (Risikogruppen):

Alkoholabusus, Diabetes mellitus, HIV-Infektion, Medikamenteneinnahme, angeborene Komplementdefeke

Die zeitlichen Abläufe der Infektion mit Meningitis-Erregern können grundsätzlich in zwei Abschnitte unterschieden werden (Ring et al. 1996):

1. Beginn der Infektion über die nasopharyngeale Kolonisation bis zur Überwindung der BlutHirn-Schranke

2. entzündliche Vorgänge in Liquor und Parenchym nach Erregerinvasion

Die Möglichkeiten des Wirts, den eindringenden Erreger effektiv abzuwehren, beschränken sich fast ausschließlich auf Phase 1. Gelingt dem Keim ein Vordringen in den Subarachnoidalraum, findet sich dort initial eine lokale Immunschwäche bei erniedrigten Konzentrationen für Komplementfaktoren und Immunglobuline mit resultierend schwacher Phagozytose-Aktivität der Leukozyten (Tunkel et al. 1990).

\subsubsection{Infektionsausbreitung - Phase 1}

Normalerweise beginnt die Entwicklung einer community-acquired-Meningitis mit der Besiedelung des Nasen-Rachen-Raumes mit einem durch Tröpfcheninfektion übertragbaren Erreger. Diese Kolonisation kann asymptomatisch oder begleitet von einer unspezifischen Pharyngitis einhergehen (Ring et al. 1996). 
Will der Keim das Liquorsystem erreichen, muss er zunächst die Abwehrmechanismen des Wirts überwinden. Zur Adhäsion an das muköse Epithel nutzen die Bakterien entweder mukosaständige Rezeptoren für Kapselantigene (S. pneumoniae, N. meningitidis) oder Fimbrien (H. influenzae, N. meningitidis, E. coli) (Cundell et al. 1995). Sie sind nun den körpereigenen Abwehrmechanismen wie IgA-Sekretion, Lysozym und dem reinigenden Zilienschlag des Flimmerepithels ausgesetzt, denen sie zum Beispiel durch die Produktion von IgA1-Proteasen entgehen (Plaut 1983). Weiterhin scheinen einige Bakterien auch eine direkt schädigende Wirkung auf die Epithelzellen und ihre Zilien zu haben. So gelingt den Bakterien die Bindung an die Schleimhaut, die Penetration der mukösen Epithelzellen via phagozytotischer Vakuolen und sie gelangen auf die basolaterale Seite des Epithels (Quagliarello und Scheld 1992).

Mit Erreichen des hämatogenen Systems müssen sich die Bakterien den Barrieren des Blutes stellen. Im intravaskulären Raum beteiligt sich vor allem das Komplementsystem an der Abwehr der Bakteriämie, besonders via alternative Komplement-Kaskade, die keines spezifischen Antikörpers bedarf und sofort wirksam ist. Hier stellt die Polysaccharidkapsel der Bakterien den wichtigsten Virulenz-Faktor dar, denn sie schützt wirksam vor dem Angriff durch neutrophile Granulozyten und der Lyse durch die Komplementkaskade (Kornelisse et al. 1995). So wird das bakterielle Überleben gefördert und die Produktion einer hochwirksamen Bakteriämie vorangetrieben. Daher sind die üblichen Erreger einer bakteriellen Meningitis allesamt kapseltragend (Spellerberg und Tuomanen 1994).

Der nächste Schritt besteht im Übertritt der Erreger von der Blutbahn in den Subarachnoidalraum durch Überwindung der Blut-Liquor-Schranke. Als Eintrittspforte hierfür werden vor allem der Plexus choronoideus, die Sinus durae matris oder die Lamina cribrosa des Siebbeins diskutiert (Pfister et al. 1994, Tunkel et al. 1990). Auch hier scheinen adhäsive Pili eine entscheidende Rolle zu spielen. Pneumokokken gelangen nach Bindung an den Rezeptor für Plättchen-aktivierendenFaktor (PAF) durch die Endothelzellen (Cundell et al. 1995). Hierfür benötigen sie Cholinbindendes Protein A, welches sie an ihrer Oberfläche tragen (Rosenow et al. 1997). Cundell konnte zeigen, dass eine dosisabhängige Reduktion der Zelladhärenz von Pneumokokken durch Antagonisten am PAF-Rezeptor möglich ist (Cundell et al. 1995).

\subsubsection{Matrix-Metalloproteinasen}

Experimentell wurde die zentrale Rolle von Matrix-Metalloproteinasen (MMP) bei der Inflammation und Störung der Blut-Liquor-Schranke nachgewiesen (Paul et al. 1998, Leib et al. 2000). Es handelt sich um Zink-abhängige Endopeptidasen, die von endogenen Gewebsinhibitoren reguliert werden und Komponenten der extrazellulären Matrix verringern können. Sie sind an zahlreichen physiologischen (Wundheilung, Angiogenese) (Mignatti und Rifkin 1996) sowie pathophysiologischen Prozessen (Tumorwachstum, Metastasierung, rheumatoide Arthritis, zerebrale Ischämie) 
maßgeblich beteiligt (Cawston 1996, Rosenberg et al. 1996). Bei der bakteriellen Meningitis werden sie u. a. von Granulozyten gebildet, führen zu einem Zusammenbruch der Blut-HirnSchranke und zur Erleichterung der Leukodiapedese. Neben der Erhöhung von Zellzahl und Proteingehalt finden sich auch höhere Werte für MMP im Liquorpunktat. Die wichtigste Rolle beim Zelltransport über die Basalmembran spielt wahrscheinlich die MMP-9 (Azeh et al. 1998), die Erhöhung der MMP-8 scheint ein spezifisches Charakteristikum bei bakterieller Meningitis zu sein (Meli et al. 2002). Der genaue Pathomechanismus für die Überwindung der Blut-HirnSchranke ist jedoch nicht in allen Details bekannt.

\subsubsection{Abwehrreaktionen des ZNS nach Erregerinvasion - Phase 2}

Hat der Keim den Liquorraum erreicht, kann eine zunächst nahezu ungestörte Vermehrung stattfinden, weil eine Abwehr durch Immunglobuline oder Komplementfaktoren initial praktisch nicht vorhanden ist. Obwohl es mit Beginn der Entzündungsreaktion zu einem Anstieg der chemotaktischen Faktoren (z. B. Komplement-Faktor C5a) und damit zu einem Anstieg der Leukozytenzahl (besonders Granulozyten) im Liquor kommt, bleibt die Immunantwort des Wirts oft ineffektiv. Dies begründet sich darin, dass die Phagozytose-begünstigende Opsonierung der Bakterien aufgrund der geringen Komplementkonzentration nur ungenügend ist. Erst mit zunehmender Schrankenstörung durch die Entwicklung der Inflammation kann das Immunsystem im Liquor aktiv werden (Quagliarello und Scheld 1992).

1.4.5 Übersicht über die Pathogenese der bakteriellen Meningitis

\begin{tabular}{|l|l|l|}
\hline \multicolumn{1}{|c|}{ Weg } & \multicolumn{1}{|c|}{$\begin{array}{c}\text { Abwehrmechanismus } \\
\text { des Wirts }\end{array}$} & $\begin{array}{c}\text { Überwindung der } \\
\text { Abwehrmechanismen } \\
\text { durch die Bakterien }\end{array}$ \\
\hline $\begin{array}{l}\text { Besiedelung und Eindringen in } \\
\text { das muköse Epithel }\end{array}$ & $\begin{array}{l}\text { IgA-Sekretion, Epithelzelle, } \\
\text { Zilien-Aktivität }\end{array}$ & $\begin{array}{l}\text { IgA-Proteasen, adhäsive Pili, } \\
\text { Ziliostase }\end{array}$ \\
\hline intravasales Überleben & Komplement-System & Polysaccharidkapsel \\
\hline $\begin{array}{l}\text { Durchdringen der Blut-Hirn-- } \\
\text { Schranke }\end{array}$ & Endothelzelle & adhäsive Pili \\
\hline Vermehrung im Liquor & zunächst keine & bakterielle Replikation \\
\hline
\end{tabular}

(Quagliarello und Scheld 1992) 
1.5 Pathophysiologie der Meningitis

\subsubsection{Allgemeines}

Spricht man von einer bakteriellen Meningitis, so ist bei genauer Betrachtung eine Entzündung von Pia mater und Arachnoidea gemeint, die gemeinsam die beiden Membranen der Leptomeninx bilden. Sie umschließen den Subarachnoidalraum, der mit dem Liquor zerebrospinalis gefüllt ist. Obwohl die Entzündung prinzipiell den gesamten Bereich der Hirnhäute von Gehirn und Rückenmark betrifft, lassen sich oft erregerspezifische Schwerpunkte der Entzündung im Bereich der Hirnbasis sowie der Konvexität des Gehirns finden. Begleitend kann es zu einem direkten Befall benachbarter Hirnstrukturen und damit zum subduralen oder ventrikulären Empyem kommen. Häufiger jedoch finden sich sterile subdurale Ergüsse (Swartz 1984).

Die Anwesenheit lebender Bakterien führt nicht sofort zu Symptomen. Entzündliche Veränderungen im ZNS und die Ausbildung klinischer Symptome bedürfen einer bakteriellen Konzentration von mehr als $10^{5} \mathrm{CFU} / \mathrm{ml}$ (Tuomanen et al. 1985). Aufgrund der limitierten Abwehrmechanismen des Wirtes im Liquor können sich die Erreger nach Erreichen des Subarachnoidalraumes schnell vermehren und im Fall der Pneumokokken Titer bis zu 109 CFU/ml erreichen (Meli et al. 2002).

\subsubsection{Erreger-spezifische Infektions-Induktion}

Das Entzündungsgeschehen wird durch definierte Bakterienbestandteile ausgelöst und durch die Ausschüttung von Zytokinen aus Makrophagen, Endothel- und Gliazellen vorangetrieben. Hierbei stehen bei den gram-positiven Keimen, wie S. pneumoniae, Zellwandfragmente (Peptidoglykane, Lipoteichonsäure) als Auslöser im Vordergrund, z. B. durch Stimulation der LeukozytenRekrutierung in den Subarachnoidalraum (Tuomanen et al. 1995). Weiterhin verfügt S. pneumoniae über sogenannte Virulenzfaktoren wie Pneumolysin oder Hyaluronidase (Tuomanen et al. 1995, Kostyukova et al. 1995, Zysk et al. 2001). Die Virulenzfakoren erleichtern die Überwindung der Blut-Hirn-Schranke durch lokale Gewebsschädigung oder Erleichterung der Transzytose (Ring et al. 1998, Zhang und Tuomanen 1999) sowie die Ausbildung der Meningitis durch Herabsetzen von Komponenten der Extrazellulärmatrix (Kostyukova et al. 1995). Experimentell zeigte sich, dass eine Einleitung von Kapsel-Polysacchariden in die Lunge oder den Liquor über 12 Stunden keine Inflammation hervorriefen (Spellerberg und Tuomanen 1994). Im Gegensatz dazu bewirkt eine intrazisternale Gabe von Zellwand- oder -Subkomponenten eine Entzündungsreaktion, die die Pathophysiologie der natürlichen Erkrankung imitiert (Tuomanen et al. 1985). Gram-negative Bakterien ( $N$. meningitidis, H. influenzae, E. coli) induzieren die ZytokinSekretion insbesondere durch Endotoxine wie Lipopolysaccharid (LPS) sowie durch Zellwandbestandteile. Endotoxin wird von wachsenden oder sterbenden Bakterien und besonders während der 
Behandlung mit lytischen Antibiotika freigesetzt (Guerra-Romeo et al. 1992, Burroughs et al. 1992).

\subsubsection{Zytokine}

Nach Erkennen bakterieller Produkte im Subarachnoidalraum reagiert der Wirt mit der Freisetzung von Zytokinen und Chemokinen. Die wichtigsten Zytokine sind Tumor-Nekrose-Faktor $\alpha$ (Kachektin, TNF- $\alpha$ ), Interleukin-1 (IL-1) und Interleukin-6 (IL-6). Aber auch Chemokine wie Interleukin-8 (IL-8), Makrophagen-inflammatorisches-Protein-1 und -2 (MIP-1, MIP-2) sind proinflammatorisch wirksam. Produziert werden diese in Monozyten und Makrophagen, aber auch andere Zellen, wie z. B. Astrozyten und Mikrogliazellen des ZNS, können Zytokine bilden. Die Freisetzung dieser Substanzen induziert eine Leukozyteneinwanderung sowie eine erhöhte Permeabilität der Blut-Hirn-Schranke (Täuber und Moser 1999). Über die Induktion Endothelstämmiger Adhäsionsmoleküle (P-Selektin, E-Selektin) wird die Rekrutierung von Granulozyten gefördert (Tang et al. 1996).

Eine Hauptfunktion der Zytokin-Freisetzung ist die Rekrutierung von polymorphkernigen Leukozyten aus den Blutgefäßen. Die initiale reversible Bindung zwischen Leukozyten und GefäßEndothelzellen wird über Proteine der Selektin-Familie vermittelt (Springer 1990), deren Expression eine Folge der inflammatorischen Zytokin-Wirkung darstellt. Es resultiert eine Anlagerung der Leukozyten entlang der Gefäßwände, bekannt als ,leukocyte rolling“ (Lawrence und Springer 1991). Infolge der Verbindung zwischen Selektin und Leukozyten kommt es zu einer Hochregulation des Integrins CD 11b/CD 18 auf der Oberfläche der Leukozyten (Lo et al. 1991). Das CD 18 Adhäsions-Molekül vermittelt die stabile Verbindung der Granulozyten mit den Endothelzellen, welche notwendig für die Transmigration in das tiefere Gewebe ist.

\subsubsection{Leukozytäre Wirkungen im ZNS}

Die eingewanderten Leukozyten aber auch ZNS-stämmige Immunzellen produzieren und sezernieren toxische Stickstoff- und Sauerstoff-Metabolite sowie Proteasen. Diese Vorgänge werden ebenfalls durch Komplementfaktoren und Zytokine angeregt. Durch die genannten Sekretionsprodukte entsteht wiederum eine schädigende Wirkung auf die Endothelzellen der zerebralen Kapillaren, die einen wesentlichen Bestandteil der Blut-Hirn-Schranke darstellen. Die Literatur beschreibt, dass bei den in den Liquorraum eingedrungenen Leukozyten deren gewebsschädigende Wirkung gegenüber ihrem Nutzen überwiegt, da die Phagozytose im Subarachnoidalraum aufgrund des Antikörper- und Komplementmangels uneffektiv ist (Tuomanen 1994). 


\subsubsection{Zerebrale Zellschäden und Komplikationen}

Eine der wesentlichen lebensbedrohlichen Komplikationen der bakteriellen Meningitis ist die Ausbildung eines Hirnödems. Pathophysiologisch kann man differenzieren zwischen vasogenem, zytotoxischem und interstitiellem Ödem (Niemöller und Täuber 1989). Das vasogene Ödem, welches hauptsächlich in der weißen Substanz lokalisiert ist, findet sich infolge erhöhter Permeabilität der zerebralen Endothelzellen. Mit dem Öffnen der Blut-Hirn-Schranke bei der Transmigration der Leukozyten wird die Ausbildung des vasogenen Ödems noch gesteigert.

Das morphologische Korrelat des zytotoxischen Ödems ist die Schwellung glialer, neuronaler und endothelialer Zellen, induziert durch Toxin-Freisetzung aus Bakterien oder Leukozyten (Täuber et al. 1993).

Das interstitielle Ödem wird durch die verminderte Resorption von Liquor durch die Granulationen der Arachnoidea (Verklebungen) sowie durch eine Viskositätssteigerung der Zerebrospinalflüssigkeit verursacht und präsentiert sich mit einem erhöhten Liquor-Ausfluß-Widerstand (Scheld et al. 1980).

Während einer Pneumokokken-Meningitis treten alle drei Typen von Ödem auf. Die Entstehung des diffusen Hirnödems bewirkt einen schnellen Anstieg des intrakraniellen Druckes bis hin zu einem Einklemmungssyndrom. Das Hirnödem kann eine intrakranielle Hypertension nach sich ziehen, jedoch können auch beide unabhängig voneinander auftreten. In einem Ratten-Model mit Pneumokokken-Meningitis zeigten Täuber et al., dass die Gabe von Methylprednisolon das Hirnödem reduzierte, jedoch nur Dexamethason gleichzeitig einen positiven Effekt auf den intrakraniellen Druck hatte (Täuber et al. 1985). Die Ursache dafür ist möglicherweise in der vasokonstriktiven Wirkung auf die zerebrale Zirkulation gelegen.

Ein weiterer wichtiger Faktor bei der Entwicklung des neuronalen Schadens und der damit verbundenen Folgen ist die verminderte Autoregulationsfähigkeit des zerebralen Blutflusses. Während der experimentellen Pneumokokken-Meningitis bei Kaninchen kann ein langsamer Anstieg des intrakraniellen Druckes beobachtet werden, der in hämodynamischem Kollaps, kritischer Reduktion des zerebralen Perfusions-Druckes, zerebraler Ischämie und dem Tod der Tiere endet (Goitein und Shapiro 1992). In der frühen Phase der Erkrankung steigt der kortikale Blutfluss (Pfister et al. 1990), welcher jedoch im Verlauf in einer Minderperfusion mündet. Der Verlust der Autoregulationsfähigkeit des zerebralen Blutflusses erlaubt dem Perfusionsdruck des Gehirns, mit Veränderungen im Körperkreislauf zu schwanken. Außerdem kommt es zu entzündlichen Veränderungen der Gefäße. Diese Vaskulitis führt zu Leckagen, Stenosen und kompletten Gefäßverschlüssen. Weiterhin entwickeln sich Vasospasmen mit einer gestörten intravasalen Gerinnung, sekundären Hirninfarkten und Sinusvenenthrombosen (Tureen et al. 1990). Welche Faktoren im Einzelnen zu diesen Veränderungen führen, bleibt noch zu erforschen; als ein potentieller Faktor 
in dem komplexen Netzwerk der vaskulären Regulation wurde Neuropeptid Y beschrieben. Es handelt sich dabei um einen Neurotransmitter, dessen signifikanter Anstieg in der Medulla oblongata während der Pneumokokken-Meningitis beobachtet werden konnte. Insgesamt führen all diese Veränderungen der Perfusion wiederum zu einer Verstärkung des Hirnödems sowie zu unkontrollierten Durchblutungsstörungen mit Hyper- bzw. Hypoperfusion und Ausbildung neuronaler Schäden (Quagliarello und Scheld 1992). Der Mangel der zerebralen Durchblutung spiegelt sich im Anstieg des zerebrospinalen Laktats wieder.

Ebenfalls bei der bakteriellen Meningitis zu beobachten ist ein Anstieg der Konzentrationen für exzitatorische Aminosäuren, z. B. Glutamat, Aspartat, Glycin (Guerra-Romeo et al. 1993). Die Glucosekonzentration im Liquor fällt, während Proteingehalt und Leukozytenzahl ansteigen. Die Situation der Hyperexzitation kombiniert mit anaerobem Stressstoffwechsel und Azidose scheint einen weiteren Grund für den beobachteten Hirnschaden darzustellen. Während beim neuronalen Schaden, insbesondere der Formatio hippocampi, ein entscheidender Anteil den exzitatorischen Aminosäuren zuzukommen scheint (Leib et al. 1996a, Tumani et al. 2000), liegt den Läsionen im Neokortex wahrscheinlich eine Ischämie zugrunde (Leib et al. 1996a, Leib et al. 1996b).

Die Entzündung im Subarachnoidalraum ist gefolgt von Prozessen, die das Hirnparenchym betreffen. Die entzündliche Infiltration von großen und kleinen Arterien und Venen kann Thrombosen zur Folge haben (Adams et al. 1948, Cairns und Russell 1946). Fokale Nekrosen werden oft beobachtet und manchmal kommt es in Folge von Verschlüssen großer Arterien zu ausgedehnten Infarkten mit katastrophalen neurologischen Konsequenzen (Rorke und Pitts 1963). Angiographische Studien an lebenden Patienten dokumentierten die vaskulären Folgen der Inflammation (Igarashi et al. 1984).

\subsection{Morphologie der Formatio hippocampi}

Die Formatio hippocampi stellt einen Teil des limbischen Systems dar. Sie setzt sich aus Hippokampus, Gyrus dentatus und entorhinalem Kortex zusammen. Der Hippokampus legt sich der medialen Wand und dem Boden des Unterhornes des Seitenventrikels halbmondförmig an und wölbt sich in dessen Lumen vor. Er wird morphologisch in drei Abschnitte, den prä-, supra- und retrokommissuralen Hippokampus untergliedert. Die Bezeichnungen beziehen sich auf die Lage zum Corpus callosum. Während die ersten beiden Abschnitte relativ kleine, rudimentäre Strukturen darstellen, ist der retrokommissurale Anteil gut entwickelt. Er ist in drei Strukturen untergliedert: Fascia dentata, Cornu ammonis (Ammonshorn), Subiculum und bildet den größten Anteil der Hippokampusformation.

Das Cornu ammonis wird in vier unterschiedliche Regionen eingeteilt, CA1 bis CA4. Die Regionen des Hippokampus zeigen einen dreischichtigen Aufbau: Stratum oriens, Stratum pyramidale 
und Stratum moleculare (zellarm). Ebenfalls einen dreischichtigen Aufbau zeigt der Gyrus dentatus: polymorphe Schicht des Hilus, Stratum granulosum und Stratum moleculare, welches direkt in das Stratum moleculare des Hippokampus übergeht. Als Hilus bezeichnet man den Bereich zwischen Gyrus dentatus und CA3 (Bildanhang Abb. 1).

Die intrinsischen Verbindungen des Hippokampus sind sehr komplex. Der Hauptinformationsfluss erfolgt über einen trisynaptischen Leitungsbogen. Dieser beginnt mit einer Projektion der Area entorhinalis zur Fascia dentata, wird von den Körnerzellen des Gyrus dentatus umgeschaltet, gelangt über Moosfasern zu den Pyramidenzellen in CA3 des Cornu ammonis und verläuft über die Schaffer'schen Kollateralen weiter zu CA1. Eine Projektion von CA1 endet in der Area entorhinalis und schließt so den Schaltkreis.

Extrinsische Zuflüsse zum Hippokampus modulieren und aktvieren den intrinsischen Schaltkreis; die wichtigsten stammen aus einer Vielzahl kortikaler Gebiete, aus der septalen Region und dem Thalamus. Mit Bahnen aus den primären visuellen, akustischen, somästhetischen und olfaktorischen Gebieten gelangen alle sensorischen Modalitäten in die Formatio hippocampi.

Die wichtigste Efferenz des Hippokampus stellt der Fornix dar, dessen Hauptursprung im Subiculum liegt, ein geringer Anteil ist aus Fasern des Ammonshorns aufgebaut (Brown und Zador 1990).

Da der Hippokampus einen Teil des limbischen Systems bildet, spielt er eine zentrale Rolle bei kognitiven Fähigkeiten wie Informationsverarbeitung und Speicherung neuer Informationen, er ist an Lernvorgängen, der räumlichen und verbalen Erinnerung sowie Gedächtnisbildung beteiligt (Scoville und Milner 1957, Sherry et al. 1992).

Im Vergleich mit anderen Hirnregionen ist der Hippokampus besonders sensibel gegenüber Ischämien und anderen schädigenden Einflüssen (Zilles 1987). Hicks et al. zeigten einen signifikanten Zusammenhang zwischen neuronalen Verlusten im Hilus des Gyrus dentatus und der Gedächtnisleistung nach traumatischen Hirnschäden (Hicks et al. 1993).

Nau et al. demonstrierten an menschlichen Präparaten bei infolge Meningitis verstorbenen Patienten apoptotische Zelluntergänge in der Körnerzellschicht des Gyrus dentatus der Formatio hippocampi (Nau et al. 1999). Neuronale Apoptosen sind im Kaninchenmodell mit S. pneumoniae bereits nach 24 Stunden nachweisbar (Zysk et al. 1996), vorwiegend im Gyrus dentatus des Hippokampus lokalisiert und auch in anderen Tiermodellen (Ratte, Maus) darstellbar (Leib et al. 1996b, Nau et al. 1999). Somit stellen neuronale Schäden der Formatio hippocampi ein typisches Muster für eine bakterielle Meningitis dar. 


\subsection{Spätschäden nach bakterieller Meningitis}

\subsubsection{Allgemeines}

Überlebende einer bakteriellen Meningitis leiden häufig an Langzeit-Folgeschäden. Besonders oft handelt es sich hierbei um Defizite beim Lernen und der Gedächtnisbildung. Verschiedene Studien beschäftigten sich daher mit den potentiellen Folgeschäden einer bakteriellen Meningitis und den Möglichkeiten ihrer Reduktion.

Anhand eines Mausmodels von Wellmer et al. wurden die Defizite des räumlichen Gedächtnisses untersucht. Die Tiere wurden trainiert, eine versteckte Plattform in einem Wasserbehälter in weniger als 90 Sekunden zu erreichen. Die Gruppe der infizierten Tiere wurde mit einer gesunden Kontrollgruppe verglichen. Es konnte gezeigt werden, dass trotz antibiotischer Behandlung mit Ceftriaxon die Gruppe der post-Meningitis-Tiere deutlich länger brauchte, die Plattform zu erreichen (Wellmer et al. 2000).

Scott et al. zeigten in einer prospektiven Studie mit einem mittleren follow-up von 8,9 Jahren verschiedenste neurologische Schäden bei Kindern während und nach einer akuten bakteriellen Meningitis auf. In der Akutphase fielen 31\% der Patienten durch fokale, sekundär generalisierte oder generalisierte Anfälle auf. Die fokalen Anfälle zeigten hierbei oft multiple Foci oder eine wechselnde Betonung der Körperhälften. Einen Monat nach der Hospitalisation litten noch 37\% an transienten neurologischen Defiziten. Es handelte sich um transiente Hemiparesen (11\%), Ataxien (4\%), Hirnnerven-Defizite (3\%), gesteigerte Reflexe (2\%) oder kombinierte Hemiparesen mit Ataxie (0,5\%). Bei 45\% der Betroffenen waren die Pathologien innerhalb von 3 Monaten wieder regredient; innerhalb von 12 Monaten litten nur noch 2 von 69 Patienten an neurologischen Auffälligkeiten. Von den untersuchten 185 Patienten zeigten sich zum Zeitpunkt der letzten Untersuchung bei $14 \%$ persistierende neurologische Defizite. Am häufigsten handelte es sich um einen bleibenden Hörverlust als isolierter Ausfall (10\%), aber auch mentale Retardierung (IQ < 70\%), Hemiparese, Tetraparese oder Erblindung (4\%) wurden diagnostiziert (Scott et al. 1990).

In seltenen Fällen tritt eine Paralyse des N. facialis auf, die jedoch nahezu immer wieder vollständig zurückgeht (Dodge 1994).

Bezüglich der Folgeschäden am besten untersucht und am häufigsten auftretend ist der Hörverlust. Es konnte gezeigt werden, dass es hierbei erregerabhängig Unterschiede in der Inzidenz gibt. Patienten mit S. pneumoniae fielen durch die höchste Inzidenz mit $31 \%$ auf, gefolgt von N. meningitidis (10,5\%) und $H$. influenzae (6\%) (Kabani und Jadavji 1992). Insgesamt sind viele der neurologischen Abnormalitäten, die während der akuten Phase der Meningitis auftreten, im Verlauf komplett rückläufig oder weniger ausgeprägt. 
Während bei Kindern kognitive Defizite (vorherrschend persistierende Lernschwierigkeiten, Defizite des Kurzzeitgedächtnisses, Konzentrations- und Verhaltensstörungen, dürftigere akademische Leistung) nach bakterieller Meningitis beschrieben sind (Taylor et al. 1984, Anderson et al. 1997, Grimwood et al. 2000), wurden bei Erwachsenen bis 2006 nur 2 systematische follow-upStudien veröffentlicht (Merkelbach et al. 2000, van de Beek et al. 2002). Nachfolgend untersuchten unter anderem Schmidt et al. die neuropsychologischen Auswirkungen bakterieller Meningitis beim Menschen unter Einhaltung strikter Auswahlkriterien, um den Einfluss von Begleiterkrankungen auf die kognitive Leistung zu minimieren. Die in die Studie eingeschlossenen Patienten waren zwischen 15 und 70 Jahre alt und zeigten keinen Alkoholismus, neuropsychologische Erkrankungen oder Neoplasmen. Die Neubewertung der kognitiven Dysfunktionen nach LangzeitÜberleben (1-12 Jahre) einer bakteriellen oder viralen Meningitis zeigte eine schlechtere kognitive Funktion (Kurzzeit- und Arbeitsgedächtnis, assoziatives Lernen) der Patientengruppen im Vergleich mit einer dem Alter angepassten Kontrollgruppe gesunder Erwachsener (Schmidt et al. 2006).

Es gilt weiterhin zu bedenken, dass ernstliche Lebens-Einschnitte, wie z. B. eine Meningitis, kritische Langzeit-Auswirkungen auf die psychische Stabilität haben können (Twamley et al. 2004, Bremner et al. 2004) und die Ausbildung einer Depression negative Effekte auf die Kognition haben kann (Penick et al. 1994). Diese direkten und indirekten kognitiven Störungen sind schwer zu unterscheiden von primärem Schäden durch die Krankheit selbst (Schmidt et al. 2006). 
1.7.2 Neurologische Komplikationen der bakteriellen Meningitis

\begin{tabular}{|l|l|l|}
\hline \multicolumn{1}{|c|}{ Akut } & \multicolumn{1}{|c|}{ Subakut } & \multicolumn{1}{c|}{ Chronisch } \\
\hline $\begin{array}{l}\text { toxische Enzephalopathie } \\
\text { zerebrales Ödem }\end{array}$ & kortikale venöse Thrombosen & Arachnoiditis \\
Herniation & Aneurysmata & Lähmung Spinalwurzel/-nerv \\
zerebraler Infarkt & Taubheit \\
\hline
\end{tabular}

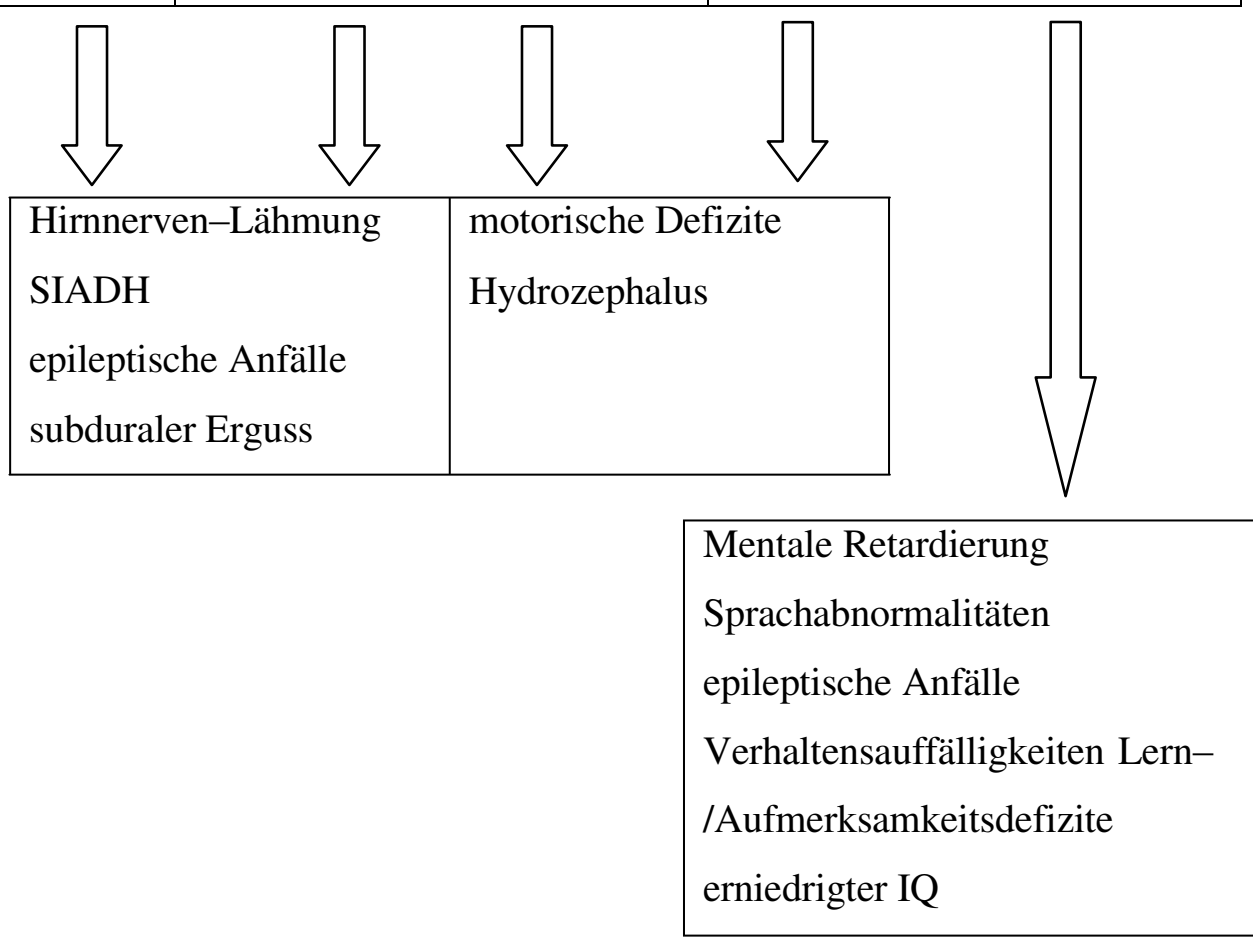

(Kabani und Jadavji 1992)

\subsection{Therapie}

\subsubsection{Antibiotische Therapie der bakteriellen Meningitis}

Das Ziel der antibiotischen Therapie der Meningitis ist eine schnelle Sterilisierung des Liquor zerebrospinalis. Bereits beim Vorliegen des rein klinischen Verdachtes auf eine bakterielle Meningitis ist die unverzögerte Einleitung einer antibiotischen Therapie zwingend indiziert.

Mit den eingesetzten Antibiotika ist ein direkter Angriff der Erreger sowie deren Elimination aus dem Subarachnoidalraum möglich, sie wirken zum Teil bakterizid, wie beispielsweise Penicilline, Cephalosporine oder auch Vancomycin. Aminoglykoside wirken zwar primär bakteriostatisch, entfalten aber auch eine sekundär bakterizide Wirkung. Der Wirkmechanismus dieser Chemotherapeutika liegt in der Hemmung der Zellwandsynthese beziehungsweise in der Störung der Membranpermeabilität. In Folge der frei werdenden Zellwandbestandteile kommt es zu einer Freisetzung proinflammatorischer Zytokine wie Endotoxine, Peptidoglykane, Lipoteichonsäure (LTA) oder Teichonsäure (TA). Durch diese Mediatoren wird die meningeale Entzündungsreakti- 
on - begleitet von Vaskulitiden und Thrombosen kleiner Hirngefäße - induziert, die in der Folge zu einer Erhöhung des intrakraniellen Druckes und zum Hirnödem führt (Nau et al. 1999, Täuber et al. 1985, Tuomanen et al. 1985). Eine zentrale Rolle bei diesen Abläufen spielen die Zytokine Interleukin-1 und TNF- $\alpha$. All dies erklärt, dass in Folge der antibiotischen Therapie Höchstwerte von proinflammatorischen Bakterienbestandteilen und Entzündungsparametern nachweisbar sind, die die Gesamtsituation der bakteriellen Meningitis noch verschlechtern.

Die Invasion und Expansion des Erregers im Subarachnoidalraum kann durch die rasche Gabe von Antibiotika gehemmt und damit die Prognose für den Erkrankten verbessert werden. Studien von Cartwright et al. sowie Strang und Pugh erbrachten den Beleg, dass durch eine bereits vor der Hospitalisation eingeleitete parenterale Antibiotikatherapie die Letalität der Menigokokkensepsis und -meningitis senkt (Cartwright et al. 1992, Strang und Pugh 1992).

Wichtig ist die Entnahme aerober und anaerober Blutkulturen, um nach Erregernachweis und Antibiogramm, welche zwei Tage nach Erregeranzucht vorliegen sollten, die Therapie entsprechend anzupassen. Die Blutentnahme muss dabei unbedingt vor der ersten Antibiotikumgabe durchgeführt werden, um die Erregeridentifikation zu ermöglichen. Bis zum Keimnachweis mittels Kultur muss der Behandelnde das in Frage kommende Erregerspektrum abschätzen und eine kalkulierte antibiotische Therapie einleiten.

Zudem sollte baldmöglichst eine Lumbalpunktion zur Erregeranzucht durchgeführt werden. Die mikroskopische Untersuchung des Gram-gefärbten Liquorpunktates ist notwendig, um eventuelle Bakterien zu identifizieren und damit die bakterielle Infektion zu bestätigen. Studien haben gezeigt, dass bei ca. $75 \%$ der Patienten, bei denen der spätere Befund der Bakterienkultur positiv ausfiel, bereits anhand der Gram-Färbung die bakterielle Genese der Meningitis gesichert werden konnte (Karandaris und Shulman 1976, Kristiansen et al. 1991). Neben der klinischen Symptomatik stehen noch einige laborchemische Parameter, wie zum Beispiel die Liquor-Leukozytose, eine erhöhte Liquor-Laktat-Konzentration, Veränderungen im Liquor-Gesamteiweiß- und LiquorGlukosegehalt, zur Diagnosefindung zur Verfügung (Schmidt und Nau 2004).

Alter und Immunstatus des Patienten stellen entscheidende Kriterien dar, nach denen sich die Wahl der Therapie richtet. Seit der Einführung des Impfstoffes gegen Haemophilus influenzae nimmt die Häufigkeit der durch ihn hervorgerufenen Meningitiden ab. Streptococcus pneumoniae und Neisseria meningitidis stellen im Erwachsenenalter die häufigsten ursächlichen Keime dar, im Kindes- und Jugendalter in umgekehrter Reihenfolge. Bei Infektionen außerhalb der Klinik sind in Deutschland ebenfalls am häufigsten Pneumokokken als Auslöser zu verifizieren. Immundefiziente Patienten sind weiterhin anfälliger für Infektionen mit Listerien. Andere Keime, wie zum Beispiel Staphylococcus aureus, Escherichia coli, Pseudomonas aeruginosa, Mykobakterien oder 
Pilze zählen zu den seltenen Meningitiserregern. Die kalkulierte Therapie sollte deshalb die oben genannten, am wahrscheinlichsten ursächlichen Keime abdecken.

\subsubsection{Resistenzentwicklung}

$\mathrm{Zu}$ einem immer größer werdenden Problem bei der Therapie der bakteriellen Meningitis mit Antibiotika entwickeln sich die zunehmenden Resistenzen der Erreger. Beispielsweise sind Neisserien in Nord- und Mitteleuropa gut empfindlich auf Penicillin G während sich in Südeuropa vermehrt Resistenzen nach unkritischem Gebrauch zeigen. Nahezu 50\% der MeningokokkenStämme sind dort nicht mehr mit Penicillin G therapierbar (Tzanakaki et al. 1992).

Betrachtet man die Resistenzlage bei Streptococcus pneumoniae, so ist die Situation noch alarmierender: in Süd- und Westeuropa sind sowohl Penicillinresistenzen, als auch intermediäre Resistenzen gegen Drittgenerations-Zephalosporine bekannt (Pineda et al. 2002). Darum sollte hier neben einem Drittgenerations-Zephalosporin im Rahmen der Initialtherapie mit Vancomycin oder Rifampicin behandelt werden (Schuchat et al. 1997, Tunkel et al. 2004).

Auch in Deutschland wurden bereits nur intermediär auf Penicillin G empfindliche Pneumokokken-Stämme beschrieben, während hochresistente Keime glücklicherweise noch selten sind. Da diese vermindert auf Penicillin G empfindlichen Stämme jedoch zunehmend häufig (1992: 1,8\%, 2000: 5,8\%) vorkommen (Reinert et al. 2003), ist eine Behandlung mit Penicillin G allein nicht mehr $\mathrm{zu}$ empfehlen. Dementsprechend ist eine Initialtherapie mit einem DrittgenerationsZephalosporin, Cefotaxim oder Ceftriaxon, indiziert (Schmidt und Nau 2004). 
Tabelle 1: Initiale Antibiotikatherapie der bakteriellen Meningitis ohne Erregernachweis

\begin{tabular}{|l|l|}
\hline Altersgruppe & Empfohlenes Antibiotikaregime \\
\hline Neugeborene & Cefotaxim plus Ampicillin ${ }^{1}$ \\
\hline Kleinkinder und Kinder & Zephalosporin der 3. Generation ${ }^{2,3}$ \\
\hline $\begin{array}{l}\text { Erwachsene: } \\
\text { - gesund, keine Abwehrschwäche, ambulant }\end{array}$ & $\begin{array}{l}\text { Zephalosporin der 3. Generation }{ }^{2} \text { plus Ampi- } \\
\text { cillin }^{4}\end{array}$ \\
- nosokomial (z. B. nach neurochirurgischer & Vancomycin plus Meropenem oder \\
$\begin{array}{l}\text { Operation oder Schädel-Hirn-Trauma) } \\
\text { Vancomycin plus Ceftazidim }\end{array}$ \\
- abwehrgeschwächte, ältere Patienten
\end{tabular}

Zusätzlich kann ein Aminoglykosid - insbesondere bei schwerstkranken Patienten - eingesetzt werden (Deutsche Gesellschaft für Pädiatrische Infektiologie 2003).

2 z. B. Cefotaxim oder Ceftriaxon

${ }^{3}$ laut Empfehlungen der Deutschen Gesellschaft für Pädiatrische Infektiologie

${ }^{4}$ In Regionen mit einem hohen Anteil penicillinresistenter Pneumokokken (z. B. Frankreich, Spanien, Ungarn, Australien, Neuguinea, Südafrika und in einzelnen Gebieten in Amerika) muss in der Initialtherapie eine Kombinationsbehandlung wie z. B. Ceftriaxon + Vancomycin oder Ceftriaxon + Rifampicin durchgeführt werden (Tunkel et al. 2004).

${ }^{5}$ Oder Vancomycin plus Cefepim; einheitliche Empfehlungen liegen in der Literatur nicht vor. Bei nachgewiesener Staphylokokken-Ventrikulitis stellt die intraventrikuläre Vancomycingabe eine wichtige Therapieoption dar (Pfausler et al. 2003).

${ }^{6}$ In Regionen mit einem hohen Anteil penicillinresistenter Pneumokokken muss in der Initialtherapie eine Kombinationsbehandlung wie z. B. Ceftriaxon + Ampicillin + Vancomycin oder Ceftriaxon + Ampicillin + Rifampicin durchgeführt werden (Tunkel et al. 2004).

(Tabelle 1: Leitlinien Deutsche Gesellschaft für Neurologie 2005) 
Tabelle 2: Antibiotikatherapie der bakteriellen Meningitis bei bekanntem Erreger

\begin{tabular}{|c|c|}
\hline Bakterieller Erreger & Üblicherweise wirksame Antibiotika $^{1}$ \\
\hline - Neisseria meningitidis & $\begin{array}{l}\text { - Penicillin G, Ampicillin, Ceftriaxon (oder } \\
\text { Cefotaxim), Rifampicin }^{2}\end{array}$ \\
\hline $\begin{array}{l}\text { - Streptococcus pneumoniae, } \\
\text { penicillinempfindlich } \\
\text { - Streptococcus pneumoniae, intermediär } \\
\text { penicillinempfindlich (MIC } 0,1-1 \mu \mathrm{g} / \mathrm{ml} \text { ) } \\
\text { - Streptococcus pneumoniae, } \\
\text { penicillinresistent (MIC > } 1 \mu \mathrm{g} / \mathrm{ml} \text { ) }\end{array}$ & $\begin{array}{l}\text { - Penicillin G, Ceftriaxon (oder Cefotaxim) } \\
\text { - Ceftriaxon (oder Cefotaxim), Meropenem, } \\
\text { Cefepim } \\
\text { - Cefotaxim (oder Ceftriaxon) + Vancomycin } \\
\text { oder } \\
\text { Cefotaxim (oder Ceftriaxon) + Rifampicin }{ }^{2}\end{array}$ \\
\hline - Haemophilus influenzae & - Ceftriaxon (oder Cefotaxim), Ampicillin \\
\hline $\begin{array}{l}\text { - Gruppe-B-Streptokokken } \\
\text { (Streptococcus agalactiae) }\end{array}$ & $\begin{array}{l}\left.\text { - Penicillin G (+ Gentamicin }{ }^{2}\right) \text {, Ceftriaxon, } \\
\text { Ampicillin }\left(+ \text { Gentamicin }^{2}\right), \text { Vancomycin }\end{array}$ \\
\hline $\begin{array}{r}\text { - Gramnegative Enterobacteriaceae } \\
\text { (z. B. Klebsiella, E. coli, Proteus) }\end{array}$ & - Ceftriaxon (oder Cefotaxim); Meropenem \\
\hline - Pseudomonas aeruginosa & $\begin{array}{l}\text { - Ceftazidim + Aminoglykosid }{ }^{2}, \text { Meropenem + } \\
\text { Aminoglykosid, Cefepim + Aminoglykosid, } \\
\text { Ciprofloxacin }\end{array}$ \\
\hline - Staphylokokken (methicillinempfindlich) & $\begin{array}{l}\text { - Cefazolin, Fosfomycin }{ }^{2}, \text { Rifampicin, } \\
\text { Vancomycin, Linezolid }{ }^{3} \text { (oder Flucloxacillin) }\end{array}$ \\
\hline - Staphylokokken (methicillinresistent) & $\begin{array}{l}\text { - Vancomycin, Fosfomycin oder Rifampicin }{ }^{2} \\
\text { (in Kombination mit Vancomycin), } \\
\text { Linezolid }^{3} \text {, Trimethoprim-Sulfamethoxazol }\end{array}$ \\
\hline - Listeria monocytogenes & $\begin{array}{l}\text { - Ampicillin +Gentamicin }{ }^{2} \text {, Trimethoprim- } \\
\text { Sulfamethoxazol, Meropenem }\end{array}$ \\
\hline - Bacteroides fragilis & - Metronidazol, Meropenem, Clindamycin \\
\hline
\end{tabular}

${ }^{1}$ Die Wahl der Antibiotika richtet sich nach dem Ergebnis der Resistenzprüfung (Antibiogramm).

${ }^{2}$ Rifampicin, Fosfomycin und Aminoglykoside dürfen wegen der Gefahr von Resistenzentwicklungen nicht in Monotherapie gegeben werden.

${ }^{3}$ Linezolid (Zyvoxid) hat ein dem Vancomycin ähnliches Wirkungsspektrum und ist gut liquorgängig; es gibt einige Berichte über den Einsatz von Linezolid bei Staphylokokkeninfektionen des Zentralnervensystems (z. B. Viale et al. 2002, Rupprecht und Pfister 2005).

(Tabelle 2: Leitlinien Deutsche Gesellschaft für Neurologie 2005) 


\subsubsection{Glukokortikoide}

Seit den 1960-er Jahren wurde in verschiedenen Studien der mögliche Benefit einer adjuvanten Therapie mit Kortikosteroiden untersucht. Die Wirkweise der Glukokortikoide besteht in der Hemmung der Prostaglandinsynthese sowie der Infiltration durch Leukozyten. Weiterhin setzen sie die kapilläre Membranpermeabilität herab und können aufgrund dessen die Entstehung eines Hirnödems eindämmen.

Odio et al. konnten 1991 zeigen, dass der Krankheitsverlauf bei Kindern, die an einer Meningitis durch $H$. influenzae erkrankt waren, nach Gabe von Dexamethason noch vor der ersten Antibiotikagabe günstig beeinflusst wurde. Er konnte weiterhin eine Reduktion der neurologischen Spätschäden beobachten (Odio et al. 1991).

Eine andere Studie belegt die niedrigere Inzidenz resultierender Hörschäden bei Kindern, wenn die Gabe von Dexamethason im Therapieschema enthalten ist (Lebel et al. 1988). Dies wurde jedoch zunächst nur für Infektionen mit $H$. influenzae nachgewiesen.

Der Nachweis der Therapie-Effizienz bei der Pneumokokken- und Meningokokken-Meningitis stand hingegen noch aus (Lebel 1992) und bleibt in zahlreichen Studien Gegenstand der Forschung. So konnte gezeigt werden, dass sowohl Kinder als auch Erwachsene, die an einer Pneumokokken-Meningitis erkrankt sind, von einer begleitenden Dexamethasontherapie profitieren (Girgis et al. 1991, Kennedy et al. 1991). Trotz allem war die routinemäßige Anwendung der adjuvanten Therapie mit Glukokortikoiden noch lange umstritten.

Im Jahr 2002 arbeitete die Gruppe um de Gans und van de Beek den Benefit einer adjuvant durchgeführten Dexamethason-Therapie bei Patienten, die an einer bakteriellen Meningitis erkrankt sind, heraus. Sie zeigten, dass sowohl die Mortalität (34\% versus 14\%) als auch das Risiko für ein ungünstiges Outcome (52\% versus 26\%) signifikant geringer waren, als in der Vergleichsgruppe. Der größte Effekt wurde bei Infektionen durch Pneumokokken beobachtet. Hieraus resultiert die insbesondere bei der Pneumokokken-Meningitis geltende Therapie-Empfehlung zur adjuvanten Dexamethason-Gabe (de Gans und van de Beek 2002).

2010 zeigten van de Beek et al. in einer Metaanalyse jedoch keinen eindeutigen Effekt einer zusätzlichen Dexamethason-Behandlung der bakteriellen Meningitis (van de Beek et al. 2010).

Es bleibt außerdem zu beachten, dass auch nachteilige Effekte bis hin zu neurotoxischen Wirkungen aus der Therapie mit Dexamethason resultieren können, z. B. Verstärkung neuronaler Schäden im Hippokampus, Hemmung der Glukose-Aufnahme in Neurone und Gliazellen (Landfield et al. 1978, Sapolsky und Palsinella 1985, Horner et al. 1990) oder Beeinträchtigung der Gedächtnisleistung (Keenan et al. 1995). Auch der Einfluss auf die Wirksamkeit bestimmter Antibiotika erwies sich als negativ durch Reduktion der Penetration der Blut-Hirn-Schranke (Schaad et al. 1995, Scheld und Brodeur 1983). 
1.8.4 Antiinflammatorische Behandlung und experimentelle Therapieansätze

Trotz einer frühzeitigen und effizienten antibiotischen Therapie bleibt die bakterielle Meningitis mit einer hohen Letalität beziehungsweise ausgeprägten neurologischen Spätschäden behaftet. Moderne antimikrobielle Substanzen haben eine exzellente bakterizide Wirkung im Liquor, und es scheint nur bedingt möglich, dass eine entscheidende Verbesserung der Prognose beruhend auf der Weiterentwicklung der antibiotischen Therapie zu erwarten ist. In den letzten Jahren wurde die Behandlung aufgrund neuer Ansätze zur Reduktion der ausgeprägten Entzündungsreaktion erweitert. Es konnte gezeigt werden, dass zahlreiche Substanzen zur Verfügung stehen, die den inflammatorischen Prozess modulieren und somit zu einer Verminderung der Zell- und Gewebeschäden beitragen. Tierexperimentelle Untersuchungen haben folgende Therapieansätze behandelt:

$\diamond \quad$ Systemische Verabreichung eines Anti-CD18-Antikörpers, der hemmend auf die Einwanderung von Leukozyten in den extravasalen Raum wirkt (Tuomanen et al. 1989, Zysk et al. 1996).

$\diamond \quad$ Injektion von Antioxidantien wie N-Acetylcystein oder Behandlung mit Radikalfängern, z. B. $\alpha$-tert-phenyl-butyl-nitron (PBN), schützt vor ischämischen neuronalen Schäden des Cortex (Leib et al. 1996b, Auer et al. 2000) und hemmt den Verlust der endogenen Antioxidantien (z. B. Glutathion) im Gehirn (Christen et al. 2001).

$\diamond \quad$ Applikation von Glutamat-Antagonisten zur Eindämmung des Neuronenschadens durch exzitatorische Aminosäuren (Leib et al. 1996a).

$\diamond \quad$ Intrazisternale Applikation von Caspase-Inhibitoren (z. B. z-VAD-fmk) wirkt protektiv vor apoptotischem Zelltod der Neuronen (Braun et al. 1999).

$\diamond \quad$ Inhibitoren von Matrix-Metalloproteinasen (GM6001 und BB1101) zur Reduktion des kortikalen und hippokampalen (nur BB1101) Schadens (Meli et al. 2002).

Dennoch besteht nach wie vor eine hohe Morbidität, so dass die Optimierung der Therapie weiterhin zentraler Gegenstand der Forschung bleiben wird. 
1.8.5 Vorgehen bei Verdacht auf bakterielle Meningitis

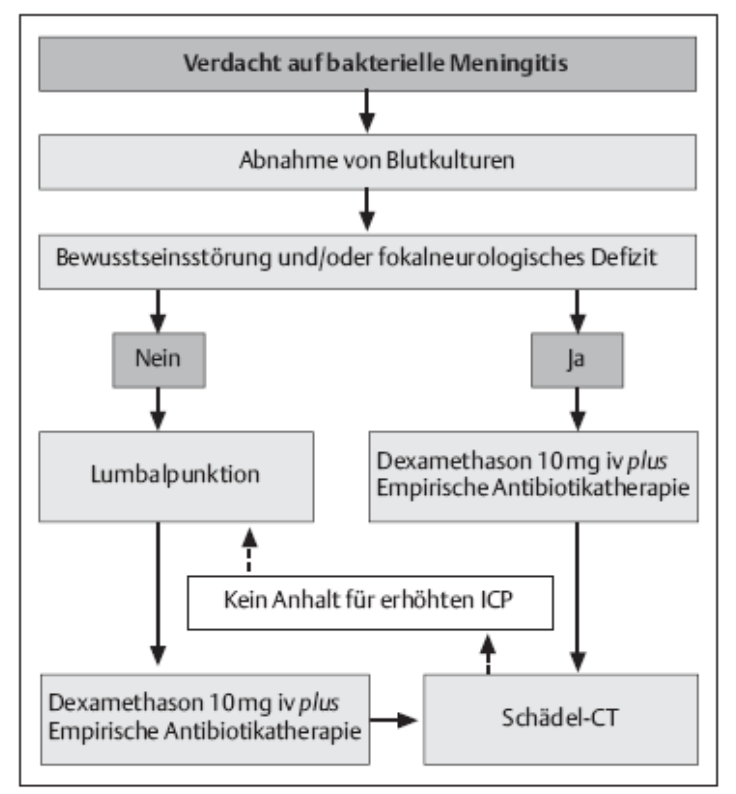

H. C. Diener u. a., Leitlinien für Diagnostik und Therapie in der Neurologie (ISBN 3-13-132413-9) (C) 2005 Georg Thieme Verlag KG, Stuttgart

(Leitlinien Deutsche Gesellschaft für Neurologie 2005)

\subsubsection{Allgemeine Therapiemaßnahmen}

Neben der spezifischen Behandlung sind je nach Allgemeinzustand des Patienten weitere allgemeine Maßnahmen zu ergreifen. Bei Zeichen der vitalen Bedrohung ist eine intensivmedizinische Überwachung unabdingbar. Patienten mit ausgeprägtem Hirnödem profitieren von einer raschen Intubation, da eine Respiratorbeatmung einen wichtigen Beitrag zur Therapie leistet. Hierbei ist eine orotracheale Intubation der nasalen vorzuziehen; falls im Verlauf ein otogener oder nasaler Erregerherd gefunden würde, bedürfte es vor der Sanierung keiner Umintubation (Schmidt und Nau 2004). Die Patienten sollten zur Hirnödem-Prophylaxe mit $30^{\circ}$ Oberkörper hochgelagert werden, um den venösen Rückfluss und damit den Liquorabfluss zu begünstigen. 


\subsection{Formen des Zelltodes}

Der Zelltod ist definiert als irreversibler Verlust der vitalen zellulären Strukturen und Funktionen. Er kommt sowohl physiologischerweise in der Organogenese während der Embryonalentwicklung und im Rahmen des Zellumsatzes bei Wechselgeweben als auch als pathologische Antwort auf verschiedene Formen der Zellschädigung vor. Morphologisch differenziert man zwischen zwei Arten des Zelltodes: Apoptose und Nekrose (Buja et al. 1993).

\subsubsection{Apoptose}

Apoptose repräsentiert ein genetisch determiniertes, aktives Sterbeprogramm der Zelle - „programmierter Zelltod“ (Padosch et al. 2001) - und stellt eine Gegenregulation zur Mitose zum Erhalt der Homöostase dar (Buja et al. 1993). Der Arzt und Philosoph Galen von Pergamon (129203 n. Chr.) beschrieb den koordinierten Untergang bestimmter Zellgruppen im Rahmen der Embryonalentwicklung von Föten und der Entwicklung von Insektenlarven (Padosch et al. 2001). 1972 wurde der Begriff erstmals genauer beschrieben (Kerr et al. 1972).

Apoptose setzt physiologischerweise während der Embryogenese, Differenzierungsvorgängen, Zell-Turn-Over (Buja et al. 1993, Gerschenson und Rotello 1992) und Involutionsprozessen (Arends und Wyllie 1991) von z. B. Ovar (O`Shea et al. 1978), Prostata (Kerr und Searle 1973) oder Endometrium (Rotello et al. 1989) ein. Andererseits spielt sie als Reaktion auf pathologische Einflüsse wie Entzündungsprozesse, virale Infekte (Vaux et al. 1994), in wachsenden und regressiven Tumoren (Kerr und Searle 1972) sowie nach zytotoxischer Tumorbehandlung (Searle et al. 1975) eine wichtige Rolle. Der apoptotische Zelltod kann experimentell ausgelöst werden durch Behandlung mit ionisierender Strahlung (Gobé et al. 1988), Glukokortikoiden (Wyllie und Morris 1982) oder Entzug spezifischer Wachstumsfaktoren (Duke und Cohen 1986, Williams et al. 1990).

Apoptotische Zellen lösen den Kontakt zu Nachbarzellen und verlieren spezielle Oberflächenstrukturen (z. B. Mikrovilli). Das Zellvolumen schrumpft, die Organellen liegen eng gepackt (Arends und Wyllie 1991), jedoch ohne Integritätsverlust der Zellorganellen oder Plasmamembran (Waters 1996). Es bilden sich bläschenförmige Ausstülpungen an der Zellmembran (Zeiose) als Vorstufe der apoptotischen Körperchen, die Zellkerngrösse nimmt ab, Chromatin verdichtet und lagert sich halbmondförmig an der Kernperipherie ab (Arends und Wyllie 1991). Chromatin wird gespalten (Buja et al. 1993), Kern und Zytoplasma zerfallen in Bruchstücke. Aus der Zelle entsteht ein Haufen runder, glatter, membranumschlossener Fragmente, die apoptotischen Körperchen, welche zum Teil nukleäre Bestandteile enthalten und durch Nachbarzellen oder Makrophagen phagozytiert werden (Arends und Wyllie 1991). Die Phagozytose der apopto- 
tischen Zellen erfolgt vor ihrer Lyse, um eine Freisetzung intrazellulärer, potentiell toxischer oder immunogener Substanzen zu vermeiden und damit die normale Struktur und Funktion des umliegenden Gewebes zu erhalten (Fadok et al. 2001).

Merkmal der Apoptose ist die internukleosomale DNA-Spaltung zu Fragmenten doppelsträngiger DNA mit ca. 180-200 Basenpaaren durch eine Endonuklease ohne Entzündungsreaktion (Arends und Wyllie 1991, Gerschenson und Rotello 1992, Gold et al. 1994) mit elektrophoretischer Darstellung als ,typical chromatin ladder“ (Rotello et al. 1989). Weiterhin Aktivierung der GewebeTransglutaminase, die zu einer Verknüpfung von zytoplasmatischen und Membranproteinen führt (Fesus et al. 1987). Keines der beiden Schlüsselproteine ist normalerweise in den Zellen vorhanden, es kommt zur de-novo-Genexpression und Akkumulation vor Apoptose (Arends und Wyllie 1991). Der Ablauf der Apoptose ist kaskadenförmig, es sind verschiedene Wege der Signalgebung und -transduktion möglich, die gemeinsame Endstrecke ist charakterisiert durch die Aktivierung von Cystein-Proteasen, den Caspasen (Cytosolische Aspartat-spezifische Proteasen).

Eine mögliche Induktion der Apoptose besteht in der Bindung von Liganden an Zytokinrezeptoren. Diese „Todesrezeptoren“ gehören zur TNF-Rezeptor-Gen-Superfamilie, zu den am besten charakterisierten Rezeptoren zählen Fas/APO-1 (= CD-95), TNFR-1 (= CD-120a) (Ashkenazi und Dixit 1998) und Nur77 (= Steroid-Rezeptor in Thymozyten). Ceramide sind als Signalmoleküle in der Lage, Apoptose zu induzieren (Wyllie 1995), ebenso wie c-jun, c-fos, c-myc und die Gene der Bcl-2-Familie als Protoonkogene. Eine c-myc-gesteuerte Apoptose kann durch Gabe von spezifischen Wachstumsfaktoren unterbrochen (Evan et al. 1992) und durch Blockierung der Funktion von c-jun oder c-fos mit spezifischen Antikörpern der Zelltod verhindern werden (Waters 1996). P53 als Onkogen-Suppressor kann einen apoptotischen Zelltod hervorrufen (Clarke et al. 1993). 


\subsubsection{Nekrose}

Viele verschiedene Faktoren, wie zum Beispiel Sauerstoffmangel, chemische Noxen, bakterielle Toxine, können eine Zelle und ihren Stoffwechsel schwer beeinträchtigen und zu Nekrose infolge einer letalen Zellschädigung führen. Auch nach physikalischer Beeinflussung durch Wärme-, Kälte- oder Strahlenexposition sowie traumatisch bedingt kann es zum nekrotischen Zelluntergang kommen (Farber 1982, Buja et al. 1993).

Die Nekrose zeigt neben Defekten der Plasmamembran-Permeabilität und der Ionentransporter eine zunehmende Beeinträchtigung des Energiestoffwechsels mit progressiver Erschöpfung der hochenergetischen Phosphate (Buja et al. 1993, Hillis und Braunwald 1977). Schließlich versagt die transmembranöse Ionenpumpe und auch die Zellmembran kann die Regulation des osmotischen Drucks nicht mehr aufrecht erhalten.

Es gibt frühe morphologische Veränderungen, die noch potentiell reversibel sind und späte irreversible Auffälligkeiten. Zu Beginn zeigen sich Kondensation und Verklumpung des nukleären Chromatins (frühe Pyknose) sowie ein intrazelluläres Ödem sowohl einzelner Organellen als auch der ganzen Zelle. Verglichen mit der Apoptose findet während der Nekrose keine Aufspaltung des Kerns in membranumschlossene Fragmente statt (Martin et al. 1998). Im weiteren Verlauf entstehen irreversible Schäden wie Pyknose, Karyorrhexis und Karyolyse, mitochondriale Läsionen mit Ausbildung amorpher Matrixverdichtungen aus osmiophilen Lipid- und Proteinaggregaten sowie lineare Verdichtungen durch Christaeverschmelzungen. Schließlich kommt es zur Ruptur der Zell- und Organellenmembranen (Searle et al. 1982). Die Freisetzung des Zellinhaltes aus nekrotischen Zellen bewirkt eine Entzündungsreaktion (Cohen 1993).

Neben den genannten morphologischen Auffälligkeiten zeigen sich Veränderungen des zellulären Elektrolythaushaltes wie zum Beispiel ein intrazellulär erniedrigter Kalium- und erhöhter Natriumspiegel infolge Inhibition der $\mathrm{Na}^{+} / \mathrm{K}^{+}$-ATPase als Resultat des ATP-Mangels. Der Natriumeinstrom wird von Chlorid- und Wassereinstrom begleitet, was zum Anschwellen der Zelle führt. Auch finden sich erhöhte Kalziumkonzentrationen in der Zelle, zunächst durch Einstrom entlang der Plasmamembran infolge Veränderungen der Kalzium-Transportsysteme, durch Freisetzung aus dem endoplasmatischen Retikulum und den Mitochondrien (Farber 1982, Buja et al. 1993), später durch zunehmende unspezifische Membranpermeabilität (Buja et al. 1993). Im Verlauf wird im Rahmen des Zellabbaus die DNA durch zahlreiche Endonukleasen in unterschiedlich große Fragmente gespalten und die Zelle erliegt dem nekrotischen Zelltod. 
Übersicht über die Unterschiede zwischen Apoptose und Nekrose

\begin{tabular}{|l|l|}
\hline Apoptose & Nekrose \\
\hline physiologisch oder pathophysiologisch & pathophysiologisch \\
\hline genetisch determiniert & nicht genetisch determiniert \\
\hline energieabhängig & nicht energieabhängig \\
\hline Proteinbiosynthese notwendig & verminderte Proteinbiosynthese \\
\hline keine Änderung des zellulären ATP-Gehalts & Abfall des zellulären ATP-Gehalts \\
\hline$\left[\mathrm{K}^{+}\right]_{\mathrm{i}}$ konstant, kein $\mathrm{Na}^{+}-$Einstrom & $\begin{array}{l}\mathrm{K}^{+}-\text {Verlust, Na }{ }^{+} \text {-Einstrom, } \\
\text { Abfall des Membranpotentials }\end{array}$ \\
\hline asynchroner Prozess einzelner Zellen & synchrones Auftreten in mehreren Zellen \\
\hline zeitlich verzögerte aktive Degeneration & unmittelbar eintretende passive Atrophie \\
\hline Zellschrumpfung & Zellschwellung \\
\hline intakte Organellen & Zerstörung von Zellorganellen \\
\hline Chromatinkondensation & Zerfall nukleärer Chromatinstrukturen \\
\hline später Verlust der Membranintegrität & früher Verlust der Membranintegrität \\
\hline keine entzündliche Begleitreaktion & entzündliche Begleitreaktion \\
\hline
\end{tabular}

(Padosch et al. 2001)

\subsection{Neurogenese}

\subsubsection{Allgemeines}

In der Embryonalperiode, die bis zum Ende der 8. Schwangerschaftswoche dauert, erfolgt die Anlage aller Organsysteme sowie die wesentliche Ausgestaltung der äußeren Körperform. Am Ende der Embryonalperiode sind alle wichtigen Organsysteme angelegt, wenn auch die meisten noch nicht funktionsfähig sind. Alle Gewebe und Organe gehen aus den drei Keimblättern Ektoderm, Mesoderm und Entoderm hervor. Sowohl das zentrale als auch das periphere Nervensystem haben ihren Ursprung im Ektoderm. In der Phase der Organogenese kommt es etwa in der dritten Woche durch Induktion zur Entstehung einer neurogenen Zellpopulation aus Ektodermzellen (Schoenwolf und Smith 1990).

Am Beginn stehen die Nervenvorläuferzellen, die sogenannten primitiven Neurone oder Neuroblasten, aus denen sich durch Proliferation differenzierte Neurone mit lang ausgewachsenen Zytoplasmafortsätzen bilden. Dieser Proliferation und der Bildung von Gliazellen folgt die Entwicklung großer Faser- und Konnektionssysteme. Überlappend mit dem Ende der Proliferationsphase (24.-26. Schwangerschaftswoche) läuft die Migrationsphase, die dadurch charakterisiert ist, dass die Neurone an den Ort ihrer Destination auswandern. Wenn die Nervenzelle ihren Platz 
erreicht hat, findet die Organisation zu späteren Funktionseinheiten statt. Hierzu gehört auch die Ausbildung synaptischer Verknüpfungen. Mit dem Ende der 40. Schwangerschaftswoche haben alle Neurone ihre endgültige Position gefunden, ca. 50\% der Nervenzellen werden jedoch wieder eliminiert (Michaelis et al. 1995).

Bis in die 1960-er Jahre hielt sich die Überzeugung, dass die Produktion neuer Neurone mit dem Ende der Embryogenese oder kurz danach abgeschlossen sei. Joseph Altmann (1963) und Walter Kirsche (1967) konnten jedoch erstmals zeigen, dass die Neurogenese nicht nur im embryonalen Gehirn sondern auch im adulten ZNS stattfindet. Altmann war der erste, dem der direkte Nachweis für die Generation neuer Neurone im Gyrus dentatus der Formatio hippocampi im adulten ZNS von Säugetieren am Beispiel der Ratte gelang (Altmann 1963, Kirsche 1967). Er konnte zeigen, dass neue Zellen aus Progenitorzellen entstehen, die zum größten Teil in der subgranulären Zone des Gyrus dentatus lokalisiert sind (Altmann und Das 1965).

In den 1980-er Jahren gelang Nottebohm erstmalig der Nachweis, dass neu generierte Zellen sich zu funktionalen Neuronen entwickeln können. Diese neuen Neurone werden durch chemische Synapsen verknüpft, können eigene Verbindungen zu anderen Regionen des Gehirns ausbilden und entwickeln morphologische und physiologische Charakteristika, die sie von älteren Neuronen nicht unterscheidbar machen (Paton und Nottebohm 1984).

In den späten 1990-er Jahren konnte die Neurogenese des adulten Gehirns in vivo und auch beim Menschen nachgewiesen werden (Gould et al. 1998, Eriksson et al. 1998).

Es konnten zwei Regionen identifiziert werden, in denen Neurogenese nicht nur während der Embryonalphase sondern auch im adulten Lebewesen stattfindet: der Gyrus dentatus des Hippokampus (Altmann und Das 1965, Gould et al. 1998, Eriksson et al. 1998) und die subventrikuläre (subependymale) Zone entlang des Seitenventrikels (Luskin 1993, Louis und Alvarez-Buylla 1994). Andere Regionen des Gehirns enthalten eine üppige Population proliferativer Vorläuferzellen, welche jedoch nur Glia generieren (Kuhn et al. 2001).

Während der Entwicklung des Hippokampus wird eine zweite germinative Zone, separiert von der Ventrikelwand entlang der Grenze zwischen Hilus und Körnerzellschicht, angelegt: die subgranuläre Zone (Altman und Bayer 1990). Die Nachkommen der proliferierenden neuronalen Stammzellen migrieren lokal, um sich in Neurone der Körnerzellschicht des Gyrus dentatus zu differenzieren (Cameron et al. 1993). Die Neurogenese im Gyrus dentatus findet das ganze Leben hindurch statt, zeigt jedoch einen konstanten Rückgang ausgehend von den frühen postnatalen Tagen (Kuhn et al. 1996). Dennoch ist Neurogenese auch im hohen Alter noch nachweisbar (Kempermann et al. 1998). Die Stammzellen im Hippokampus enthalten auch Progenitorzellen für Glia, Körnerzellneurone und Gefässendothelien. Die neuronalen Stammzellen der subgranulären Zone 
des Hippokampus proliferieren in Clustern, welche um die Peripherie kleiner Kapillaren lokalisiert sind (Palmer et al. 2000).

Die subependymale Zone des Seitenventrikels wird als residuelle Proliferationszone aus dem embryonalen Neuralrohr angesehen (Kuhn et al. 2001). Die hier gebildeten Vorläuferzellen treten in den rostralen Migrationsstrom ein, vollziehen ihre letzten Zellteilungen, wandern in das olfaktorische System und differenzieren sich dort in neue Neurone (Luskin 1993). Dabei werden zwei neuronale Phänotypen generiert: GABAerge Körnerzellen und dopaminerge periglomeruläre Interneurone (Betarbet et al. 1996, McLean und Shipley 1988), in anderen Studien wurde auch die Differenzierung in Gliazellen nachgewiesen (Goldman 1995).

Aufgrund des begrenzten Platzes im knöchernen Schädel liegt nahe, dass neben der Neurogenese auch ein Zellverlust im ZNS stattfinden muss. Biebl et al. zeigten, dass der apoptotische Zelltod in Regionen mit Neurogenese ein häufiges Merkmal darstellt (Biebl et al. 2000), der in allen Phasen der Neurogenese stattfindet. Dabei tritt Zelltod signifikant häufiger in neurogenetischen Gehirnarealen als in anderen Bereichen des ZNS auf. Trotz dieser Zellverluste wächst die Zahl der neuronalen Zellen im olfaktorischen System und dem Gyrus dentatus kontinuierlich an und überwiegt den Verlust im Verlauf des Lebens der Ratte (Bayer et al. 1982, Kaplan et al. 1985).

Durch die Arbeit mit terminal kranken Patienten konnte bestätigt werden, dass auch Menschen neue Neurone ausbilden: Tumor-Patienten wurde in einmaliger Dosis (250mg) der Proliferationsmarker Bromdesoxyuridin (BrdU) zu diagnostischen Zwecken injiziert, um die Tumorzellproliferation zu beobachten. Es fiel auf, dass die post mortem untersuchten Gewebe des Hippokampus und der subventrikulären Zone auch BrdU-markierte Neurone präsentierten. Eine systematische Verabreichung von BrdU führt zur Markierung aller sich teilenden Zellen, und so gelang tatsächlich der Nachweis neugeborener Neurone in der Körnerzellschicht des Gyrus dentatus aller Individuen (Eriksson et al. 1998).

Im Vergleich zu Säugetieren findet sich bei Wirbeltieren, die nicht zu den Säugetieren gehören, eine kontinuierliche Entwicklung neuer Neurone in vielen Regionen des adulten ZNS (Zupanc 2001).

In diversen tierexperimentellen Versuchen wurde untersucht, welchen Einfluss verschiedene Stimuli auf die Neurogeneserate im Gyrus dentatus haben.

Experimentelle Studien von Kempermann und Van Praag konnten zeigen, dass die Stimulation der Neurogenese im Gyrus dentatus durch eine abwechslungsreiche Umgebung und eine erhöhte motorische Aktivität der Versuchstiere gesteigert werden kann. Sie schufen eine Umgebung, die sie als „enriched environment“ bezeichneten. Die Tiere konnten sich mit verschiedenen Gegenständen wie Laufrädern oder Tunneln beschäftigen und hatten durch die Haltung in der Gruppe auch soziale Kontakte. Anhand dieses Versuchsaufbaus konnte ein stimulierender Einfluss auf die Neurogenesesrate im Gyrus dentatus des Hippokampus bei der adulten Maus nachgewiesen wer- 
den. Auch eine bessere Leistung im Lernverhalten, eine Verbesserung der Gedächtnisfunktion sowie eine gesteigerte synaptische Plastizität sind damit assoziiert. Stress hingegen wurde in Beziehung gesetzt zu erniedrigten Neurogeneseraten und negativer Beeinträchtigung des Gedächtnisses (Kempermann et al. 1997, Kempermann 2002, van Praag et al. 1999, van Praag et al. 2002). Die physische Aktivität scheint ebenfalls ein starker Aktivator der Proliferation hippokampaler neuronaler Stammzellen zu sein. Bei Bewegung auf dem Laufrad verdoppelte sich die hippokampale Neurogenese im Vergleich zur Haltung in einem Standardlaborkäfig ohne körperliche Aktivität. Das legt die Vermutung nahe, dass physiologische Parameter wie Blutfluss, GlukoseAufnahme und Neovaskularisation Mediatoren dieses Effektes sein können (van Praag et al. 1999, Kuhn et al. 2001).

Ebenfalls tierexperimentell getestet wurde der Einfluss pharmakologischer Stimuli. So konnte bei der Gabe von Antidepressiva wie Tianeptine oder Lithium eine Steigerung der Neurogeneserate beobachtet werden. Sie wirken dem negativen Einfluss von Stress entgegen (Chen et al. 2000, Czèh et al. 2001, Malberg et al. 2000).

Dem Einsatz von Glukokortikoiden folgt ein Abfall der Proliferation aus Progenitorzellen (Kuhn et al. 1996, Cameron und McKay 1999), während eine Adrenalektomie die Neurogenese stimuliert (Cameron und Gould 1994, Cameron et al. 1995). Im Kontrast dazu stimuliert das ovariale Steroid Östrogen die Proliferation der Körnerzell-Vorläuferzellen des Gyrus dentatus bei weiblichen adulten Ratten (Tanapat et al. 1999).

Weiterhin zeigte sich, dass neuronale Transmitter wie NMDA-Rezeptor-Agonisten die Proliferationsrate von Neuronen ebenso vermindern (Hailer et al. 1999, Cameron et al. 1995) wie der Verlust des Botenstoffes Serotonin (Brezun und Daszuta 1999), NMDA-Rezeptor-Antagonisten stimulieren hingegen die Proliferation (Cameron et al. 1995).

Ein direkter Stimulus für die Progenitorzellen sind Wachstumsfaktoren; durch EGF, FGF-2 oder IGF-1 wird die Proliferation angeregt (Kuhn et al. 1997, Wagner et al. 1999, Aberg et al. 2000). Vorläuferzellen des Gyrus dentatus produzieren nachweislich EGF-Rezeptoren, und die direkte Infusion des Wachstumsfaktors in den Gyrus dentatus stimuliert die Proliferation (Tanapat und Gould 1997).

Auch als Reaktion auf pathologische Ereignisse im ZNS wird Neurogenese beobachtet; so kommt es bei Epilepsien, Ischämien und traumatischen Läsionen zu einer erhöhten Proliferationsrate von Stammzellen im Gyrus dentatus und in der subventrikulären Zone (Liu 1998, Hailer et al. 1999, Peterson 2002).

Eine im Tiermodell induzierte epileptische Aktivität führt unabhängig vom Mechanismus der Anfallsinduktion (chemisch oder elektrisch) zu einer markanten Neurogenese-Einleitung im Gyrus dentatus (Gray und Sundstrom 1998, Nakagawa et al 2000). Jedoch sind nicht alle mit Epilep- 
sie in Beziehung stehenden strukturellen Veränderungen mit einer modifizierten Neurogenese verknüpft. Die Progenitorzell-Proliferation nach Krampfanfällen wird durch Bestrahlung inhibiert, wohingegen das synaptische Remodeling der Moosfaser-Nervenbahnen nicht verändert ist (Parent et al. 1999). Die intrazerebrale Infusion von z-VAD-fmk, einem Breitspektrum-CaspaseInhibitor, führt zu einem temporären Anstieg der Proliferation neuronaler Precursorzellen in der subgranulären Zone nach Status epilepticus (Ekdahl et al. 2001).

Fokale oder globale Ischämie wurde ebenfalls als potent beschrieben, Neurogenese im Gyrus dentatus zu induzieren (Liu et al. 1998, Takagi et al. 1999).

Infolge traumatischer Läsionen kann gleichfalls eine transiente Erhöhung der StammzellProliferation der Ventrikelwand beobachtet werden (Reznikow 1975, Tzeng und Wu 1999), jedoch konnten diese Studien keinen neuronalen Beitrag der Stammzellen zur Seite der Läsion demonstrieren.

Neuere Studien beschreiben wnt-Proteine als Schlüssel-Regulatoren des neuronalen StammzellVerhaltens in der embryonalen Entwicklung (Lie et al. 2005). Während der Entwicklung tragen sie zum Erhalt der Stammzellen bei und fördern die Neurogenese (Morris et al. 2007). Dieser besondere wingless-type (wnt) Proliferationsweg ist in der Entwicklungsliteratur gut beschrieben. Er reguliert die embryonale neuronale Stammzell-Neubildung, die Bestimmung des Zellschicksals und die Zellproliferation (Ciani und Salinas 2005). Er spielt eine wichtige Rolle bei der neuronalen Migration, axonalen Wegfindung, dendritischen Morphogenese und synaptischen Differenzierung während der neuronalen Entwicklung bei Nicht-Vertebraten und Vertebraten (Fradkin et al. 2005). Die Aktivierung ist über die Bindung von wnt-Glykoproteinen an Rezeptoren reguliert, in deren Folge der Abbau eines Protein-Komplexes steht. Dieser Proteinkomplex führt zu einem Abbau von $\beta$-catenin, wenn er aufgebaut wird. Die Aktivierung von wnt sichert also den Erhalt des Transcriptionsfaktors $\beta$-catenin. Weiterhin kann wnt zur Freisetzung von intrazellulärem Kalzium führen (Ciani und Salinas 2005). wnt-3 wird in der hippokampalen Nische (Zone der Stammzellpopulation) exprimiert. wnt-5 ist an der Regulation der Entwicklung dopaminerger Neurone beteiligt (Castelo-Branco et al. 2003).

Wnt findet sich bei der Stammzell-Regulation vieler Gewebe beim Erwachsenen, einschließlich Haut und Blut. Studien zeigten, dass es eine wichtige Rolle bei der Erhaltung der Pluripotenz der Stammzellen spielt und eine Inhibition von wnt die neuronale Differenzierung embryonaler Stammzellen induziert.

Wnt-Signalgebung wurde auch bei der hippokampalen Neurogenese der adulten Ratte beobachtet. Die Expression erfolgt durch hippokampale Astrozyten während hippokampale Stamm-/ Progenitorzellen Rezeptoren und Signalkomponenten für wnt exprimieren (Lie et al. 2005). 
In vitro-Versuche mit Stammzell-ähnlichen Zellen des Knochenmarks zeigten deren Potential, Neurone zu generieren (Woodbury et al. 2000), und einige dieser Zellen wandern nach traditioneller Knochenmarks-Transplantation in das ZNS (Mezey et al. 2000). Auch zeigen in vitro-Daten die neuronale Differenzierung aus glialen Quellen und damit die Präsenz einer glialen Progenitorzelle mit dem Potenzial zur neuronalen Differenzierung. Die Möglichkeit, neuronale Stammzellen aus verschiedenen Geweben zu generieren, die nicht nur ihren individuellen Phänotyp annehmen sondern auch spezifische axonale und dentritische Verbindungen ausbilden, fokussiert die Forschung auf die zugrundeliegenden molekularen Mechanismen. Ein genaueres Verständnis der neuronalen Orientierung und Bewegung, Ausbildung synaptischer Kontakte und Beeinflussung des voll differenzierten ZNS ist essentiell. Bei all den bereits nachgewiesenen Einflüssen auf die Neurogenese, bleiben der exakte Mechanismus und mögliche Schlüssel-Gene, die die neurale Proliferation und Differenzierung beeinflussen, noch zu erforschen. Die Kenntnis der Signalgebung und beteiligten Zellen in diesem Prozess ist wichtig, da Strategien zum Ersatz neuronaler Zellen von unserer Fähigkeit abhängen, die einzelnen Schritte der Induktion und Modulation zu beeinflussen: Stammzellproliferation, Bestimmung des Zell-Schicksals, Progenitor-Migration und Differenzierung in spezifische neuronale Phänotypen (Kuhn et al. 2001).

\subsubsection{Neurogenese bei Meningitis}

Ca. ein Drittel der Überlebenden einer bakteriellen Meningitis leiden an neurologischen Spätfolgen mit Beeinträchtigung der Gedächtnisfunktion. Die in Folge einer Meningitis hervorgerufenen neuronalen Schädigungen wurden in verschiedenen Tiermodellen untersucht. Adulte Mäuse und junge Ratten zeigten nach Überleben einer bakteriellen Meningitis Defizite im räumlichen Lernvermögen (Wellmer et al. 2000, Loeffler et al. 2001).

Tiermodelle mit experimenteller Meningitis sowie menschliche Autopsiefälle verdeutlichen, dass die neuronale Schädigung am häufigsten im Bereich der Formatio hippocampi lokalisiert ist (Zysk et al. 1996, Nau et al. 1999, Loeffler et al. 2001). Die deutlichste Ausprägung des Neuronenschadens ist dort in der Körnerzellschicht des Gyrus dentatus zu finden (Zysk et al. 1996). Apoptotische Zellen im Stratum granulare des Gyrus dentatus werden in $70 \%$ menschlicher Todesfälle infolge bakterieller Meningitis gefunden (Nau et al. 1999).

Unterschiedliche Stimuli führten in verschiedenen Versuchsmodellen zu einer erhöhten oder erniedrigten Neurogeneserate mit Expression neuronaler Marker. Durch die Schaffung eines „enriched environment" konnte bei 70-90\% der überlebenden Zellen die Expression neuronaler Marker gezeigt werden (van Praag et al. 1999a, van Praag et al. 1999b).

Neben der Proliferationsrate und Expression von neuronalen Markern wurde auch der Effekt der gesteigerten Neurogenese auf die Gehirnfunktionen und das Lernverhalten Gegenstand der Untersuchungen. Wenn die Tiere in einer Umgebung untergebracht waren, die ihnen Abwechslung und 
motorische Aktivität erlaubte, konnte neben der gesteigerten Neuroproliferation auch eine Leistungssteigerung bei hippokampalen Lernaufgaben nachgewiesen werden (Kempermann et al. 1997).

Ein Experiment von Shors et al. zeigte weiterhin, dass eine wesentliche Reduktion neu gebildeter Neurone bei der adulten Ratte eine negative Beeinträchtigung des ,hippocampal-dependent trace conditioning" zur Folge hatte, eine Aufgabe, bei der die Tiere Stimuli assoziieren müssen, die zeitlich separiert sind (Shors et al. 2001).

Die differenzierte Erforschung der Bedeutung der gesteigerten Proliferation von Progenitorzellen als Ausdruck der Regeneration des ZNS nach einer ausgeprägten Schädigung, wie beispielsweise einer bakteriellen Meningitis, ist Gegenstand der aktuellen Forschung. Da in verschiedenen Studien gezeigt werden konnte, dass neben einer adäquaten medikamentösen Therapie auch Umwelteinflüsse, intellektuelle und soziale Anforderungen einen positiven Einfluss auf die Neurogenese haben, stehen Aspekte der Neurogenese-Stimulation ebenfalls im Interesse der Wissenschaft (van Praag et al. 1999a, van Praag et al. 1999b, Shors et al. 2001).

\subsection{Ziel der Arbeit}

Trotz stets verbesserter und effektiver antibiotischer Therapien leiden Patientin mit Pneumokokken-Meningitis noch immer häufig an schweren Komplikationen und Spätschäden. Es besteht deshalb weiterhin die Notwendigkeit, das Verständnis der pathophysiologischen Vorgänge, der möglichen Therapieansätze und Optionen der Regeneration des zentralen Nervensystems zu vertiefen.

Die heute gut etablierten Tiermodelle zur Erforschung der bakteriellen Meningitis sind das erstmals 1974 beschriebene Kaninchen-Modell der Pneumokokken-Meningitis (Dacey und Sande 1974), das adulte (Pfister et al. 1990) und neonatale Rattenmodell (Leib et al. 1996b) sowie das Mausmodell der Pneumokokken-Meningitis (Nau et al. 1999).

Ziel dieser Arbeit war die Gegenüberstellung und Suche nach Zusammenhängen von Zelluntergang und Neurogenese infolge bakterieller Meningitis mit Streptococcus pneumoniae im Kaninchen- sowie im Mausmodell: Kommt es in der Folge einer bakteriellen Meningitis zu einer Aktivierung der Neurogenese und zu einer Stimulation neuroregenerativer Mechanismen? 


\section{MATERIAL UND METHODEN}

\subsection{Tiermodelle}

Die Versuche wurden vom Tierschutzbeauftragten der Universität Göttingen und der Bezirksregierung Braunschweig (Niedersachsen) geprüft und genehmigt.

\subsubsection{Das Kaninchenmodell}

Für den Versuch wurde ein Stamm von Streptococcus pneumoniae Typ 3 eingesetzt. Dieser war aus dem Liquor eines adulten, an Meningitis erkrankten Patienten isoliert worden (freundlicherweise überlassen von M. G. Täuber, Universität Bern, Schweiz). Die Tiere wurden für den gesamten Zeitraum des Versuches narkotisiert. 12 Stunden nach Infektion wurde die antibiotische Therapie mit Ceftriaxon begonnen.

\section{Verwendete Substanzen und Dosierungen}

$\diamond$ Ceftriaxon $\left(\right.$ Rocephin $^{\circledR}$ ), $20 \mathrm{mg} / \mathrm{kg}$ Bolus, Erhaltungsdosis $10 \mathrm{mg} / \mathrm{kg} / \mathrm{h}$

(Hoffmann-LaRoche, Grenzach-Whylen, Deutschland)

$\diamond$ Ketamin, 25 mg/kg (CP-Plasma, Burgdorf, Deutschland)

$\diamond$ Xylazin $\left(\right.$ Rompun $\left.^{\circledR}\right), 5 \mathrm{mg} / \mathrm{kg}$ (Bayer AG, Leverkusen, Deutschland)

$\diamond$ Urethan, 3x3 g (Sigma-Aldrich, Taufkirchen, Deutschland)

$\diamond$ Thiopental (Trapanal $\left.{ }^{\circledR}\right), 75$ mg (Byk Gulden, Konstanz, Deutschland)

$\diamond$ Bromdesoxyuridin (BrdU), $50 \mathrm{mg} / \mathrm{kg}$ (Sigma-Aldrich, Taufkirchen, Deutschland)

$\diamond 4 \%$-iges Paraformaldehyd: auf 100ml 0,1M Phosphatpuffer $\left(\mathrm{Na}_{2} \mathrm{HPO}_{4}\right.$ und $\mathrm{KH}_{2} \mathrm{PO}_{4}$ im Verhältnis 81,8:18,2) wurden $4 \mathrm{~g}$ Formaldehyd gelöst. Nach Erhitzen auf $70^{\circ} \mathrm{C}$ und Zugabe von 10 Tropfen $1 \mathrm{M} \mathrm{NaOH}$ wurde die Lösung nach Abkühlen filtriert.

\section{$\diamond$ Eiweißglycerin}

$\diamond$ 3-Aminopropyltriethoxy-Silane, 98\% (Sigma-Aldrich, Taufkirchen, Deutschland)

\section{Versuchstiere und Versuchsgruppen}

Der Versuch wurde mit Weißen Neuseeländer Kaninchen (Gewicht 2-3 kg, Alter 3 Monate) durchgeführt, die zufällig auf zwei Versuchsgruppen verteilt wurden. Die erste Gruppe umfasste $\mathrm{n}=10$ Kaninchen und diente als Kontrollgruppe. Diese Tiere wurden nicht infiziert und erhielten lediglich die Anästhesie mit Urethan über 24 Stunden sowie die Antibiotikatherapie mit Ceftriaxon. Die zweite Gruppe enthielt $\mathrm{n}=11$ Versuchstiere und stellte die mit $S$. pneumoniae infizierte Gruppe dar, die - wie die erste Gruppe - über 24 Stunden mit Urethan narkotisiert und ebenfalls 
mit Ceftriaxon behandelt wurde. Beide Versuchsgruppen erhielten intravenös BrdU zur Markierung proliferiender Zellen.

\section{$\underline{\text { Versuchsablauf }}$}

Der Versuch begann damit, dass die Kaninchen durch intramuskuläre Gabe von Ketamin (25 $\mathrm{mg} / \mathrm{kg}$ ) und Xylazin $(5 \mathrm{mg} / \mathrm{kg}$ ) narkotisiert wurden. Anschließend wurden den Tieren die Ohren und der Nacken rasiert. Allen Tieren wurden zwei Zugänge gelegt, am linken Ohr ein arterieller, am rechten Ohr ein venöser. Der arterielle Zugang diente der Blutentnahme, über den venösen Zugang wurden den Tieren die oben genannten Substanzen appliziert.

Die Narkose wurde für die Dauer des gesamten Versuches aufrechterhalten. Hierzu erhielten die Tiere Urethan als 30\%-ige Lösung in $\mathrm{H}_{2} \mathrm{O}, 3 \mathrm{~g}$ Urethan in der ersten Stunde, in den nächsten vier Stunden weitere $3 \mathrm{~g}$ und wiederum $3 \mathrm{~g}$ bis zum Ende der Versuchsdurchführung (24 Stunden).

Die Infektion der Tiere der Versuchsgruppe zwei, mit $10^{6}$ KBE S. pneumoniae Typ 3, erfolgte intrathekal zum Zeitpunkt 0 Stunden. Die antibiotische Behandlung mit Ceftriaxon wurde 12 Stunden nach Infektion begonnen. Zunächst erhielten die Kaninchen 20 mg/kg iv. als Bolus und im Folgenden $10 \mathrm{mg} / \mathrm{kg} / \mathrm{h}$ iv. als Erhaltungsdosis über 12 Stunden. 24 Stunden nach Infektion wurden die Tiere mit Thiopental 75 mg iv. getötet.

\section{Gewebeentnahme und Fixierung}

Nach Tötung der Versuchstiere wurde das Gehirn entnommen. Zu diesem Zweck wurde die Medulla oblongata vom Rückenmark abgetrennt. Sofort nach der Entnahme wurden die rechte und linke Hemisphäre voneinander getrennt, der rechte Frontalkortex wurde entfernt und der verbliebene dorsale Anteil in 4\%-igem Paraformaldehyd für 24 Stunden fixiert. Die Präparation der linken Hemisphäre erfolgte so, dass die Formatio hippocampi heraus präpariert und der linke Kortex isoliert wurden. Der rechte Frontalkortex sowie der Kortex und das Hippokampus-Gewebe der linken Hemisphäre wurden bei $-70{ }^{\circ} \mathrm{C}$ konserviert.

\section{Herstellung der Schnitte}

Nach Fixierung wurden die entnommenen Gewebe in aufsteigender Alkoholreihe entwässert und in Paraffin eingebettet. Nachfolgend wurden Schnitte von $1 \mu \mathrm{m}$ Dicke angefertigt. Die Objektträger wurden für die HE-Färbung mit Eiweißglycerin und für die anderen Färbungen mit Silan beschichtet. Die Schnitte wurden im Anschluss getrocknet. 


\subsubsection{Das Mausmodell}

Im Rahmen der Versuchsreihe wurden Mäuse ebenfalls mit dem Keim Streptococcus pneumoniae Typ 3 infiziert. Der Bakterienstamm (minimale Hemmkonzentration/minimale bakterizide Konzentration von Ceftriaxon 0,03/0,06 mg/l) wurde auf Blutagarplatten bei $37{ }^{\circ} \mathrm{C}$ kultiviert, mit $0,9 \% \mathrm{NaCl}$ abgeerntet und bei $-70{ }^{\circ} \mathrm{C}$ aufbewahrt. 24 Stunden nach Infektion wurde die Antibiotikatherapie mit Ceftriaxon begonnen.

\section{Verwendete Substanzen und Dosierungen}

$\diamond$ Ceftriaxon $\left(\right.$ Rocephin $^{\circledR}$ ), $100 \mathrm{mg} / \mathrm{kg}, 2 \mathrm{x}$ täglich über 5 Tage

(Hoffmann-LaRoche, Grenzach-Whylen, Deutschland)

$\diamond \mathrm{NaCl}, 0,9 \%$-ige Lösung (Merck AG, Darmstadt, Deutschland)

$\diamond$ Bromdesoxyuridin (BrdU), 50 mg/kg, 5 x 3-stündlich, 30 Stunden bis 18 Stunden vor Tötung

(Sigma-Aldrich, Taufkirchen, Deutschland)

$\diamond$ Ketamin, 100 mg/kg (CP-Plasma, Burgdorf, Deutschland)

$\diamond$ Xylazin $\left(\right.$ Rompun $\left.^{\circledR}\right), 10 \mathrm{mg} / \mathrm{kg}$ (Bayer AG, Leverkusen, Deutschland)

$\diamond 4 \%$-iges Paraformaldehyd: auf 100ml 0,1M Phosphatpuffer $\left(\mathrm{Na}_{2} \mathrm{HPO}_{4}\right.$ und $\mathrm{KH}_{2} \mathrm{PO}_{4}$ im Verhältnis 81,8:18,2) wurden $4 \mathrm{~g}$ Formaldehyd gelöst. Nach Erhitzen auf $70^{\circ} \mathrm{C}$ und Zugabe von 10 Tropfen $1 \mathrm{M} \mathrm{NaOH}$ wurde die Lösung nach Abkühlen filtriert.

$\diamond$ Eiweißglycerin

$\diamond 3$-Aminopropyltriethoxy-Silane 98\% (Sigma-Aldrich, Taufkirchen, Deutschland)

\section{Versuchstiere und Versuchsgruppen}

Als Versuchstiere dienten männliche C57BL/6-Mäuse (Gewicht 26-37 g, Alter 5-7 Monate) (Charles River GmbH, Sulzfeld, Deutschland). Die Tiere wurden zufällig auf zwei Versuchsgruppen aufgeteilt. Die erste Versuchsgruppe mit $\mathrm{n}=35$ Tieren stellte die mit $S$. pneumoniae infizierte Gruppe dar. Die zweite Gruppe enthielt $\mathrm{n}=30$ Tiere und diente als nicht-infizierte Kontrollgruppe; sie erhielten keine antibiotische Therapie. Allen Tieren wurde BrdU intraperitoneal appliziert.

\section{$\underline{\text { Versuchsablauf }}$}

Den Tieren der ersten Versuchsgruppe wurde zur Infektion $10 \mu \mathrm{l}$ 0,9\%-ige NaCl-Lösung, die $10^{4}$ KBE von Streptococcus pneumoniae enthielt, in das rechte Frontalhirn injiziert. Die Tiere der Kontrollgruppe erhielten eine Injektion mit steriler 0,9\%-iger NaCl-Lösung ebenfalls in das rechte Frontalhirn. Nach 24 Stunden wurde die subkutane antibiotische Therapie begonnen. Hierzu erhielten die Tiere $100 \mathrm{mg} / \mathrm{kg}$ Ceftriaxon zwei Mal täglich über fünf Tage. Das Intervall zwischen Infektion und Therapiebeginn wurde kurz gewählt, um die Mortalität möglichst gering zu halten. 
Die körperliche Beeinträchtigung in Folge der Meningitis wurde während der antibiotischen Behandlungszeit durch wiederholte Seiltests bewertet (Wellmer et al. 2000).

Zur Beurteilung der proliferativen Aktivität der neuronalen Progenitorzellen der subventrikulären Zone des Gyrus dentatus erhielten vier entsprechende Gruppen von Tieren (sechs aus der Gruppe der infizierte Tiere, sechs Kontrolltiere) an den Tagen 2, 6, 10 und 16 nach Infektion fünf intraperitoneale Injektionen von BrdU (50 mg/kg) in 3-stündlichen Intervallen von 30 Stunden bis 18 Stunden vor der Tötung. Um eine Aussage zum Langzeitüberleben der BrdU-markierten Zellen treffen zu können, wurden weitere Gruppen von Tieren (sechs infizierte Tiere, sechs Kontrolltiere) zwischen Tag 7 und Tag 10 zwei Mal täglich mit einer BrdU-Injektion (50 mg/kg) behandelt und weitere vier Wochen später getötet (Tag 38 nach Infektion). Zur Beurteilung der basalen Proliferationsrate erhielten 6 Mäuse BrdU ohne weitere Behandlung und wurden noch am Tag der Injektion getötet. Zur Tötung der Tiere wurde eine Anästhesie mit Ketamin 100 mg/kg und Xylazin $10 \mathrm{mg} / \mathrm{kg}$ durchgeführt und die Tiere mit 4\%-igem Formalin perfundiert.

\section{Gewebeentnahme und Fixierung}

Nach Tötung der Versuchstiere wurde das Gehirn entnommen und bei $-70{ }^{\circ} \mathrm{C}$ konserviert.

\section{Herstellung der Schnitte}

Nach Fixierung wurden die entnommenen Gewebe in aufsteigender Alkoholreihe entwässert und in Paraffin eingebettet. Nachfolgend wurden Schnitte von $1 \mu \mathrm{m}$ Dicke angefertigt. Die Objektträger wurden für die HE-Färbung mit Eiweißglycerin und für die anderen Färbungen mit Silan beschichtet. Die Schnitte wurden im Anschluss getrocknet. 


\subsection{Färbemethoden}

Für unsere Arbeiten nutzten wir bereits etablierte Färbemethoden, die schnell reproduzierbar, lichtmikroskopisch darstellbar und mit so wenig Präparationsschritten wie möglich durchführbar waren.

\subsubsection{Hämatoxylin-Eosin-Färbung (HE)}

Die Hämatoxylin-Eosin-Färbung wurde nach dem neuropathologischen Standardprotokoll durchgeführt. Es handelt sich um eine der am weitesten verbreiteten Routinefärbemethoden, bei der durch zwei verschiedene Einzelfärbungen die Zellkerne mit der DNA blau und die Zellplasmaproteine rot erscheinen. Die Methode diente als Übersichtsfärbung der gewonnen Schnitte.

\section{Verwendete Substanzen und Dosierungen}

$\diamond$ Xylol (Merck AG, Darmstadt, Deutschland)

$\diamond$ Ethanol, $100 \%, 90 \%, 70 \%, 50 \%$

$\diamond$ Aqua dest.

$\diamond$ Hämalaun nach Meyer (Merck AG, Darmstadt, Deutschland)

$\diamond \mathrm{HCl}-\mathrm{Alkohol}$

$\diamond$ Leitungswasser

$\diamond$ Eosin, 0,1\%-ige Gebrauchslösung: $10 \mathrm{ml}$ 1\%-ige Stammlösung + $90 \mathrm{ml}$ Aqua dest.

+ 1 Tropfen konzentrierte Essigsäure

\section{Durchführung}

Die Schnitte wurden zunächst für 30 Minuten bei $60^{\circ} \mathrm{C}$ in den Brutschrank gegeben. Entparaffinieren in einer absteigend konzentrierten Alkoholreihe (3x Xylol je 5 Minuten, Ethanol 100\% 2x3 Minuten, 90\% und 70\% je 2 Minuten, 50\% kurz eingetaucht). Nach Spülung in Aqua dest. standen die Schnitte 10 Minuten in Hämalaun (nach Meyer). Danach 10-15 Sekunden Spülen in HClAlkohol und weitere 10 Minuten Bläuen in Leitungswasser. Abschließend für 4 Minuten Tränken in Eosin, Fixation durch Eintauchen in aufsteigende Alkoholkonzentrationen (50\%, 70\%, 90\%, 100\% Xylol) und Eindeckeln. 


\subsubsection{In-Situ-Tailing (IST)}

Beim apoptotischen Zelltod kommt es durch internukleosomale DNA-Spaltung zur DNAFragmentation. Dabei entstehen viele neue DNA-3`-OH-Enden in apoptotischen Zellkernen. Zur Markierung dieser Enden doppel- oder einzelsträngiger DNA wird beim In-Situ-Tailing die Terminale Transferase (DNA-Deoxynucleotidylexotransferase) benutzt. Durch die Zugabe von Digoxigenin-dUTP-markierten Nukleotiden (DIG-UTP) kommt es zur Hybridisierung an die denaturierte, zu markierende DNA, indem DIG-UTP alle 20-25 Nukleotide in die neusynthetisierte DNA eingebaut wird. Durch Bindung eines Alkalische-Phosphatase-gekoppelten AntiDigoxigenin-Antikörpers werden die neugebildeten DNA-Stränge markiert und mittels chromogenem Substrat NBT/BCIP die apoptotischen Zellkerne schwarz angefärbt. Durch Gegenfärbung mit Kernechtrot können die intakten Zellkerne rot den apoptotischen gegenübergestellt werden (Roche Diagnostics, Version 1, Januar 2000).

Die Markierung apoptotischer Zellen mittels In-Situ-Tailing in vitro und in vivo stellt ein sensitives Verfahren dar. Mit dieser Färbung ist eine Differenzierung der zwei Mechanismen Apoptose und Nekrose im frühen Stadium des Zelltodes möglich. Um die Sensitivität der Färbung zu untermauern, wurde durch Gold et al. die Tailing-Reaktion mit einer Giemsa-Färbung verglichen, die eine komplette Korrelation zwischen der Markierung durch die Terminale Transferase und der typischen Morphologie der Apoptose zeigte (Gold et al. 1994). Heute ist das In-Situ-Tailing als Standardverfahren zum Nachweis des apoptotischen Zelltodes neuronaler Zellen weit verbreitet.

\section{Verwendete Substanzen und Dosierungen}

$\diamond$ Xylol (Merck AG, Darmstadt, Deutschland)

$\diamond$ Ethanol, $100 \%, 96 \%, 70 \%, 50 \%$

$\diamond$ Aqua dest.

$\diamond$ Proteinase K (Sigma, Deisenhofen, Deutschland): Stammlösung 5 mg/ml (in TBS)

für die Gebrauchslösung 1:50 verdünnt (Andauung)

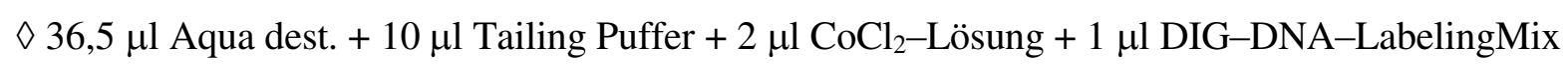

$+0,5 \mu \mathrm{l}$ terminale Transferase-Lösung pro Schnitt (Roche Diagnostics, Mannheim, Deutsch land) (Tailing-Mix)

$\diamond$ Tris Buffered Saline $($ TBS $)=17 \mathrm{~g} \mathrm{NaCl}$ (J. T. Baker, Holland) $+12,1 \mathrm{~g}$ TRIS $($ Carl Roth GmbH \& Co, Karlsruhe, Deutschland) ad $1900 \mathrm{ml}$ Aqua dest. $+1 \mathrm{M}-\mathrm{HCl}$ bis ph 7,5 eingestellt (Puffer)

$\diamond$ FCS, 10\%-ig (Biochrom KG, Berlin), in TBS verdünnt (Serum)

$\diamond 50 \mathrm{ml}$ NBT/BCIP-Substratpuffer $\left(12,11 \mathrm{~g}\right.$ TRIS $+5,84 \mathrm{~g} \mathrm{NaCl}+10,17 \mathrm{~g} \mathrm{MgCl}_{2}$ ad 11 Aqua dest. auf pH 9,5) $+225 \mu \mathrm{l} \mathrm{NBT}+175 \mu \mathrm{l}$ BCIP (Chromogen)

$\diamond$ Kernechtrot (Gegenfärbung) 
$\diamond$ IMMU-MOUNT (Thermo Shandon, USA) (Eindeckeln)

\section{Durchführung}

Entparaffinieren der $1 \mu \mathrm{m}$ dicken Schnitte in Xylol (3x10 Minuten) und absteigenden Ethanolkonzentrationen $(2 \times 100 \%, 1 \times 96 \%, 1 \times 70 \%, 1 \times 50 \%$; je 3 Minuten), anschließend wurden sie mehrfach in Aqua dest. und TBS gespült. Andauung mit Proteinase K. Dazu wurden $100 \mu \mathrm{l}$ der Gebrauchslösung aufgetragen und für 15 Minuten bei $37^{\circ} \mathrm{C}$ in einer feuchten Kammer inkubiert. Danach 2x Spülung in TBS und für 5 Minuten Stellen in eiskaltes TBS. Nach Auftragen von $50 \mu 1$ Tailing-Mix und Auflegen von Deckgläsern erneut Inkubieren der Schnitte bei $37{ }^{\circ} \mathrm{C}$ in einer feuchten Kammer. Nach 1 Stunde wurden die Deckgläser in einer Küvette mit TBS abgelöst und die Schnitte 4-5x in TBS gespült. Auftragen von $100 \mu 1$ 10\%-igem FCS und Inkubation in der feuchten Kammer für weitere 15-20 Minuten bei Raumtemperatur. Nach vorsichtigem Abklopfen der Flüssigkeit wurde im nächsten Schritt der mit Alkalischer Phosphatase-gekoppelte AntiDigoxigenin-Antikörper in einer Verdünnung von 1:250 (mit 10\%-igem FCS) aufgetragen und 1 Stunde bei Raumtemperatur stehen gelassen. Vor Entwicklung der Schnitte mit chromogenem Substrat erneute Spülung in TBS, 4-5x. Nach 5 Minuten Entwicklungszeit wurde eine erste mikroskopische Kontrolle durchgeführt und die Schnitte am Ende der Entwicklung in Aqua dest. vom restlichen Chromogen gereinigt. Zum Abschluss Gegenfärbung mit Kernechtrot für 10 Minuten und Spülung in Leitungswasser. Eindeckeln mit IMMU-MOUNT. 


\subsubsection{Anti-Bromdesoxyuridin-Färbung (Anti-BrdU)}

Proliferierende Zellen bauen in Gegenwart von 5-Brom-2-Desoxyuridin (BrdU) dieses als Thymidin-Analogon während der DNS-Synthese (S-Phase des Zellzyklus) in die DNA ein. Bei der Färbung mit BrdU kommt es zu einer Bindung des monoklonalen Antikörpers gegen das Thymidin-Analogon 5-Brom-2-Desoxyuridin, der das in die DNA eingebaute BrdU erkennt. Hierfür muss die im Zellkern vorliegende DNA zuvor denaturiert/fixiert beziehungsweise partiell degradiert werden, so dass zum Teil DNA-Einzelstränge vorliegen. Der Antikörper reagiert nicht Kreuz mit zellulären Komponenten wie Thymidin, Uridin oder DNA. Die Anti-BrdU-Färbung wird in der Immunozyto- und Immunohistochemie zum qualitativen Nachweis von proliferierenden Zellen auf Einzel-Zell-Ebene durch Licht-Mikroskopie genutzt (Roche Diagnostics, Version 3, November 1999).

Cameron und McKay zeigten in ihrer Studie 2001, dass der S-Phasen-Marker BrdU als spezifischer, quantitativer und nicht-toxischer Marker zum Nachweis sich teilender Zellen im Gyrus dentatus der adulten Ratte eingesetzt werden kann, wenn hohe Dosen gegeben werden $(300 \mathrm{mg} / \mathrm{kg})$. Beim Einsatz niedriger Dosen kommt es nur zur Markierung eines Bruchteiles der SPhase-Zellen (Cameron und McKay 2001). Zuvor war bereits der Einsatz von BrdU bei der embryonalen Neurogenese gut untersucht worden. Die intraperitoneale Gabe von $50 \mathrm{mg} / \mathrm{kg}$ ist die geringste mögliche Dosis, die zur Markierung der Zellen in der S-Phase in der Region der kortikalen ventrikulären Zone bei der embryonalen Maus ausreicht und gleichzeitig keine toxischen Phänomene zur Folge hat (Miller und Nowakowski 1988). Neben dem Nutzen von BrdU sind auch Nachteile bekannt, z. B. dass es nicht absolut spezifisch für sich teilende Zellen ist, sondern auch solche Neurone markiert, die mit der Reparatur kleiner Mengen von DNA beschäftigt sind (Selden et al. 1993). Auch kann es als Mutagen wirken, hohe Dosen haben einen nachteiligen Effekt bei embryonalen und neonatalen Ratten (Kolb et al. 1999).

Für den zuverlässigen Nachweis neurogenetischer Zellen im Gyrus dentatus der Formatio hippocampi ist BrdU heute ein gut etablierter und häufig eingesetzter Marker. Aus diesem Grund zogen auch wir BrdU als Marker für unsere Studie heran.

\section{Verwendete Substanzen und Dosierungen}

$\diamond$ Xylol (Merck AG, Darmstadt, Deutschland)

$\diamond$ Ethanol, $100 \%, 96 \%, 70 \%, 50 \%$

$\diamond$ Aqua dest.

$\diamond$ Citratpuffer, 2,1 g Citronensäure-1-Hydrat auf 11 Aqua bidest. auffüllen und pH auf 6 einstellen (Merck AG, Darmstadt, Deutschland) (Behandlung im Mikrowellengerät)

$\diamond$ PBS, 9,55 g auf 11 Aqua bidest. (Dulbecco, Biochrom AG, Berlin, Deutschland) (Puffer) 
$\diamond \mathrm{H}_{2} \mathrm{O}_{2}$ (Merck AG, Darmstadt, Deutschland) (Peroxidaseinhibitor)

$\diamond$ FCS, 10\%-ig (Biochrom KG, Berlin, Deutschland), in TBS verdünnt (Serum)

$\diamond$ Anti-Bromdesoxyuridin-POD; monoklonaler Antikörper gegen das Thymidin-Analogon 5-

Brom-2'-Desoxyuridin, Fab-Fragmente konjugiert mit Peroxidase (Roche Diagnostics, Mann heim, Deutschland) (Antikörper)

$\diamond$ Anti-MAP-2, monoklonaer Maus-Antikörper, 1:400 verdünnt (Roche Diagnostics, Mannheim, Deutschland)

$\diamond$ Rabbit Anti-TUC-4 Protein, polyklonaler Antiköper, 1:1,500 verdünnt (Chemicon International Inc)

$\diamond$ Maus Anti-beta-tubulin-Antikörper, monoklonal, 1:500 verdünnt (Covence, Richmond, CA)

$\diamond 3,3-$ Diaminobenzidin (DAB-Substrat) (Roche Diagnostics, Mannheim, Deutschland) (Substrat lösung)

$\diamond$ Hämalaun nach Meyer (Merck AG, Darmstadt, Deutschland) (Gegenfärbung)

$\diamond$ löslicher APAAP-Komplex

$\diamond$ Neufuchsin

$\diamond$ IMMU-MOUNT (Thermo Shandon, USA) (Eindeckeln)

\section{Durchführung}

Entparaffinieren der Schnitte in Alkohol (3x 10 Minuten Xylol; 2x100\%, 1x96\%, 1x70\%, 1x50\% Ethanol je 3 Minuten) und Spülen in Aqua dest. Einstellen in Citratpuffer (pH 6), 5x3 Minuten Kochen in der Mikrowelle und Spülen mit PBS. Um die endogene Peroxidase zu blockieren, wurde 30\%-iges $\mathrm{H}_{2} \mathrm{O}_{2}$ in einer Küvette mit PBS auf 0,3\% verdünnt (50 ml PBS $+500 \mu \mathrm{H}_{2} \mathrm{O}_{2} 30 \%$ ) und die Schnitte für 15 Minuten hineingestellt. Im Anschluss erneut Waschen in PBS (3x), bevor jeweils $100 \mu \mathrm{l}$ 10\%-iges FCS (in PBS verdünnt) aufgetragen und die Schnitte 20 Minuten bei Raumtemperatur inkubiert wurden. Im nächsten Schritt Überschichten der Schnitte mit $100 \mu \mathrm{l}$ Anti-BrdU-Antikörper $(1 \mathrm{U} / \mathrm{ml})$ und Inkubation in feuchter Kammer für 2,5 Stunden bei Raumtemperatur. 3x Waschen in PBS, Auftragen der Substratlösung DAB (1:10) und 3-10 Minuten Entwicklung unter mikroskopischer Kontrolle. Nach Abschluss der Entwicklung Spülung in $\mathrm{H}_{2} \mathrm{O}$, Gegenfärben mit Hämalaun.

Einzelne Schnitte des Mausmodells wurden ausgewählt und zusätzlich mit den entsprechend verdünnten Antikörpern Anti-MAP-2, Anti-TUC-4 und Anti-beta-Tubulin überschichtet. AlkalinPhosphatase/Anti-Alkalin-Phosphatase-Methode und Visualisieren mit Neufuchsin. Eindeckeln mit IMMU-MOUNT. 
2.3 Quantifikation der apoptotischen und BrdU-markierten Zellen

Sowohl bei den Mäusen als auch bei den Kaninchen wurden die HE-gefärbten Schnitte gebraucht, um die Fläche der Körnerzellschicht zu messen. Dazu wurde ein Contron Videoplan Morphometrie-Computer (Grundig, Deutschland) genutzt. Für die Zählungen der Apoptosen bzw. proliferierenden Zellen im Gyrus dentatus wurden jeweils die entsprechend gefärbten Folgeschnitte herangezogen.

In den angrenzenden Hirnarealen wurde die Dichte der BrdU-markierten Zellen ebenso wie die der durch In-Situ-Tailing markierten Zellen - mit apoptotischer Morphologie - gezählt. Die Dichte der immunomarkierten und apoptotischen Zellen wurde als Anzahl der markierten Zellen der Körnerzellschicht des Gyrus dentatus pro $\mathrm{mm}^{2}$ angegeben.

Zur Feststellung, dass es sich bei den mittels In-Situ-Tailing bzw. BrdU-markierten Zellen um Neurone handelt, wurde ergänzend ausgewertet, ob Doppel-Markierungen mit MAP-2, TUC-4 und beta-Tubulin vorliegen. Außerdem wurden Doppel-Markierungen von In-Situ-Tailing und BrdU im Kaninchenmodell $(n=6)$ angelegt.

\subsection{Statistische Analyse}

Die Unterschiede zwischen den einzelnen experimentellen Gruppen wurden mit dem MannWhitney-U-Test untersucht. Ein p-Wert $<0.05$ wurde als statistisch signifikant betrachtet. Die erhobenen Daten werden in Diagrammen als Mediane und Quartile (25. und 75. Perzentil) wiedergegeben. 


\section{ERGEBNISSE}

Es ist bekannt, dass mit Hilfe verschiedener Marker in tierexperimentellen Studien neu-generierte Neurone identifiziert werden können. Diese Methoden haben wir im Rahmen der vorgelegten Arbeit ebenfalls genutzt, um in zwei verschiedenen Tiermodellen die bei einer bakteriellen Meningitis ablaufenden Zelluntergänge den Proliferationen neuer Zellen gegenüberzustellen.

Die Ergebnisse der beiden Tiermodelle werden nachfolgend im Einzelnen dargestellt. Die entsprechenden mikroskopischen Bilder der histologischen Schnitte des Maus- und Kaninchenmodells sind im Bildanhang präsentiert.

\subsection{Ergebnisse Mausmodell}

Die im Mausmodell mit Streptococcus pneumoniae infizierten Tiere $(\mathrm{n}=35)$ entwickelten alle eine Meningitis. Da fünf Tiere bereits während der akuten Phase der Infektion verstarben, wurden sie von den weiteren Analysen ausgeschlossen. Die übrigen infizierten Tiere $(n=30)$ erholten sich vollständig von der Infektion im Anschluss an die antibiotische Behandlung mit Ceftriaxon.

Mittels wiederholter Seiltests wurde die Beeinträchtigung der körperlichen Aktivität bei den Meningitis-Mäusen im Vergleich zur nicht-infizierten Kontrollgruppe ( $\mathrm{n}=30)$ untersucht. Hierbei zeigte sich, dass die erkrankten Tiere ein schlechteres Ergebnis und damit eine größere Einschränkung aufwiesen $(\mathrm{p}=0.001)$.

In den nach Tötung der Mäuse hergestellten Schnitten gelang bei allen Tieren der Nachweis BrdU-positiv gefärbter Zellen in der subgranulären Zone des Gyrus dentatus (Bildanhang Abb. 3). Es fiel auf, dass am sechsten Tag nach intrazerebraler Infektion mit Streptococcus pneumoniae die Dichte der mit Brd-U markierten neuronalen Progenitorzellen in der Meningitis-Gruppe höher waren als in der Kontroll-Gruppe, in welcher die Tiere intrazerebral ausschließlich Kochsalzlösung erhalten hatten (Bildanhang Abb. 4). Die Differenz war mit $\mathrm{p}=0,004$ signifikant. Im Unterschied dazu erreichten die Abweichungen an den Tagen zwei und zehn nach Infektion nur nahezu statistische Signifikanz $(\mathrm{p}=0,06)$.

Weiterhin konnte gezeigt werden, dass in der Gruppe der an Meningitis leidenden Tiere die Dichte der BrdU-positiven Zellen am zweiten Tag nach der Infektion einen Höchststand erreichte. In den Tagen danach ging sie langsam wieder zurück (Diagramm A). 
Um das weitere Überleben und die neuronale Zugehörigkeit der neugeborenen Zellen beurteilen zu können, wurden zusätzlich an einzelnen ausgewählten Schnitten Färbungen mit Antikörpern gegen BrdU kombiniert mit dem neuronalen Marker MAP-2 angefertigt (vier Wochen nach der letzten Injektion von BrdU, entspricht 38 Tage post infectionem). Anschließend wurde die Dichte derjenigen Zellen mit einer Doppelmarkierung für BrdU und MAP-2 gemessen. Hiermit konnten wir folgende Nachweise erbringen: dadurch dass MAP-2-Isoformen ausschließlich in neuronalen Zellen exprimiert werden, konnten die BrdU-positiven Zellen als eindeutig neuronalen Ursprunges identifiziert werden. Andererseits gelang es uns zu zeigen, dass die Zellen mehrere Wochen nach der Infektion noch nachweisbar sind und nicht einem frühen Zelltod erliegen (Bildanhang Abb. 6).

Die Anzahl der BrdU-markierten Zellen, die in den Tieren mit stattgehabter Meningitis gefunden wurde, war höher als in der Kontrollgruppe $(\mathrm{p}=0,02)$. Überdies war die Dichte der doppelt immuno-markierten Zellen in der Gruppe der Tiere nach Meningitis höher ( $p=0,005)$ (Diagramm B). Annäherungsweise $60 \%$ der neugeborenen Zellen bei den Meningitis-Tieren differenzierten sich in Neurone und migrierten tiefer in die Körnerzellschicht (Bildanhang Abb. 5), was durch die Färbung mit dem neuronalen Marker MAP-2 gezeigt wurde (Bildanhang Abb. 6).

Die BrdU-positiven Zellen waren weiterhin für die neuronalen Marker TUC-4 und beta-Tubulin positiv (Bildanhang Abb. 7, 8), hier wurden ebenfalls einzelne Schnitte doppelt immunomarkiert. Das neuronale Markerprotein TUC-4 wird fast ausschließlich in früh-postmitotischen Neuronen in erster Linie im Zytoplasma und typischerweise in der Hochphase des axonalen Wachstums exprimiert. Damit kann neben der Eindeutigkeit des neuronalen Ursprunges auch gezeigt werden, dass die doppelt-positiven Zellen weder adulte Neurone noch neuronale Progenitorzellen sind.

Das Zytoskelett-Protein beta-Tubulin besteht aus verschiedenen Gewebe-spezifischen Isoformen, beta-III-Tubulin gilt als Neuronen-spezifisch. Somit zeigten wir auch mit diesem gut etablierten Marker, dass es sich bei den mittels BrdU-Färbung identifizierten neu gebildeten Zellen tatsächlich um Neurone handelt. 


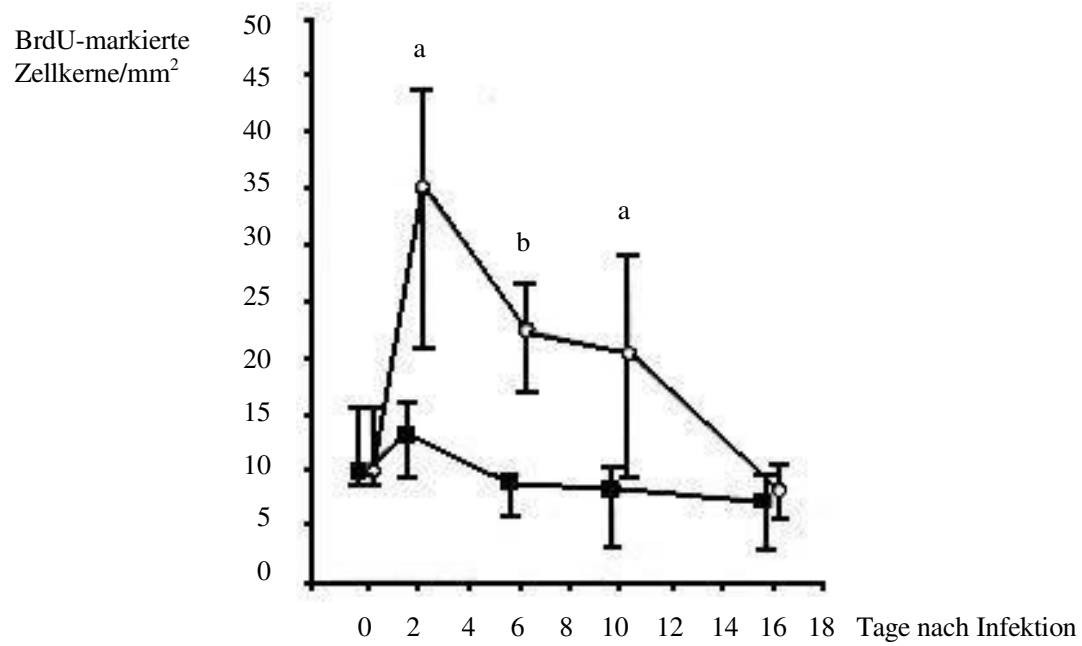

Diagramm A: Dichte BrdU-positiver Zellen in der subgranulären Zone des Gyrus dentatus der Maus nach Induktion einer bakteriellen Meningitis (Kreise) und in der Kontrollgruppe (Kästchen) an Tag 0, 2, 6, 10 und 16 nach Infektion, $\mathrm{n}=6$ zu jedem Zeitpunkt. a: $p=0.06$ gegenüber Kontrolle, $b: p=0.004$ gegenüber Kontrolle.

Median, 25\%- und 75\%-Quantile.

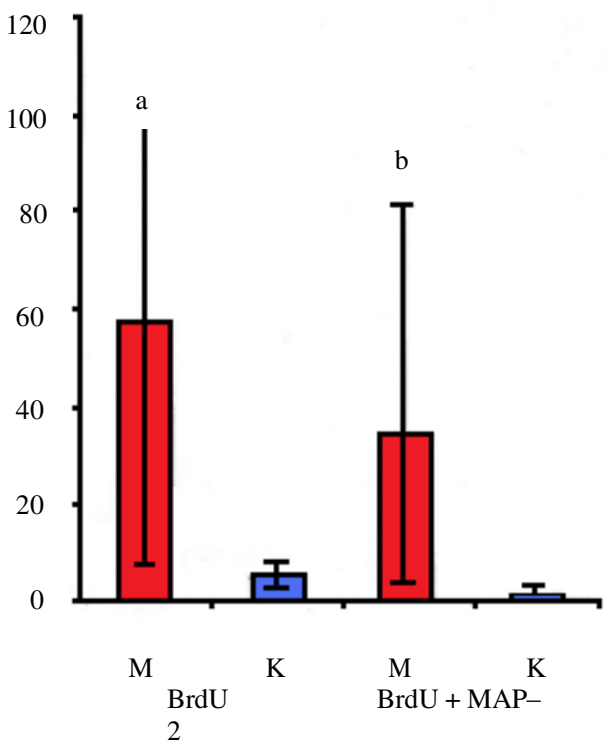

Diagramm B: Dichte BrdU-positiver bzw. BrdU- und MAP-2 positiver Zellen im Gyrus dentatus der Maus 38 Tage nach Induktion einer bakteriellen Meningitis

(28 Tage nach Exposition gegenüber BrdU), $\mathrm{n}=6$. M: Meningitis, K: Kontrolle. a: $p=0.02$ gegenüber Kontrolle, $b: p=0.005$ gegenüber Kontrolle.

Median, 25\%- und 75\%-Quantile. 


\subsection{Ergebnisse Kaninchenmodell}

Im Kaninchenmodell wurden $n=9$ Tiere aus der Versuchsgruppe $n=9$ Tieren in der Kontrolgruppe gegenübergestellt.

\subsubsection{Entzündungsparameter im Liquor}

Während des Experimentes wurde neben dem Laktat- und Proteinspiegel im Liquor zerebrospinalis auch die Anzahl der weißen Blutkörperchen bestimmt. Diese Parameter sind bei einer ablaufenden Entzündungsreaktion des ZNS regelmäßig erhöht. Die - im Rahmen der in unserem Versuch induzierten bakteriellen Meningitis mit Streptococcus pneumoniae - gemessenen Werte waren im Vergleich zu den gesunden Kontroll-Tieren ebenfalls erhöht. Die genannten Parameter werden nachfolgend einzeln dargestellt.

\section{a. Leukozyten}

Die Anzahl der Leukozyten wurde in beiden Gruppen (Meningitis-Tiere und nicht-infizierte Kontrollgruppe) 12 und 24 Stunden nach Versuchsbeginn im Liquor zerebrospinalis gemessen. Hierbei zeigten sich deutlich höhere Werte in der Gruppe der mit bakterieller Meningitis infizierten Kaninchen gegenüber der Kontrollgruppe. Der Unterschied war sowohl 12 als auch 24 Stunden nach Infektion mit $\mathrm{p}<0.05$ signifikant (Tabelle 1 ).

\section{b. Laktat}

Die Laktatwerte im Liquor wurden zur Beurteilung der anaeroben Glykolyse während der ablaufenden Meningitis gemessen und die erhaltenen Konzentrationen mit denen der Kontrollgruppe (nicht-infizierte Kaninchen) verglichen. Auch hier zeigte sich eine Differenz mit höheren Konzentrationen in der Gruppe der infizierten Tiere. Beide Messungen (12 und 24 Stunden nach Infektion) zeigten im Vergleich der erkrankten mit den gesunden Tieren mit $\mathrm{p}<0.05$ statistische Signifikanz (Tabelle 1).

\section{c. Protein}

Der Proteingehalt des Liquor zerebrospinalis kann als Ausdruck für die erhöhte Permeabilität der Blut-Hirn-Schranke während einer Infektion des ZNS betrachtet werden. In unserem Versuch fiel auch für diesen Wert ein signifikanter Unterschied $(\mathrm{p}<0.05)$ zwischen der Gruppe der an Meningitis leidenden und den gesunden Kontroll-Tieren auf (Tabelle 1). 


\subsubsection{Apoptosen im Gyrus dentatus des Hippokampus}

Im von uns untersuchten Kaninchenmodell wurden die angefertigten Schnitte nach Anfertigung der verschiedenen Färbungen auf apoptotische Zellen mikroskopiert und ausgewertet. Hierbei zeigte sich, dass sowohl bei den gesunden, nicht-infizierten Tieren als auch bei den an Streptococcus pneumoniae-Meningitis leidenden Kaninchen Apoptosen im Gyrus dentatus des Hippokampus nachgewiesen werden konnten. Die neuronalen Apoptosen in der Körnerzellschicht des Gyrus dentatus wurden wie folgt identifiziert:

\section{Hämatoxylin-Eosin-Färbung:}

Mit dieser Färbung wurden in den Schnitten Chromatinverdichtungen und Kondensationen sowie gelegentlich auftretende apoptotische Körperchen dargestellt (Bildanhang Abb. 9, 10). Die Flächenmessung des Gyrus dentatus wurde an diesen Schnitten durchgeführt.

\section{In-Situ-Tailing (IST):}

Die beim apoptotischen Zelltod in Folge internukleosomaler DNA-Spaltung auftretenden DNAFragmentationen können mit dieser Färbung am entstehenden freien DNA-3`-Ende markiert und die apoptotischen Zellkerne schwarz angefärbt werden. Die Gegenfärbung mit Kernechtrot erlaubt die Abgrenzung gegenüber vitalen Zellkernen (rot). Die Quantifizierung erfolgte anhand der angefertigten Schnitte (Bildanhang Abb. 11-14).

Die Dichte der Apoptosen in der Körnerzellschicht des Gyrus dentatus wurde auf die gemessenen Flächen der jeweiligen Schnitte bezogen und als Anzahl pro $\mathrm{mm}^{2}$ ermittelt.

Da der apoptotische Zelltod als physiologischer Prozess ebenso in gesunden Geweben abläuft, erwarteten wir, in unserem Versuch apoptotische Zelluntergänge auch bei den nicht-infizierten Tieren nachzuweisen. Die Anzahl der apoptotischen neuronalen Zellen lag in der Kontrollgruppe bei 40,6 Apoptosen/mm² (Median).

Im Rahmen einer bakteriellen Meningitis kommt es ebenfalls zum apoptotischen Zelltod der Neurone. Die Auswertung der neuronalen Apoptosen im Gyrus dentatus zeigte entsprechend höhere Werte für die erkrankten Tiere. Die Dichte der apoptotischen Neurone lag im Median bei 227 Apoptosen $/ \mathrm{mm}^{2}$. Dier Unterschied erreichte mit $\mathrm{p}<0.0001$ statistische Signifikanz (Tabelle 1). 


\subsubsection{Neurogenese im Gyrus dentatus des Hippokampus}

Zur Beurteilung der Neurogeneserate wurden für beide Gruppen (infizierte und gesunde Tiere) die entsprechend identifizierten Zellen in der Körnerzellschicht des Gyrus dentatus ausgezählt. Um die neu gebildeten Neurone darstellen zu können, wurde folgende Methode verwendet:

\section{Anti-Bromdesoxyuridin-Färbung (Anti-BrdU):}

Proliferierende Zellen bauen in Gegenwart von BrdU dieses als Thymidin-Analogon während der DNS-Synthese in die DNA ein. Durch die Markierung mit einem Antikörper gegen BrdU können auf Einzel-Zell-Ebene jene Zellen lichtmikroskopisch nachgewiesen werden, die während der Replikation BrdU in die DNA eingebaut haben.

Die Dichte der proliferierenden Neurone in der Körnerzellschicht des Gyrus dentatus wurde analog zur Dichte der Apoptosen als Anzahl pro $\mathrm{mm}^{2}$ angegeben.

BrdU-positive Zellen in der subgranulären Zone des Gyrus dentatus konnten in allen Tieren nachgewiesen werden. Im Einzelnen lag die Dichte der BrdU-markierten Zellen in der Gruppe der infizierten Tiere im Median bei 51,7 pro $\mathrm{mm}^{2}$. Die Auswertung der Kontrollgruppe mit den gesunden Tieren ergab eine Dichte von 24,1 positiven Zellen pro $\mathrm{mm}^{2}$ (Median).

Die Differenz zwischen den beiden Gruppen 24 Stunden nach induzierter Meningitis erreichte somit statistische Signifikanz mit $\mathrm{p}=0,03$ (Diagramm C, Bildanhang Abb. 15-18).

Um bei BrdU-positiven Zellen einen frühen apoptotischen Zelltod auszuschließen, wurden ergänzend Doppelmarkierungen mit IST und Anti-BrdU-Antikörpern durchgeführt. Hierbei zeigte sich, dass weniger als $10 \%$ der BrdU-positiven Zellen zugleich im IST positiv gefärbt waren.

In der Kontrollgruppe konnte keine Korrelation zwischen der Dichte BrdU-markierter Zellen und der Dichte der IST-positiven Zellen bemerkt werden (Spearman's rank correlation coefficient $\mathrm{r}_{\mathrm{s}}=$ $-0.07, \mathrm{p}=0.88)$.

In der Gruppe der Meningitistiere war die Korrelation zwischen der Anzahl proliferierender und apoptotischer Zellen schwach und erreichte keine statistische Signifikanz $\left(r_{s}=0.65, p=0.07\right)$. 
3.3 Tabellarische Übersicht der Laborwerte im Kaninchenmodell

\begin{tabular}{|l|c|c|}
\hline & Meningitis & Kontrolle \\
\hline Leukozyten (1/microl) 12h & $288(128 / 565)^{*}$ & $0(0 / 11)$ \\
Leukozyten (1/microl) 24h & $5141(3371 / 9429)^{*}$ & $11(6 / 43)$ \\
\hline Laktat (mmol/l) 12h & $4.3(3.3 / 5.9)^{*}$ & $1.5(1.4 / 1.7)$ \\
Laktat (mmol/l) 24h & $8.7(6.9 / 9.1)^{*}$ & $1.5(1.3 / 1.9)$ \\
\hline Protein (mg/l) 12h & $944(667 / 1725)$ & $627(527 / 786)$ \\
Protein (mg/l) 24h & $3940(2573 / 4260)^{*}$ & $1397(1020 / 1829)$ \\
\hline Apoptotische Neurone & $227(98.7 / 339.3)^{*}$ & $40.6(37.3 / 44.8)$ \\
$\left(\mathbf{1} / \mathbf{m m}^{2}\right) \mathbf{2 4 h}$ & $51.7(36 / 57.1)^{*}$ & $24.1(18.5 / 44.4)$ \\
\hline BrdU-markierte Zellen & & \\
$\left(\mathbf{1} / \mathbf{m m}^{\mathbf{2}}\right) \mathbf{2 4 h}$ & & \\
\hline
\end{tabular}

Tab. 1: Leukozytenzahl, Konzentrationen von Laktat und Protein im Liquor. Zahl der apoptotischen und BrdUpositiven Neurone in der Körnerzellschicht des Gyrus dentatus pro $\mathrm{mm}^{2}$.

Alle Werte wurden 12 bzw. 24 Stunden nach Infektion gemessen und werden als Median sowie 25\%- und 75\%Quantile in Klammern angegeben.

Die mit * markierten Werte in der Meningitisgruppe sind mit $\mathrm{p}<0,05$ gegenüber der Kontrollgruppe statistisch signifikant.

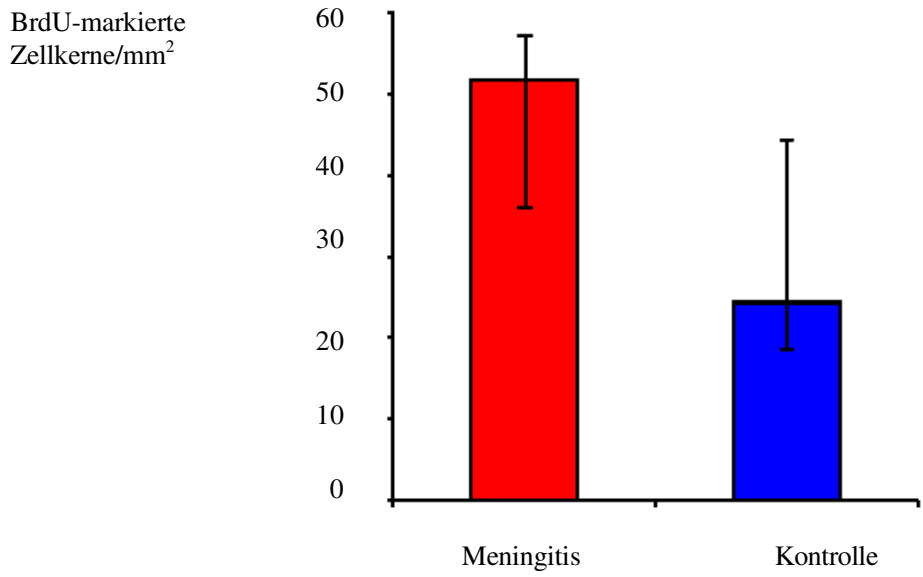

Diagramm C: Anzahl BrdU-positiver Zellen, angegeben in 1/mm². Median, 25\%- und 75\%-Quantile. 


\section{DISKUSSION}

\subsection{Allgemein}

Während der Ausbildung des Nervensystems sterben 50-80\% der Zellen, die geboren werden, bevor sie ausgewachsen sind (Oppenheim 1991). Mit Abschluss der embryonalen Entwicklung des ZNS verbleiben in verschiedenen Regionen neuronale Stammzellen, die während des gesamten weiteren Lebens proliferative Aktivität zeigen. Außerdem können diese Zellen von ihrem ursprünglichen Ort auswandern und in ein Neuronennetzwerk integriert werden, um dort spezifische Funktionen zu übernehmen. Biebl et al. zeigten 2000, dass nur ein kleiner Teil dieser neuronalen Zellen dauerhaft überlebt. Der überwiegende Teil unterliegt dem apoptotischen Zelltod (Biebl et al. 2000).

Die beiden Gehirnregionen, die diesbezüglich am besten untersucht sind, sind der Gyrus dentatus des Hippokampus und die subventrikuläre Zone des Seitenventrikels (SVZ) (Eriksson et al. 1998, Kornack und Rakic 1999, Kirschenbaum et al. 1994). Stammzellen wurden aber auch in Regionen nachgewiesen, die unter normalen Bedingungen keine neurogenetische Aktivität zeigen; Striatum und Septum (Palmer et al. 1995), Rückenmark (Shihabuddin et al. 1997), zerebraler Cortex und Corpus callosum (Palmer et al 1997).

Unterschiedliche Mechanismen sind an der Regulation der adulten Neurogenese beteiligt. Die verschiedenen intrazellulären und molekulargenetischen Vorgänge unterliegen multiplen Einflüssen. Bei der Regulation der Neurogenese im Hippokampus können in vivo drei Gruppen unterschieden werden (Kempermann 2002):

1. physiologisch (Alter, Geschlecht, saisonale Einflüsse, Aktivität)

2. pathologisch

3. chemisch (Medikamente, Hormone, Neurotransmitter, Wachstumsfaktoren)

Verschiedene pathologische zerebrale Zustände wurden bezüglich proliferativer Vorgänge neuronaler Zellen untersucht. Nach einer experimentellen Autoimmunenzephalomyelitis konnte ebenso eine erhöhte Neurogenese nachgewiesen werden (Picard-Riera et al. 2002) wie im Tiermodell bei Epilepsie, Trauma und ischämischem Insult (Liu et al. 1998, Dash et al. 2001, Peterson 2002).

Potts et al. fanden hingegen in ihren experimentellen Untersuchungen nach Trauma eine verminderte neuronale Proliferationsrate im Hippokampus (Potts et al. 2009). 
In der vorgelegten Arbeit wurden der apoptotische Zelltod und die Neurogenese mittels zweier Tiermodelle untersucht. Sowohl im Maus- als auch im Kaninchenmodell wurde eine gesunde Kontrollgruppe einer mit Streptococcus pneumoniae infizierten Meningitisgruppe gegenübergestellt. Wir haben jeweils die im Gyrus dentatus des Hippokampus beobachtete neuronale Schädigung sowie das Regenerationspotential anhand der Anzahl Apoptosen und Proliferation neuronaler Progenitorzellen ausgewertet. Um die Anzahl der apoptotischen und neu gebildeten Neurone in beiden Tiermodellen vergleichen zu können, wurden die ausgezählten Zellen pro Flächeneinheit $\left(\mathrm{mm}^{2}\right)$ angegeben.

In Folge der ausgelösten Infektion kam es neben der induzierten neuronalen Schädigung der Hippokampus-Region auch zu einer erhöhten Proliferationsrate der neuronalen Progenitorzellen in der subgranulären Zone des Gyrus dentatus.

Sowohl das Kaninchen- als auch das Maus-Modell sind seit vielen Jahrzehnten anerkannte und gut etablierte Tiermodelle zur Verbesserung des Verständnisses der Abläufe bei der bakteriellen Meningitis. Erste Dokumentationen stammen aus den 1960-er und frühen 1970-er Jahren (Perry und Cluff 1963, Isamukhamedov et al. 1964, Tsai et al. 1975). Neben der Untersuchung der pathologischen Vorgänge im ZNS während der Infektion können die Beeinflussung durch unterschiedliche Therapie-Ansätze ebenso wie regenerative Prozesse zuverlässig dargestellt werden.

\subsection{Apoptotischer Zelltod bei Neuronen}

Neuronale Zellen können sowohl im Rahmen physiologischer Abläufe als auch in Folge pathologischer Einflüsse dem apoptotischen Zelltod unterliegen. Dieser Vorgang ist dadurch gekennzeichnet, dass Zellen in stets der gleichen Form auf diverse Reize oder Schädigungen reagieren. Die verschiedenen Stimuli, die den apoptotischen Zelluntergang auslösen sowie die körpereigenen Regulationsmechanismen wurden bereits in der Einleitung detailliert dargestellt. Die neuronale Apoptose der Zellen des Gyrus dentatus im Hippokampus stellt auch während der bakteriellen Meningitis ein übliches Merkmal der Zellschädigung dar (Zysk et al 1996, Nau et al. 1999).

Der apoptotische Zelltod von Neuronen und seine Beeinflussung ist seit Jahren Bestandteil der Meningitis-Forschung. Es ist bekannt, dass es auch bei der neuronalen Entwicklung im Rahmen der Embryogenese zum Zelltod von Neuronen kommt. Das Vorliegen neurotropher Faktoren, wie z. B. Nervenwachstumsfaktor (nerve growth factor, NGF), ist essentiell für das Überleben der Zellen. Durch Entzug von NGF in vitro setzt innerhalb 24-48 Stunden der apoptotische Zelltod ein (Martin et al. 1988). 
Neuronale Degenerationen finden sich weiterhin nach unterschiedlichen zerebralen Schädigungen, z. B. in Folge ischämisch-hypoxischer Abläufe (Iwai et al. 1995) und kann zudem experimentell, u. a. durch ionisierende Strahlung ausgelöst werden (Gobé et al. 1988).

Ebenfalls ist bekannt, dass exzitatorische Neurotransmitter in vivo und in vitro durch ihre neurotoxische Wirkung in Folge erhöhter Exposition (z. B. Glutamat) zur DNA-Fragmentation und damit neuronalen Apoptose führen können. Dies geschieht durch Inhibition der Endonuklease und mRNA-Synthese (Kure et al. 1991). Die Toxizität von Glutamat soll bei diversen Erkrankungen (z. B. Epilepsie, M. Parkinson, M. Alzheimer) an der Pathogenese beteiligt sein (Lipton und Rosenberg 1994).

Der Entzug von Steroidhormonen kann einen apoptotischen Zelluntergang bei Neuronen auslösen. Im Tiermodell konnte nach Adrenalektomie eine vermehrte Expression von p53 und ein Anstieg der neuronalen Apoptosen im Gyrus dentatus nachgewiesen werden (Schreiber et al. 1994). Hierbei ist interessant, dass der Hormonentzug einen sehr komplexen Einfluss auf den Zellstoffwechsel zu haben scheint, denn es konnte auch eine gesteigerte Neurogenese gezeigt werden (Cameron und Gould 1994).

Wir demonstrierten in unserer Arbeit anhand der beiden Tiermodelle lichtmikroskopisch mittels In-Situ-Tailing den apoptotischen Zelltod in Folge einer experimentell ausgelösten Meningitis mit Streptococcus pneumoniae. Zur histologischen Darstellung wurde dabei die immunohistochemische Markierung der bei der Apoptose entstehenden nukleären DNA-Fragmentationen (Gold et al. 1994) genutzt. Diese Technik kann sowohl für in Paraffin eingebettete Gewebeschnitte als auch bei Zellkulturen herangezogen werden (Gold et al. 1993, Ansari et al. 1993). Außerdem wurden die typischen morphologischen Kriterien - Kondensation und Schrumpfen des Zellkernes sowie schmales Zytoplasma - zur Identifizierung des apoptotischen Zelltodes mit herangezogen. Mittels der ebenfalls angefertigten HE-Färbung erhielten wir eine Übersichtsfärbung, an der die Flächenbestimmung erfolgte. Die HE-Färbung stellt eine weit verbreitet Routinefärbung dar.

Der apoptotische Zelltod der Körnerzellen des Gyrus dentatus ist ein häufiges Merkmal der Zellschädigung im Verlauf einer bakteriellen Meningitis (Zysk et al. 1996, Nau et al. 1999). In unserer Studie waren die apoptotischen Zelluntergänge der Neurone in der Körnerzellschicht des Gyrus dentatus bereits 24 Stunden nach Beginn der Infektion nachweisbar. Währenddessen fanden wir in anderen Hirnregionen keine Anzeichen für apoptotische Neurone. Die erhöhte Vulnerabilität der neuronalen Zellen des Gyrus dentatus bei abgelaufener Meningitis ist ein bekanntes Merkmal und war auch in unseren Untersuchungen nachvollziehbar. 
Im Gegensatz dazu zeigen Tiere mit hypoxisch-ischämischen Schädigungen vor allem Läsionen in der CA1-Region des Hippokampus. Dieses Areal (Sommer'scher Sektor) ist auf Grund der Gefäßversorgung des Hippokampus durch Äste der Arteria cerebri posterior besonders empfindlich gegenüber Durchblutungsstörungen (Iwai et al. 1995).

Die Anzahl der neuronalen Apoptosen im Kaninchenmodell lag in der vorliegenden Studie im Median bei 227 Zellen/mm².

Im Gegensatz dazu ist bekannt, dass die Dichte apoptotischer Zellen infolge neurodegenerativer Erkrankungen beim Menschen niedriger ist. So konnten Lassmann et al. bei Patienten mit klinisch und histologisch gesicherter Alzheimer-Erkrankung zwischen 3,3 und 52,5 Neurone pro mm2 mit DNA-Fragmentationen nachweisen (Lassmann et al. 1995).

Nau et al. untersuchten bei 20 Autopsiefällen nach Subarachnoidalblutung und globaler zerebraler Hypoxie lichtmikroskopisch das Auftreten neuronaler Apoptosen beim Menschen mittels IST. Im Gyrus dentatus des Hippokampus zeigten sich bei Subarachnoidalblutung 4.0/mm² apopotische Neurone und bei zerebraler Hypoxie 3.6/ $\mathrm{mm}^{2}$. Demgegenüber waren bei den 10 Kontrollpatienten, die in Folge nicht-neurologischer Erkrankungen starben, 0 Apoptosen pro $\mathrm{mm}^{2}$ nachweisbar (Nau et al. 2002).

Somit ist die Anzahl apoptotischer Neurone im Gyrus dentatus des Hippokampus nach bakterieller Meningitis um ein vielfaches höher, verglichen mit neurodegenerativen Erkrankungen, nach Subarachnoidalblutungen oder zerebraler Hypoxie. Hierin spiegelt sich auch die Schwere der Auswirkungen nach einer bakteriellen Infektion in der von uns untersuchten Region des ZNS wieder. 


\subsection{Neurogenese bei Neuronen}

In den 1960-er Jahren konnte entgegen der bis dahin gängigen Überzeugung demonstriert werden, dass die Neubildung von Neuronen im ZNS nicht nur während der embryonalen Entwicklung sondern auch in definierten Arealen im adulten ZNS stattfindet (Altmann 1963). Es ist bekannt, dass die Neurogenese im Gyrus dentatus des adulten Gehirnes durch diverse Stimuli beeinflussbar ist; sie kann infolge Stress (Gould et al. 1998) oder durch pharmakologische Reize (Supplementation von exzitatorischen Aminosäuren, adrenalen Steroiden) erniedrigt (Cameron et al. 1995, Cameron et al. 1998) sowie durch Training, Beschäftigung und bestimmte medikamentöse Therapien erhöht sein (Czèh et al. 2001). Die unterschiedlichen Einflüsse auf die Neurogeneserate wurden im Kapitel Neurogenese in der Einleitung bereits detailliert ausgeführt.

Die adulte Neurogenese im Gyrus dentatus wurde erstmals im Jahr 1965 beschrieben (Altmann und Das 1965). In der Folge wurde in zahlreichen Studien gezeigt, dass Neurone, die im Gyrus dentatus der adulten Ratte produziert wurden, nicht nur ein synaptisches Input erhalten, sondern auch Axone in den Moosfaser-Bahnen ausbilden und einige verschiedene neuronale Marker ausgereifter Neurone exprimieren (Gould und Tanapat 1997, Cameron et al. 1993).

Allgemein kann die Neurogenese als ein Prozess mit drei Abschnitten beschrieben werden: Proliferation, Migration und Differenzierung. Der in diversen experimentellen Studien nachgewiesene ähnliche zeitliche Ablauf der Neurogenese legt die Vermutung nahe, dass nach verschiedenen Auslösern einer Schädigung des zentralen Nervensystems ein gleichartiger ReparaturMechanismus einsetzt, um die Zellproliferation zu induzieren. Die Variation der nachgewiesenen Zellproliferationen nach Meningitis mag ein interindividuell unterschiedlich großes Potential für die Neurogenese widerspiegeln.

Die vorliegende Arbeit beschäftigte sich mit dem Nachweis neu gebildeter neuronaler Zellen im Gyrus dentatus der Formatio hippocampi anhand der Tiermodelle Kaninchen und Maus nach abgelaufener experimenteller bakterieller Meningitis mit Streptococcus pneumoniae. An den hergestellten Schnittpräparaten konnte mit Hilfe der Anti-BrdU-Färbung lichtmikroskopisch die Neurogeneserate ausgewertet werden.

Die Etablierung dieser Färbemethode zur Darstellung von S-Phase-Zellen im ZNS gelang 1988 Miller und Novakowski und wurde nachfolgend häufig zum Nachweis adulter Neurogenese eingesetzt. Eine intraperitoneale Applikation von BrdU von 50mg/kg stellt die Dosis dar, bei der alle in der S-Phase befindlichen Zellen ohne toxische Nebenwirkungen markiert werden (Miller und Novakowski 1988). Als möglicher Nachteil dieser Färbemethode bleibt festzuhalten, dass es 
eventuell nicht absolut spezifisch für sich teilende Zellen ist, da potentiell auch solche Zellen markiert werden können, die einen kleinen Anteil DNA reparieren (Schmitz et al. 1999).

In unserer Arbeit konnten wir in beiden Tiermodellen eine gesteigerte Proliferationsrate neuronaler Progenitorzellen in der subgranulären Zone des Gyrus dentatus nach abgelaufener Infektion mit Streptococcus pneumoniae im Vergleich zu den gesunden Tieren nachweisen. Der Unterschied in den Gruppen war in beiden Tiermodellen statistisch signifikant.

Dieses Ergebnis findet in der Literatur Übereinstimmung in verschiedenen Tiermodellen nach unterschiedlichen Schädigungen des ZNS.

Neben abgelaufener transienter Ischämie (Iwai et al. 2002, Felling und Levison 2003) konnte ebenfalls nach Neurotrauma (Dash et al. 2001), hypoxisch-ischämischer Enzephalopathie (Mattiesen et al. 2009), septisch-metastatischer Enzephalitis (Tauber et al. 2011) sowie bei Temporallappen-Epilepsie bei pädiatrischen Patienten (Blumcke et al. 2001) eine gesteigerte Neurogenese als Antwort auf die schädigende Wirkung nachgewiesen werden.

Die Stimulation der Zellproliferation (BrdU-positive Zellen) im Mausmodell wurde während der ersten Woche nach Infektion beobachtet (Peak an Tag 2), danach nahm sie bis auf einen basalen Level ab. Diese Beobachtung ist vergleichbar mit dem zeitlichen Verlauf bei experimenteller Ischämie oder nach traumatischen ZNS-Verletzungen (Liu et al. 1998, Dash et al. 2001). Diese Beobachtung suggeriert, dass gleichartige Mechanismen neuronaler Zellproliferation durch ganz unterschiedliche zerebrale Schädigungen induziert werden können.

Die exakten Faktoren, die zur Induktion und Regulation der gesteigerten Proliferation der Progenitorzellen beitragen und die Möglichkeit ihrer Beeinflussung sind weiterhin Gegenstand der Forschung.

Mögliche, an der Regulation der Neurogenese durch Stimulation der Progenitorzellen beteiligte Einflüsse sind neurotrophe Faktoren und die cAMP-Kaskade. Die Aktivierung der cAMPKaskade im Mausmodell führt zur Steigerung der Neurogenese (Nakagawa et al. 2002). Jin et al. zeigten 2002 eine Erhöhung des Stammzellfaktors in kortikalen Kulturen nach Hypoxie, welche sowohl in vitro als auch in vivo zu einer Stimulation der Neurogenese führte (Jin et al. 2002). Auch die Migration und das axonale Wachstum werden durch Interaktionen zwischen Neuronen und Astrozyten reguliert (Menet et al. 2001). 
Zur besseren Beurteilung des weiteren Schicksals der neugeborenen Zellen im Mausmodell wurden diejenigen Zellen untersucht, welche nach 4 Wochen noch vorlagen. Hierbei zeigten annähernd 60\% der nach 28 Tagen nachweisbaren BrdU-positiven Zellen eine Expression neuronaler Proteine. Daraus kann abgeleitet werden, dass nach einer bakteriellen Meninigits nicht nur eine Stimulation neuronaler Progenitorzellen, sondern auch ein Überleben der Zellen möglich ist und eine Differenzierung in funktionsfähige Neurone stattfinden kann.

Die Zellen migrieren in die Körnerzellschicht des Gyrus dentatus und exprimieren später neuronale Proteine und Marker wie TUC-4, MAP-2 und beta-Tubulin.

Ähnliche Ergebnisse zeigten Van Praag et al. Sie konnten in ihren Studien demonstrieren, dass 70-90\% der überlebenden Zellen nach Neurogenese-Stimulation durch Training (Laufrad) und „enriched environment“ den neuronalen Marker NeuN exprimieren (Van Praag et al. 1999a).

Untersuchungen von Nakagawa et al. bestätigen die Expression des neuronalen Markers NeuN in 75-80\% der BrdU-positiven Zellen in Mäusen nach Stimulation der Neurogenese durch Rolipram (Nakagawa et al. 2002).

Im Kaninchenmodell differenzieren bis zu 80\% der neuronalen Progenitorzellen in der subgranulären Zone des Gyrus dentatus in Neurone (Gueneau et al. 1982).

Das neuronale Markerprotein TUC-4 wird in früh-postmitotischen Neuronen in erster Linie im Zytoplasma und typischerweise in der Hochphase des axonalen Wachstums exprimiert (Quinn et al. 1999, Minturn et al. 1995). Es wird hingegen nicht in neuronalen Progenitorzellen oder erwachsenen Neuronen exprimiert (mit geringfügigen Ausnahmen). Die Daten legen nahe, dass TUC-4 eine Rolle beim axonalen Wachstum und der Wegfindung spielt, ebenso wie möglicherweise in dem Prozess, der wachsenden Axonen ermöglicht, die richtige Route zu wählen und Ziele zu erreichen (Quinn et al. 1999). Die Expression von TUC-4 zeigt zudem eine Koinzidenz mit der Expression des früh-neuronalen Markes beta-Tubulin (Quinn et al. 1999).

Tubulin ist der Hauptbestandteil von Mikrotubuli, essentiellen Zytoskelett-Proteinen, welche an der Zellteilung beteiligt sind. Es gibt mehrere gewebsspezifische Isoformen, beta-III-Tubulin wird als Neuronen-spezifischer Marker angesehen.

MAP-2 gehört zu einer Gruppe von mit Mikrotubuli verbundenen Proteinen. Die Isoform MAP-2 wird nur in neuronalen Zellen und hier speziell im Perikaryon und Dendriten exprimiert.

Der Nachweis neuronaler Proliferation mit Expression neuronaler Markerproteine im Gyrus dentatus des Hippokampus führt zu der Überlegung, dass suffiziente endogene Reparaturmechanismen vorliegen. Die entstandenen neuronalen Zerstörungen in Folge bakterieller Meningitis kön- 
nen somit eingegrenzt und partiell behoben werden. Dadurch kann ein wichtiger Beitrag zur Limitierung der Konsequenzen und Folgeschäden nach einer solchen Erkrankung geleistet werden.

Im vorgestellten Kaninchenmodell fiel weiterhin auf, dass nahezu alle apoptotischen Zellen ohne Markierung bei der Anti-BrdU-Färbung waren. Das deutet darauf hin, dass die neu generierten BrdU-positiven Neurone nicht sofort wieder zerstört werden. Stattdessen scheint eine effektive neuroregenerative Antwort auf eine Verletzung bzw. Schädigung des betroffenen Areales des ZNS möglich zu sein.

In wie weit aus der nachgewiesenen neuronalen Regeneration eine Verbesserung der Funktionsfähigkeit der Formatio hippocampi nach bakterieller Meningitis resultiert, bleibt zu erforschen. Ein Grund des bisher ausstehenden Nachweises, ob die neuen Neurone wirklich funktionstüchtig werden, ist, dass die Methoden zur Untersuchung der neuronalen Meningitis auf fixierte Gewebe beschränkt sind (Van Praag et al. 2002).

Mehrere in Studien dargelegte Hinweise deuten auf eine funktionelle Signifikanz der hippokampalen Neurogenese hin.

Der hochregulierende Effekt des „enriched environment“ bei der hippokampalen Neurogenese in adulten Mäusen ging mit einer Verbesserung der hippokampalen Leistung beim Abrufen von Lernaufgaben einher (Kempermann et al. 1997).

Eine Reduktion der Anzahl der neu generierten Neurone bei der adulten Ratte verschlechterte die Hippokampus-abhängige Spur-Konditionierung, bei der ein Tier zeitlich voneinander getrennte Impulse verknüpfen muss (Shors et al. 2001).

In ähnlicher Weise korrelierte die Zellproliferation im Gyrus dentatus negativ mit der Reaktionsfähigkeit des Bewegungsapparates auf neue Impulse (Lemaire et al. 1999).

Van Praag et al. zeigten, dass neu generierte Neurone im Gyrus dentatus des Hippokampus der adulten Maus verschiedene neuronale Eigenschaften besitzen: sie haben eine neuronale Morphologie, können passive Membraneigenschaften aufweisen, Aktionspotentiale und funktionelle synaptische Eingaben generieren, die denen gleichartig sind, die man in reifen Körnerzellen findet (Van Praag et al. 2002).

Tauber et al. zeigten 2009, dass durch „enriched environment“ keine weitere Steigerung der Meninigitis-induzierten Neurogeneserate oder des räumlichen Lernvermögens erreicht werden konnte (Tauber et al. 2009).

Daten von Liebetanz et al. beschrieben bei bakterieller Meningitis mit Streptococcus pneumoniae eine verlängerte Überlebenszeit der Tiere, geringere Mortalität, abgeschwächte entzündliche Re- 
aktion und darüber hinaus eine Zunahme der Differenzierung proliferierender Zellen in adulte Neurone im Gyrus dentatus der Maus durch körperliches Training vor Beginn der Infektion (Liebetanz et al. 2012).

Bekanntermaßen ist die Neurogenese im Gyrus dentatus des Hippokampus neben körperlichem Training und „enriched environment" auch empfindlich gegenüber pharmakologischen Einflüssen. Hierdurch ergeben sich verschiedene Möglichkeiten einer positiven oder negativen Beeinflussung der Proliferation von Progenitorzellen und ihrer weiteren Entwicklung.

Die intrazerebroventrikuläre Infusion des Breitspektrum Caspase-Inhibitors z-VAD-fmk führt zu einer vorübergehenden Erhöhung der Dichte der proliferierenden Progenitorzellen in der subgranulären Zone nach Status epilepticus. Der Mechanismus wird in der Regulation der Apoptose neu gebildeter Neurone erklärt; die apoptotischen Vorgänge der neuen Neurone werden durch die Caspase-Inhibitoren vorübergehend supprimiert, so dass eine erhöhte Neurogeneserate durch Reduktion des apoptotischen Zelltodes der neu gebildeten Neurone assoziiert sein kann (Ekdahl et al. 2001).

Eine reduzierte Neurogeneserate kann durch Alterung, Umgebungs- oder psychosozialen Stress sowie Verabreichung von Glukokortikoiden ausgelöst sein (Kuhn et al. 1996, Cameron und McKay 1999). Stress als Ursache für strukturelles Remodelling im adulten Hippokampus wurde vor allem bei depressiven Erkrankungen untersucht. Hierbei konnte neben der Suppression der Neurogenese und einer Volumenreduktion des Hippokampus eine Kürzung der Dendriten beobachtet werden (Gould et al. 1998, Magariños et al. 1996). Der Stress-induzierten Reduktion der Proliferationsrate der granulären Vorläuferzellen im Gyrus dentatus (33\%) kann durch die Gabe des modifizierten trizyklischen Antidepressivums Tianeptin vorgebeugt werden (Czèh et al. 2001). Die Beobachtungen lassen sich in der Wirkung des Neurotransmitters Serotonin als Entwicklungsregulatorisches Signal erläutern. Pränataler Mangel von Serotonin (5-Hydroxytryptamine) führt zu einem verspäteten Einsetzen der Neurogenese in den Zielregionen (Lauder 1990). Außerdem fördert Serotonin die Differenzierung kortikaler und hippokampaler Neurone (Lavdas et al. 1997).

Das räumliche Lernen von Ratten bei der „Morris water maze“ führte zu einer Erhöhung der Überlebensrate der neugeborenen neuronalen Zellen. Dies legt einen nützlichen Effekt eines frühzeitigen Trainings nach zerebralen Schädigungen nahe (Ambrogini et al. 2000). Neueste Studien zeigen im Maus-Modell, dass körperliches Training vor einer Infektion das Überleben einer bakteriellen Meningitis erhöhen und die Neurogenese im Gyrus dentatus des Hippocampus stimulieren kann (Liebetanz et al. 2012). 
Umgekehrt sind auch negative Einflüsse erforscht worden. Der glutamaterge N-Methyl-DAspartat-(NMDA-)Rezeptorblocker MK-801 (Dizocilpin) supprimiert die nach einem Schlaganfall erhöhte Neurogeneserate und stellt somit den Nutzen einer prolongierten NMDARezeptorblockade in Frage (Arvidsson et al. 2001).

Folglich können therapeutische Interventionen, die zu einer Verstärkung der endogenen Neurogenese und dem Überleben der neu generierten Neurone nach Hirnschädigungen beitragen, möglicherweise zu neuen Strategien der Neuroprotektion und Neurorehabilitation bei der bakteriellen Meningitis führen.

Sowohl in unserer Arbeit als auch in diversen anderen Studien konnte eine gesteigerte Neurogeneserate nach zerebralen Schädigungen mit den bisher bekannten Möglichkeiten der Beeinflussung dargestellt werden.

Interessant bleibt die Frage, wodurch nach unterschiedlichen Erkrankungen oder Trauma des ZNS eine oft ähnlich oder gleichförmig ablaufende regenerative Antwort in bestimmten Hirnarealen nachweisbar ist. Welche Einflüsse in der Regulation der komplexen Abläufe von NeurogeneseInduktion, Überleben der neugebildeten Neurone, Ausrichtung und Differenzierung existieren?

Als zentrale Proteine in der Signalkette wurden diejenigen der wnt-Familie identifiziert. Sie stellen Schlüsselregulatoren des neuronalen Stammzellverhaltens bei der embryonalen Entwicklung dar. Lie et al. zeigten 2005, dass wnt-Signalmoleküle (insbesondere wnt-3) auch bei der hippokampalen Neurogenese des Erwachsenen und der erwachsenen Hippokampus-Funktion wichtige Regulatoren sind. Eine Überexpression von wnt-3 führt zu einer gesteigerten Proliferation adulter hippokampaler Stammzellen in vitro und in vivo während eine Blockade eine Reduktion der Neurogenese in vitro und nahezu vollständige Aufhebung in vivo nach sich zieht (Lie et al. 2005).

Auch konnte ein neuroprotektiver Einfluss von wht auf Nervenzellen, z. B. vor AlzheimerErkrankung, gezeigt werden (Toledo et al. 2008). Bei der bakteriellen Meningitis konnte bei gesteigerter Neurogenese im Gyrus dentatus eine Expression von wnt-3 experimentell nachgewiesen werden (Gerber et al. 2009).

Eine ebenfalls wichtige Rolle, nicht nur beim embryonalen sondern auch beim adulten Gehirn, scheinen Wachstumsfaktoren wie z. B. BDNF (brain-derived neurotrophic factor) zu spielen (Tauber et al. 2005).

Im Rahmen entzündlicher ZNS-Erkrankungen, wie einer bakteriellen Meningitis, greifen auch ausgeschüttete Immunmodulatoren in die Regulation des weiteren Krankheitsverlaufes ein. Inter- 
leukin-4 und Interferon- $\gamma$ beeinflussen die Neurogenese im Mausmodell positiv (Butovsky et al. 2006). Interleukin-6 und TNF- $\alpha$ senken die Proliferationsrate neuronaler Stammzellen im Hippokampus (Monje et al. 2003).

$\mathrm{Ob}$ und in welchem Ausmaß die nachgewiesene neuronale Regeneration nach S. pneumoniaeMeningitis einen Einfluss auf die Funktionen des zentralen Nervensystems im Sinne einer Verbesserung der hippokampalen Funktion hat, bleibt weiter zu eruieren.

Auch sind vermutlich viele an der Regulation neuroregenerativer und -proliferativer Vorgänge des adulten ZNS beteiligte Faktoren noch nicht bekannt. Die in den letzten Jahren neu gewonnenen Erkenntnisse stimmen optimistisch, dass in der Zukunft neue oder adaptierte Behandlungsmöglichkeiten zur Verfügung stehen, die die bisherige antiinflammatorische und antibiotische Therapie ergänzen. 


\section{ZUSAMMENFASSUNG}

Die bakterielle Meningitis stellt ein Krankheitsbild mit noch immer hoher Letalität dar. Trotz effektiver antibiotischer Behandlung sind die Verläufe oft schwerwiegend und die Patienten leiden in einer hohen Anzahl der Fälle unter Komplikationen und Spätschäden. Die neuronale Schädigung der Formatio hippocampi ist ein bekanntes Merkmal der bakteriellen Meningitis, sowohl im Tiermodell als auch bei erkrankten Patienten. Der Nachweis einer gesteigerten Neurogeneserate nach bakterieller Meningitis im Tiermodell stellt damit eine wichtige Beobachtung dar.

In der vorliegenden Arbeit haben wir die nach einer induzierten bakteriellen Meningitis mit Streptococcus pneumoniae ablaufenden apoptotischen und neuroregenerativen Vorgänge im Tiermodell untersucht. Hierfür wurden die beiden gut etablierten Modelle der Maus und des Kaninchens herangezogen. Es wurden jeweils gleich große Gruppen infizierter Tiere mit gesunden Tieren aus der Kontrollgruppe verglichen.

Das untersuchte Hirnareal war der Gyrus dentatus des Hippokampus. Die apoptotischen Zellen wurden mittels IST und die proliferierenden Progenitorzellen mittels BrdU-Färbung immunhistochemisch nachgewiesen. Um den neuronalen Ursprung der neugebildeten Zellen bestätigen zu können, wurden im Mausmodell einzeln ausgewählte Schnitte ergänzend mit neuronalen Markern (MAP-2, TUC-4 und beta-Tubulin) gegengefärbt. Wir konnten in beiden Tiermodellen eine signifikant erhöhte Proliferationsrate neuronaler Progenitorzellen nach abgelaufener Meningitis zeigen. Die Ergebnisse können somit als Hinweis auf das vorhandene Regenerationspotential des ZNS, insbesondere des Gyrus dentatus des Hippokampus, interpretiert werden.

Dieser Nachweis bildet die Grundlage zur Erforschung weiterer Therapieansätze, in dem nicht nur die Reduktion der neuronalen Schädigung in Folge Einsatz neuer Therapeutika, sondern auch Einflüsse zur Optimierung der Neurogenese in geschädigten Hirnarealen fokussiert werden. Für die weiterhin notwendige Erarbeitung effektiver neuroprotektiver Strategien in der Behandlung der bakteriellen Meningitis kann mit den genannten Tiermodellen ein wichtiger Beitrag geleistet werden. Die zentralen Abläufe der neuronalen Schädigung sowie reparativer Regenerationsvorgänge im Bereich der Formatio hippocampi sind zuverlässig und reproduzierbar mittels etablierter Färbungen mikroskopisch gut darstell- und quantifizierbar. 


\section{BILDANHANG}

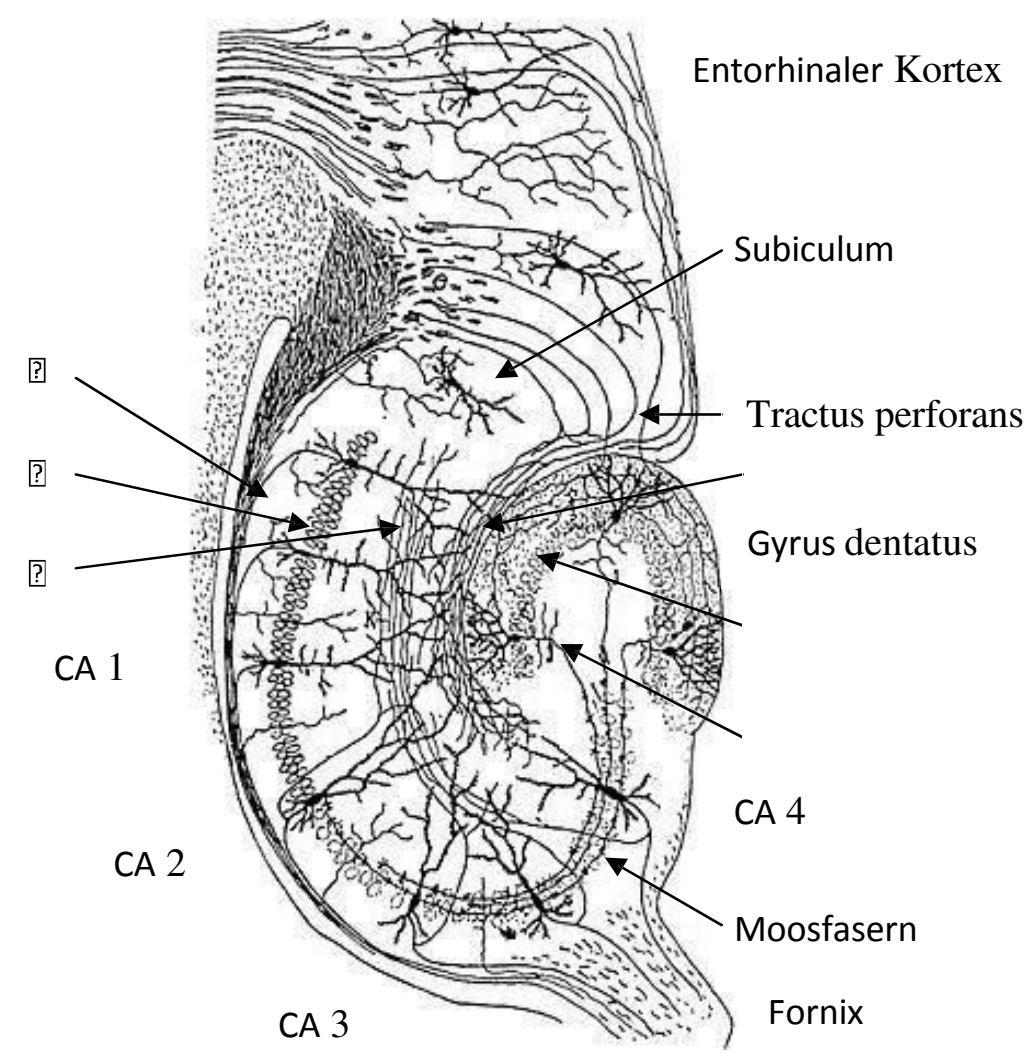

Abbildung 1: Formatio hippocampi mit entorhinalem Kortex, Subiculum, Gyrus dentatus und Regionen CA 1 bis CA 4 des Hippokampus. Die Zellschichten bestehen aus Stratum oriens (1), Stratum pyramidale (2), Stratum moleculare (3) des Hippokampus, Stratum moleculare (4), Stratum granulosum (5) und Hilus (6) des Gyrus dentatus (modifiziert nach Brown und Zador 1990, S. 348).

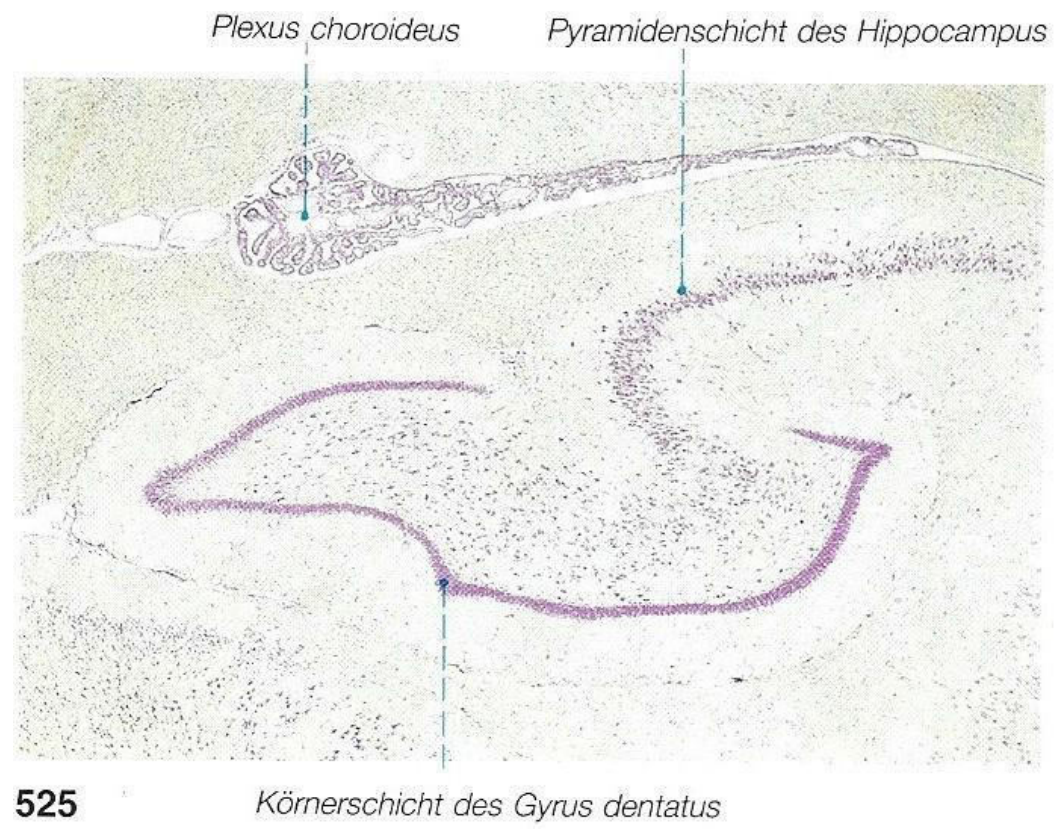

Abbildung 2: Hippokampus, histologisches Präparat (Sobotta 1997, S. 234) 


\section{Histochemische Schnitte der Körnerzellschicht des Gyrus dentatus der Maus}

(Abbildungen 3-8)

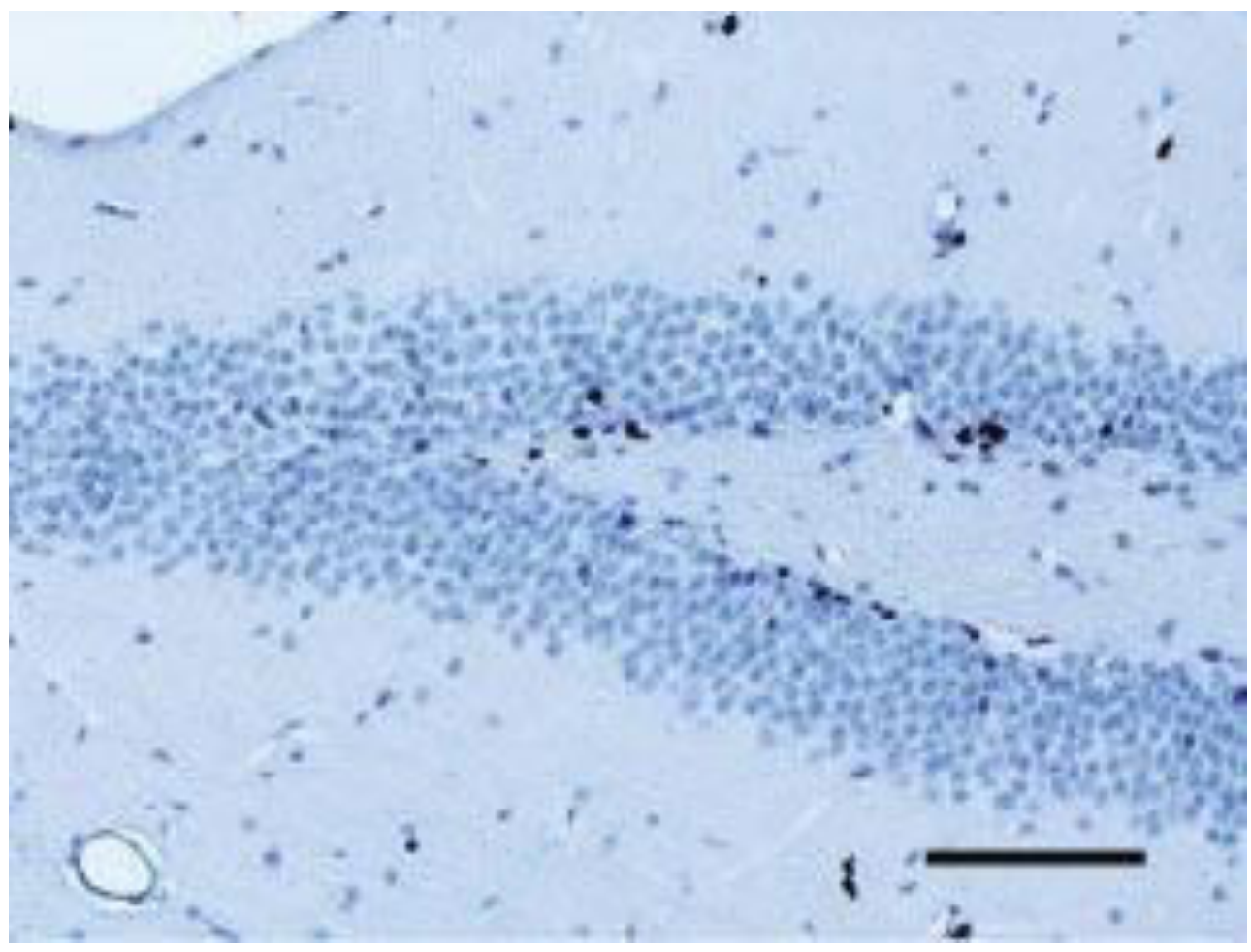

Abbildung 3: Erhöhter BrdU-uptake sechs Tage nach Infektion mit Streptococcus pneumoniae.

$(\mathrm{Maßstab} \triangleq 100 \mu \mathrm{m})$

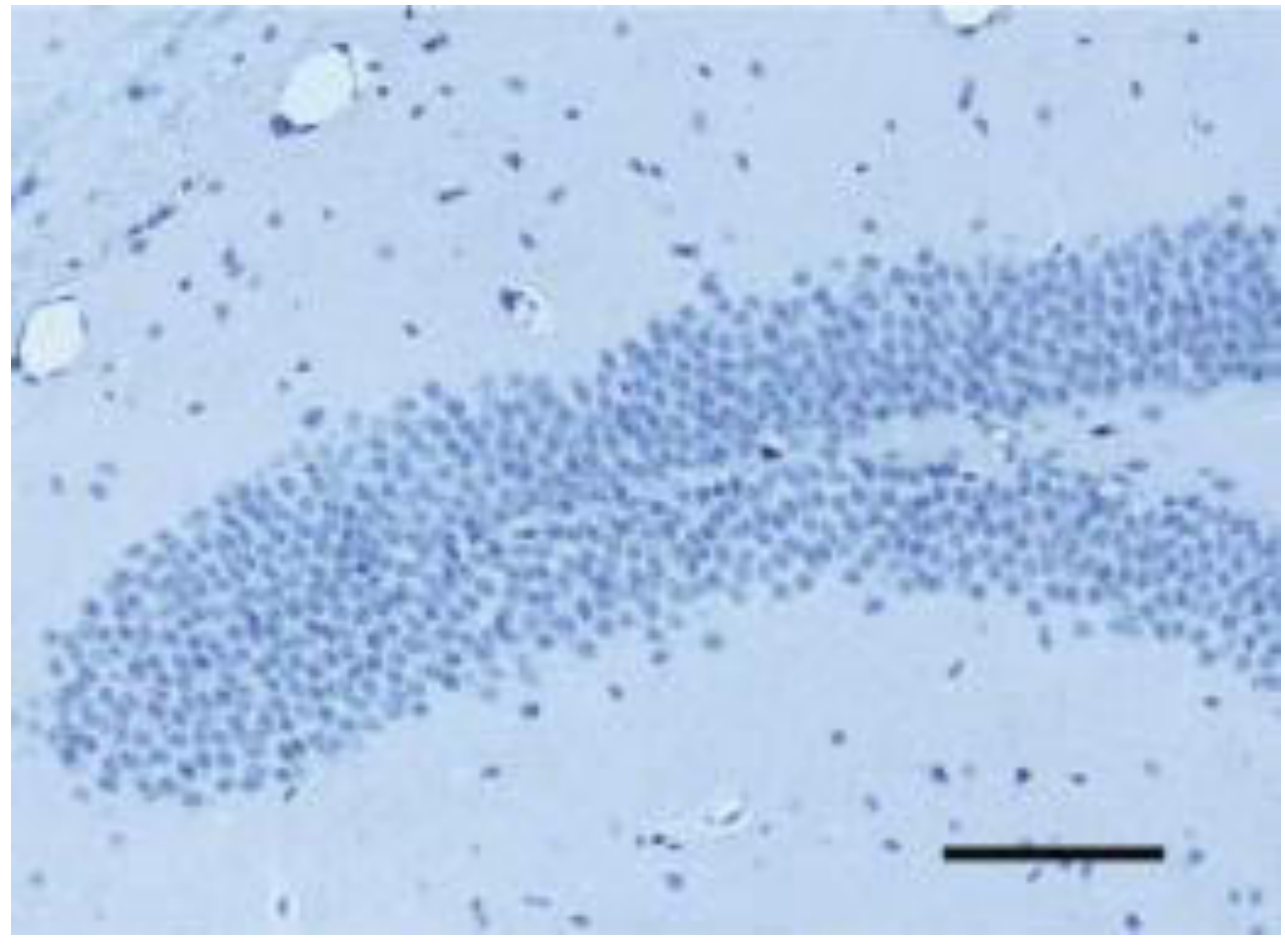

Abbildung 4: Schnitt aus der nicht-infizierten Kontrollgruppe sechs Tage nach intrazerebraler Applikation von Kochsalzlösung.

$(\mathrm{Maßstab} \triangleq 100 \mu \mathrm{m})$ 


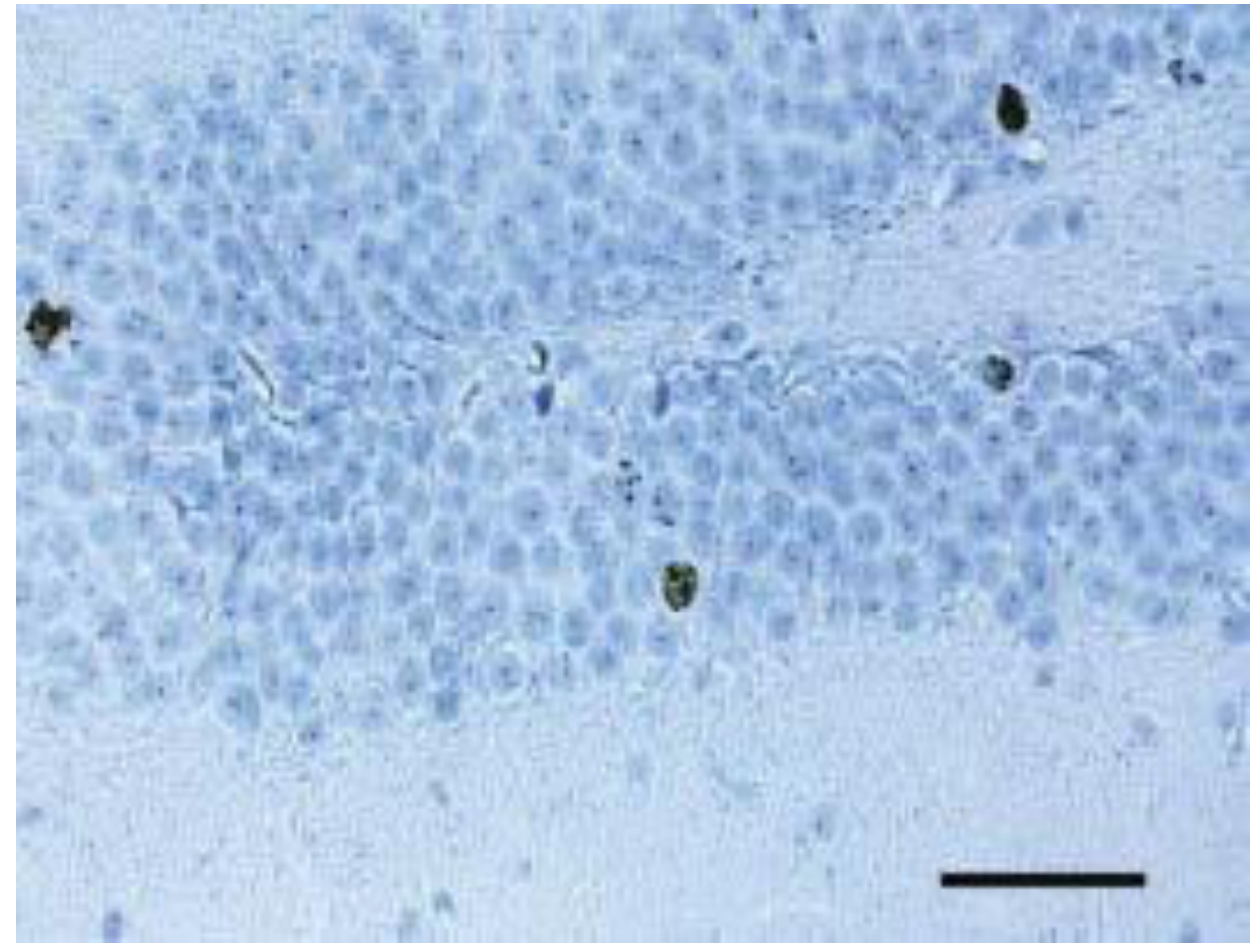

Abbildung 5: BrdU-Aufnahme 38 Tage nach Infektion/28 Tage nach Exposition gegenüber BrdU. Die Zellen migrieren tiefer in die Körnerzellschicht.

$(\mathrm{Maßstab} \triangleq 50 \mu \mathrm{m})$

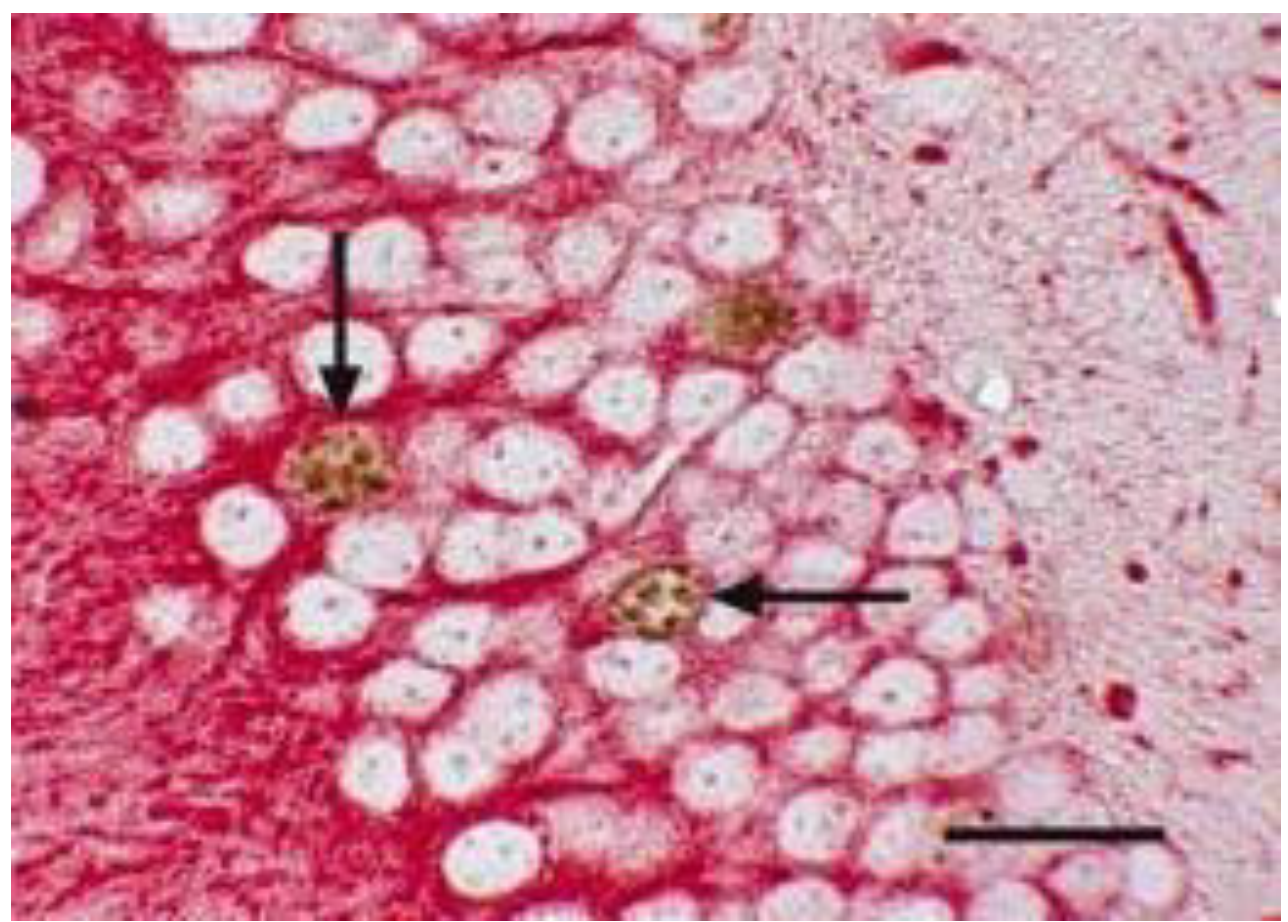

Abbildung 6: Körnerzellen des Gyrus dentatus mit Doppelmarkierungen 38 Tage nach Infektion mit Antikörpern gegen BrdU und MAP-2 (Pfeile).

$(\mathrm{Maßstab} \triangleq 20 \mu \mathrm{m})$ 


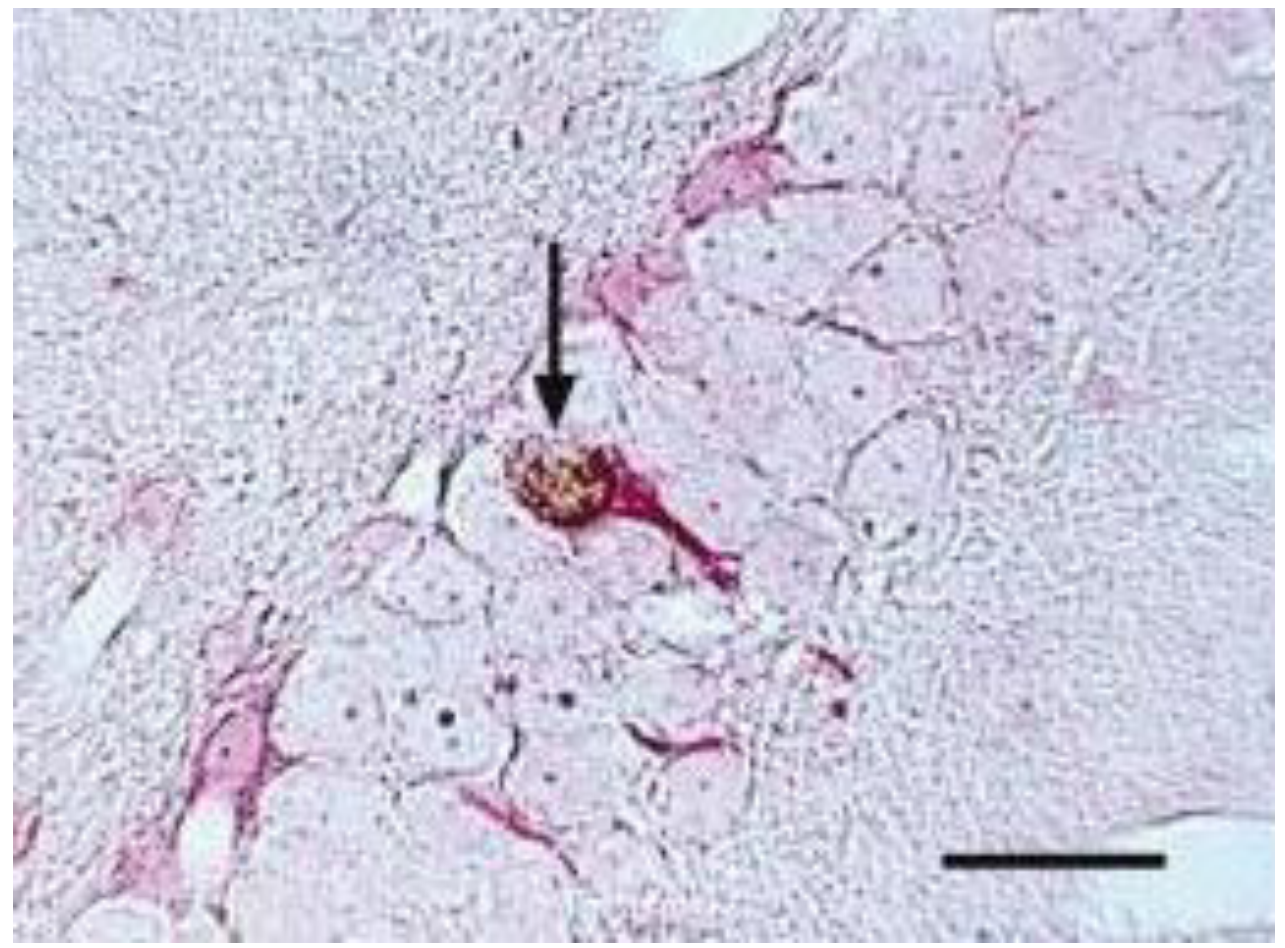

Abbildung 7: Körnerzellen des Gyrus dentatus mit Doppelmarkierungen 38 Tage nach Infektion mit Antikörpern gegen BrdU und TUC-4 (Pfeile).

$(\mathrm{Maßstab} \triangleq 20 \mu \mathrm{m})$

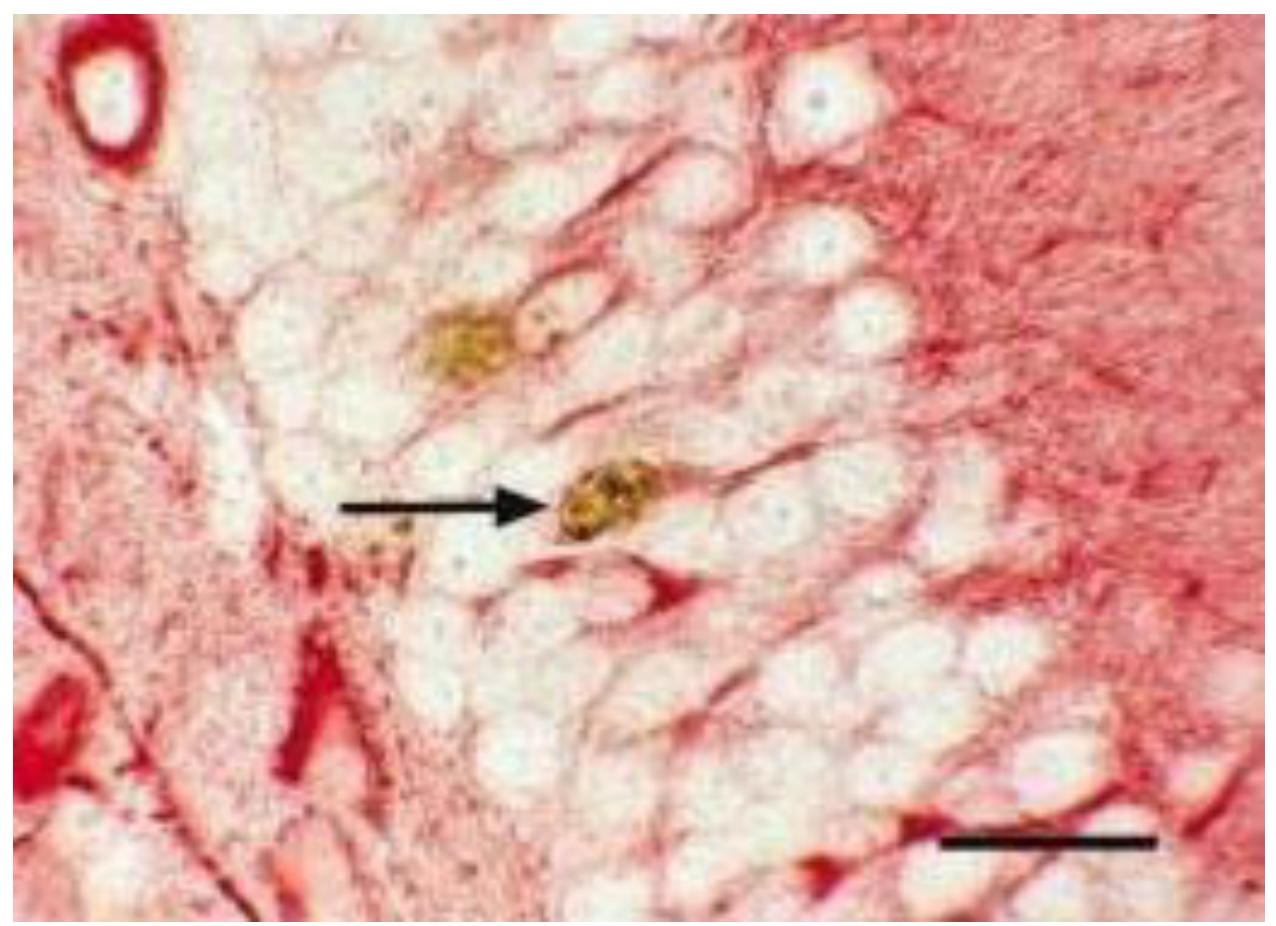

Abbildung 8: Körnerzellen des Gyrus dentatus mit Doppelmarkierungen 38 Tage nach Infektion mit Antikörpern gegen BrdU und beta-Tubulin (Pfeile).

$(\mathrm{Maßstab} \triangleq 20 \mu \mathrm{m})$ 
Histochemische Schnitte der Körnerzellschicht des Gyrus dentatus des Kaninchens (Abbildungen 9-18)

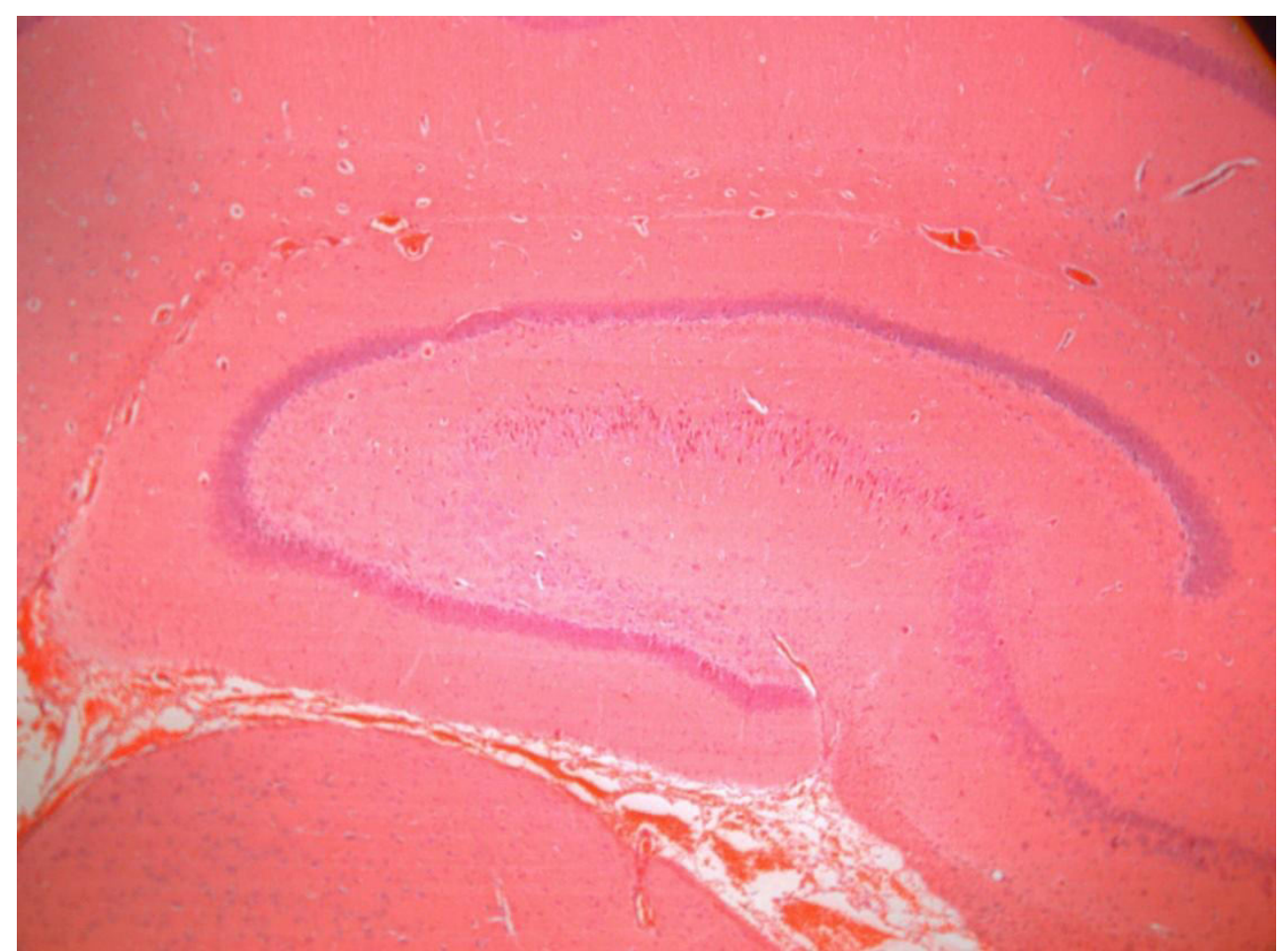

Abbildung 9: HE-Übersichtsfärbung des Gyrus dentatus eines infizierten Tieres.

(4-fache Vergrößerung).

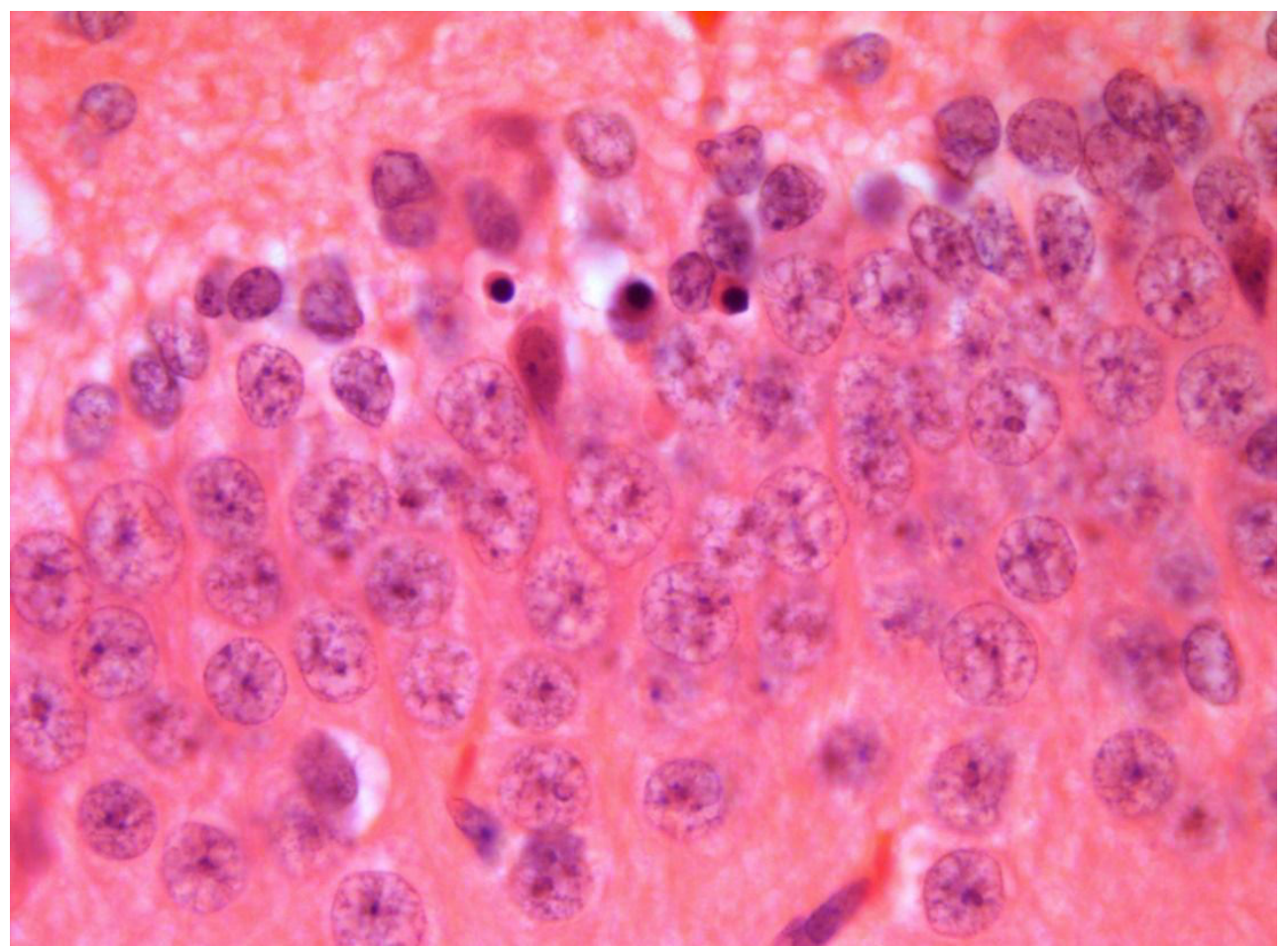

Abbildung 10: Ausschnittsvergrößerung der HE-Färbung (Abbildung 9) eines infizierten Tieres. (100-fache Vergrößerung). 


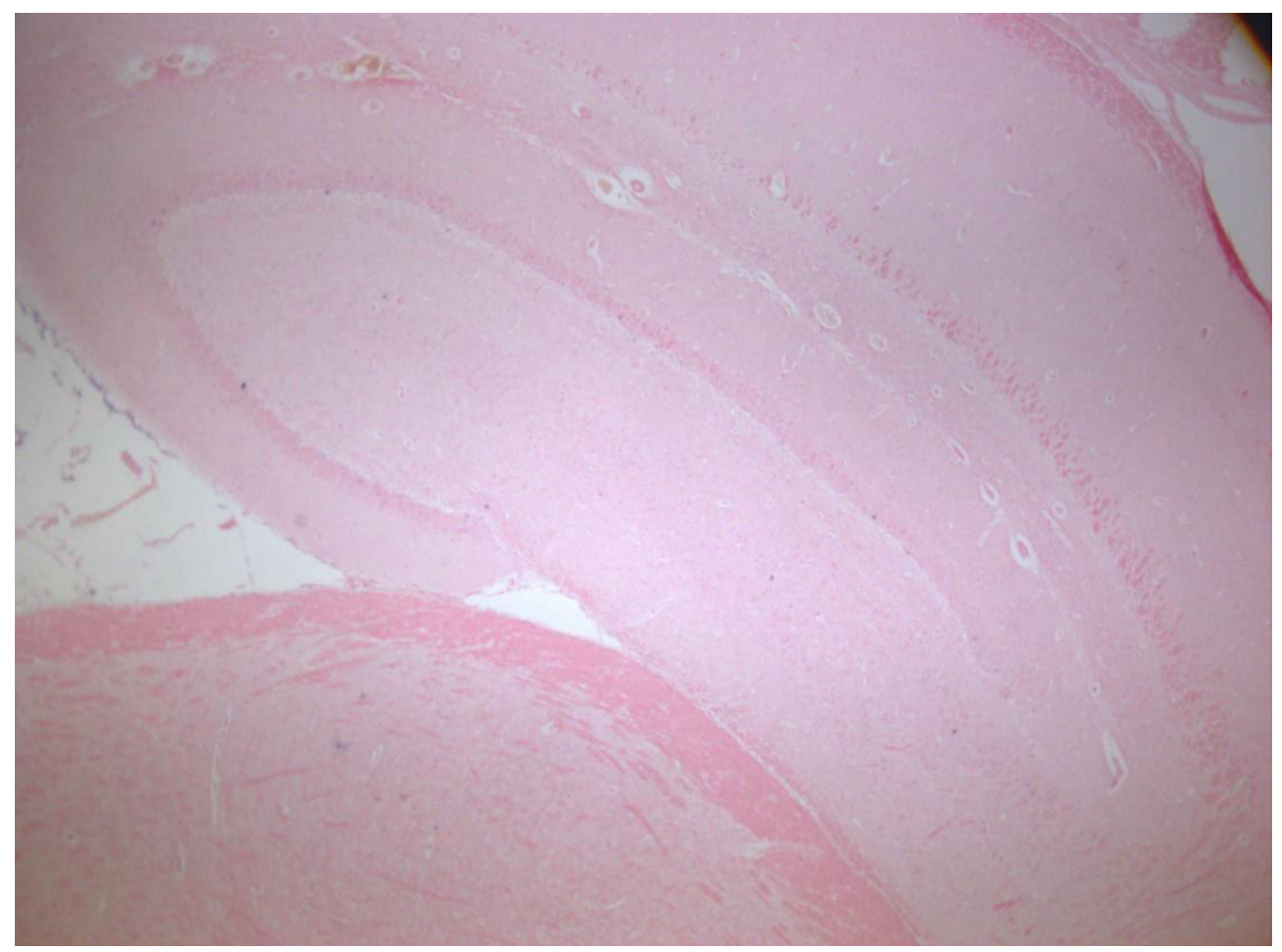

Abbildung 11: IST-Übersichtsfärbung des Gyrus dentatus eines nicht-infizierten Tieres aus der Kontrollgruppe.

(4-fache Vergrößerung).

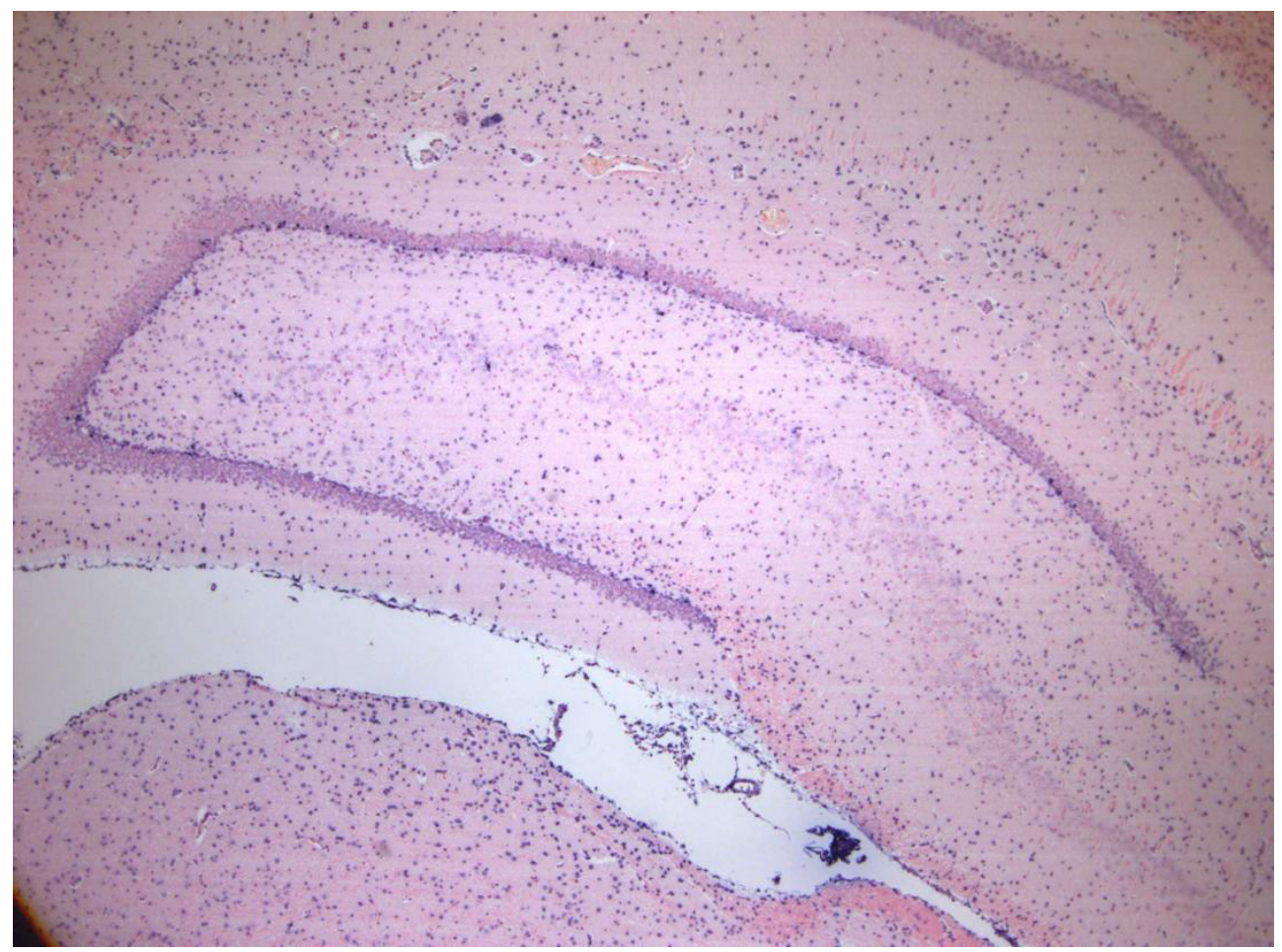

Abbildung 12: IST-Übersichtsfärbung des Gyrus dentatus eines infizierten Tieres. (4-fache Vergrößerung). 


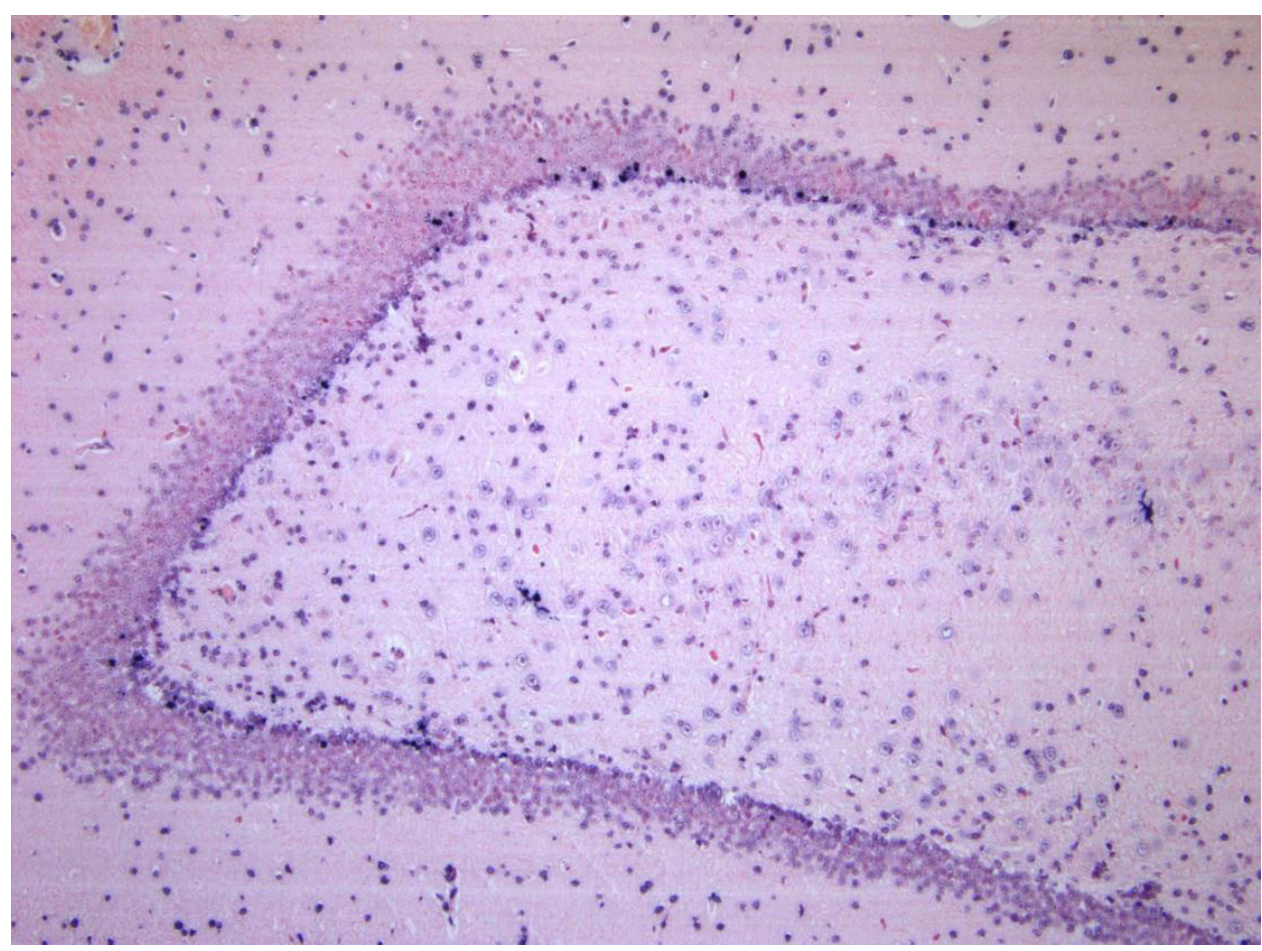

Abbildung 13: Ausschnittsvergrößerung IST-Färbung (Abbildung 12) eines infizierten Tieres. (10-fache Vergrößerung).

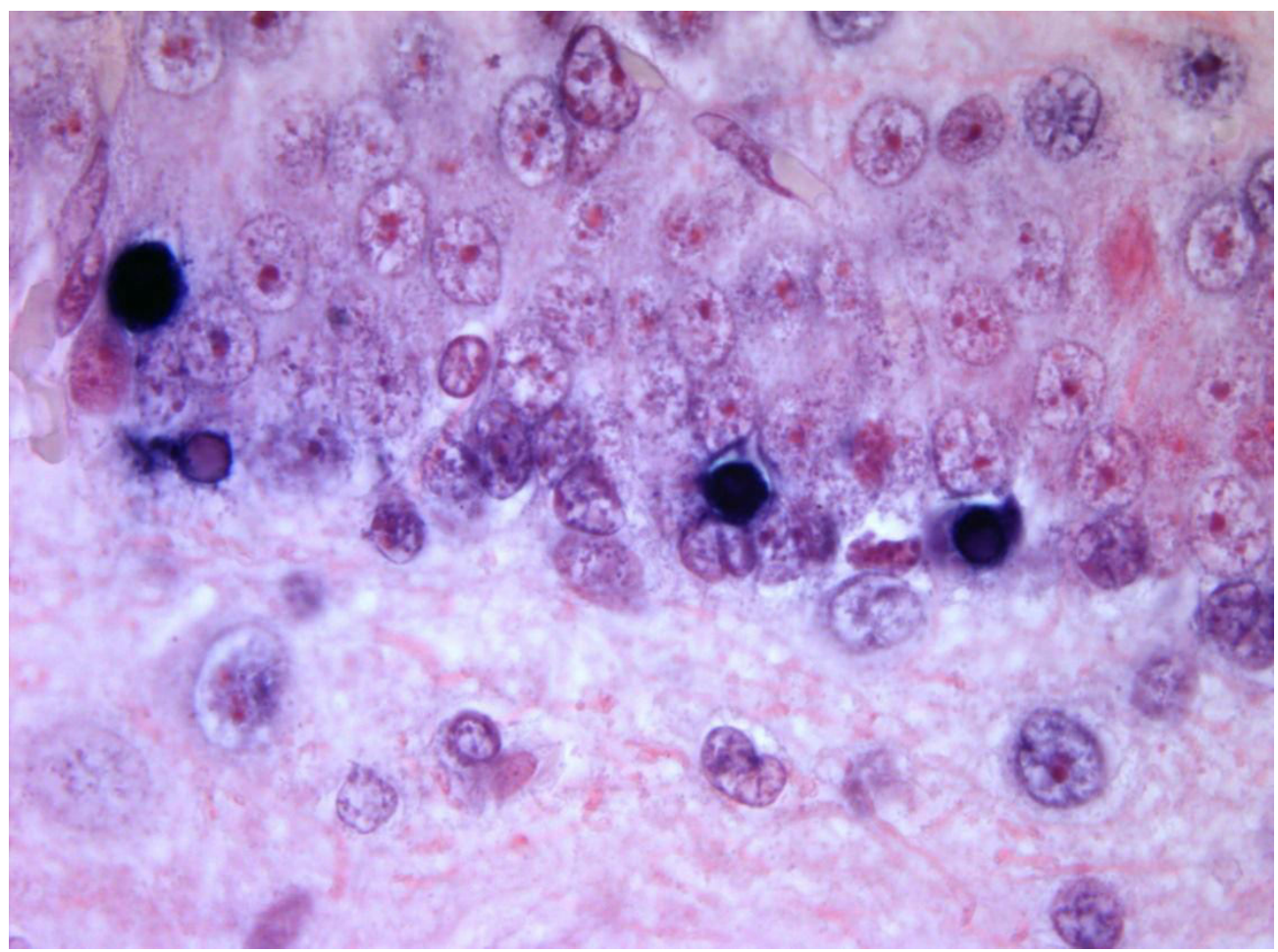

Abbildung 14: Ausschnittsvergrößerung IST-Färbung (Abbildung 12) eines infizierten Tieres. (100-fache Vergrößerung). 


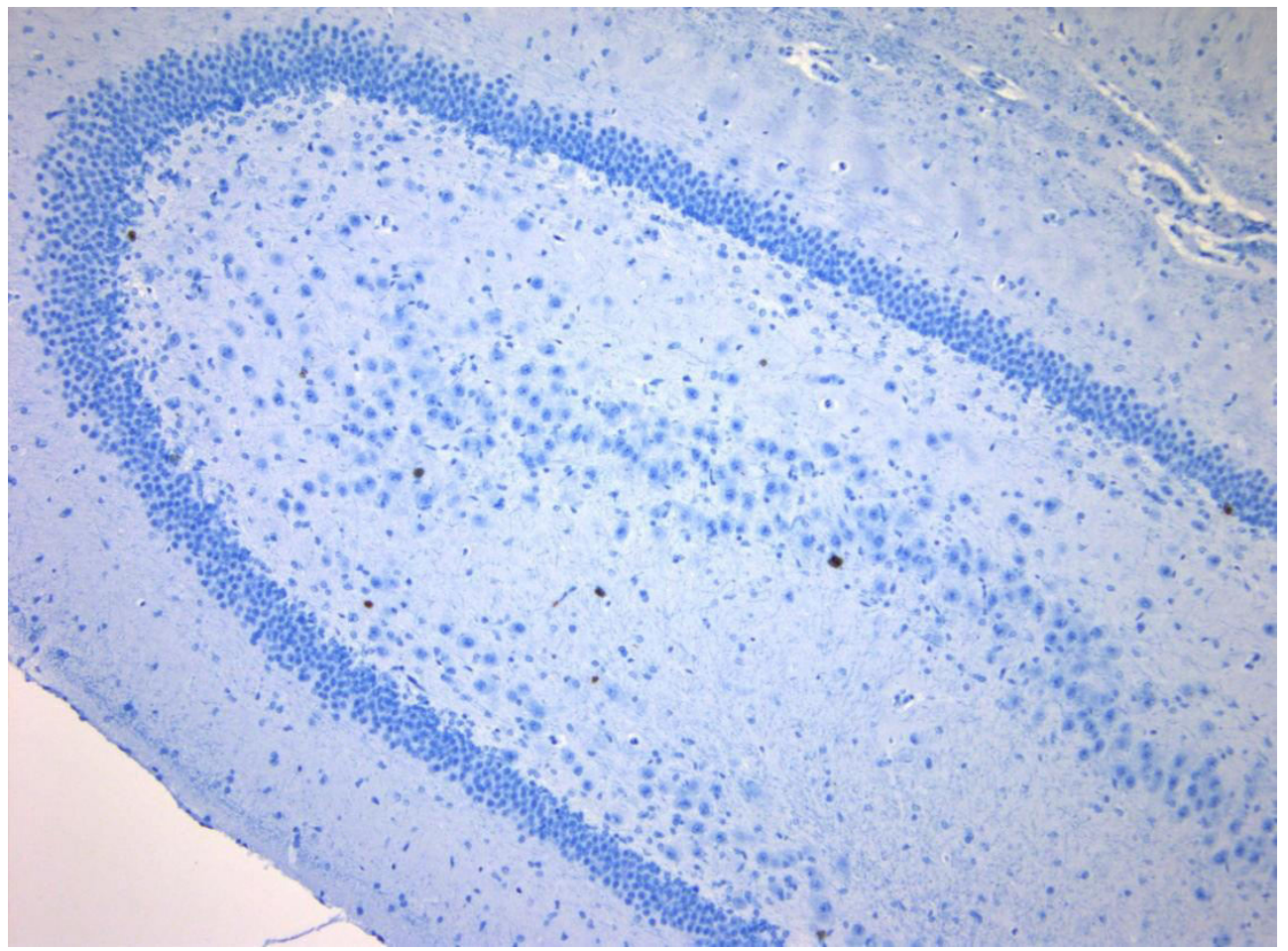

Abbildung 15: BrdU-Übersichtsfärbung des Gyrus dentatus eines nicht-infizierten Tieres aus der Kontrollgruppe.

(10-fache Vergrößerung).

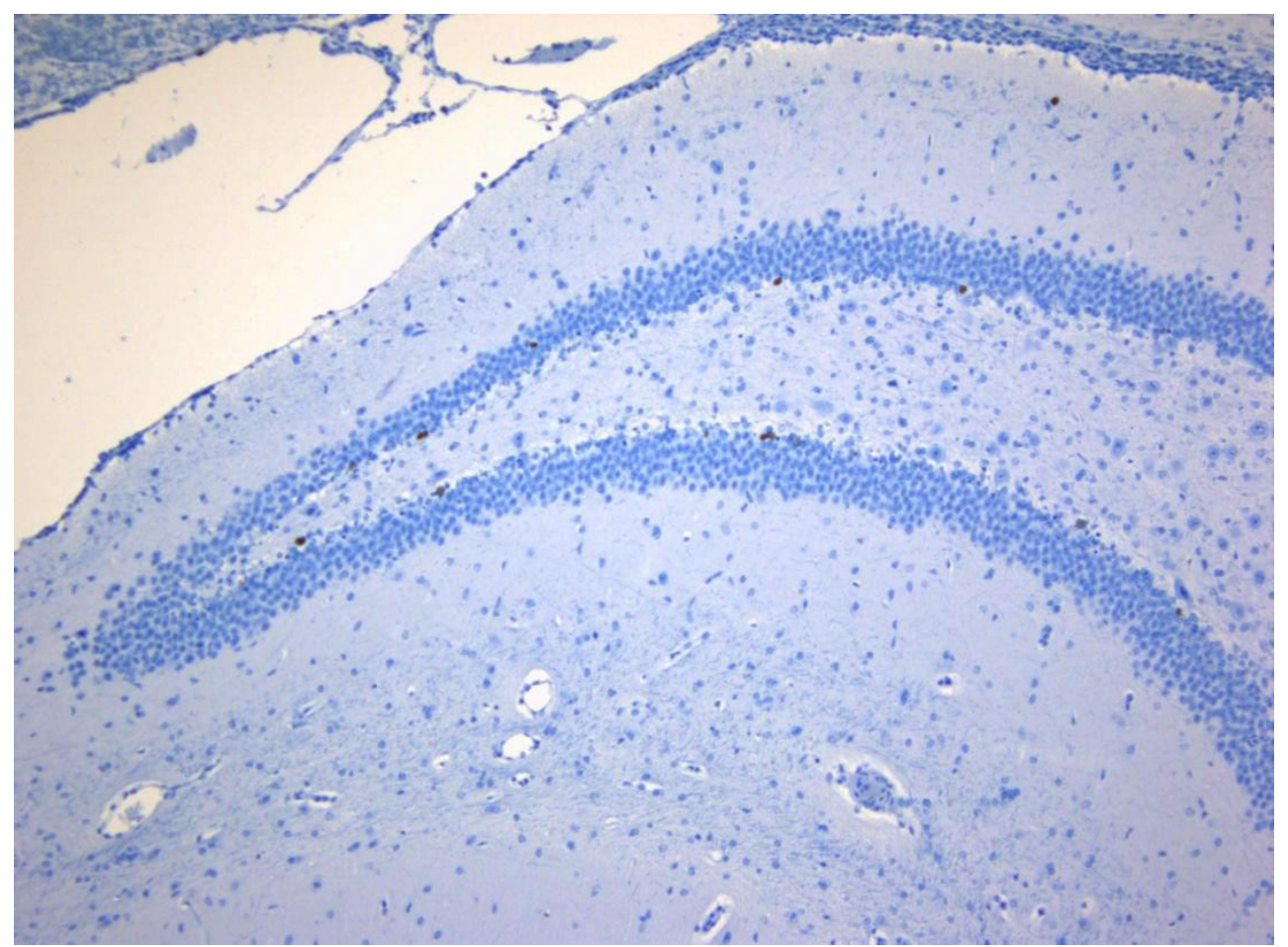

Abbildung 16: BrdU-Übersichtsfärbung des Gyrus dentatus eines infizierten Tieres. (10-fache Vergrößerung). 


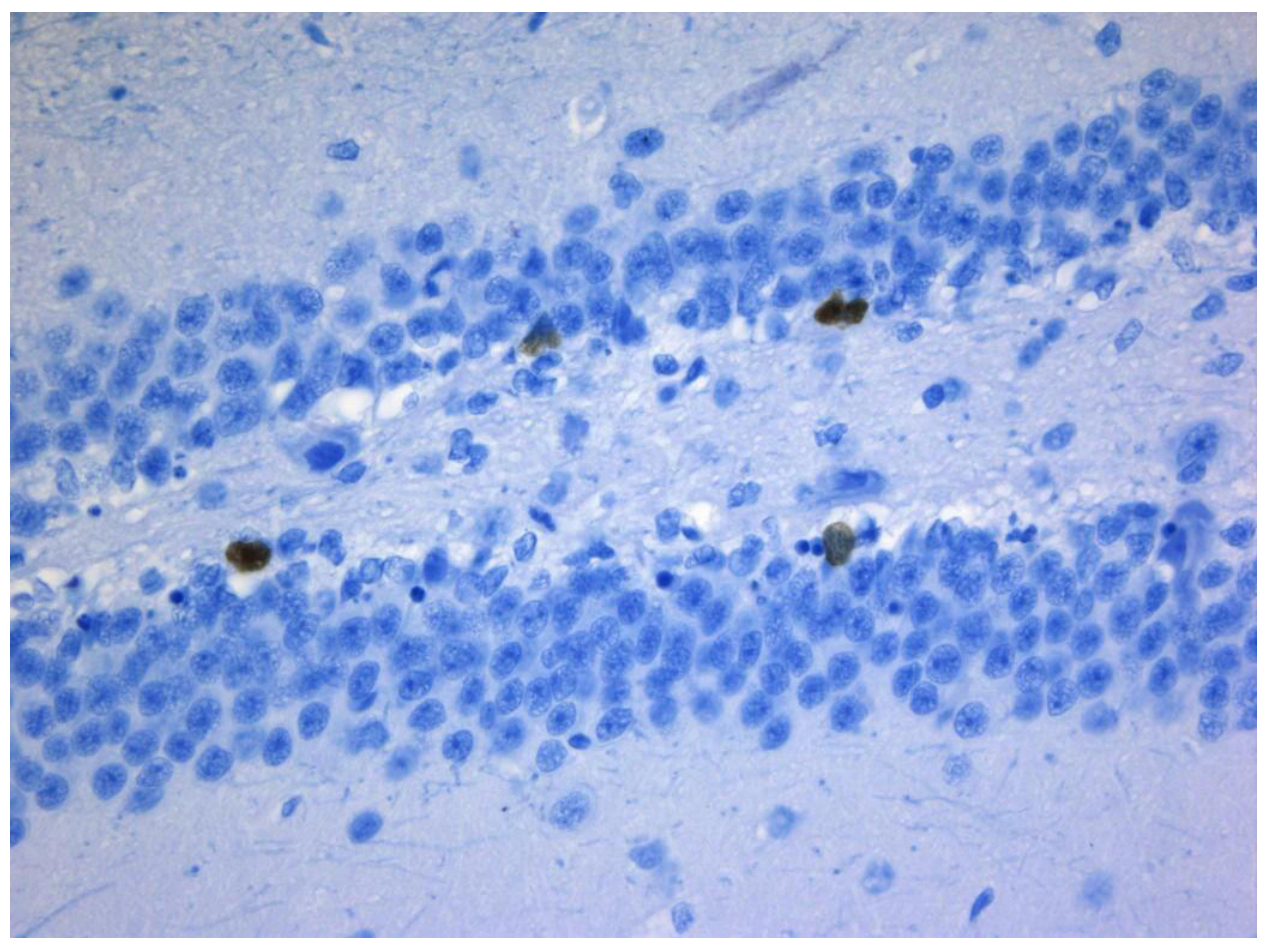

Abbildung 17: Ausschnittsvergrößerung BrdU-Färbung (Abbildung 16) eines infizierten Tieres. (40-fache Vergrößerung).

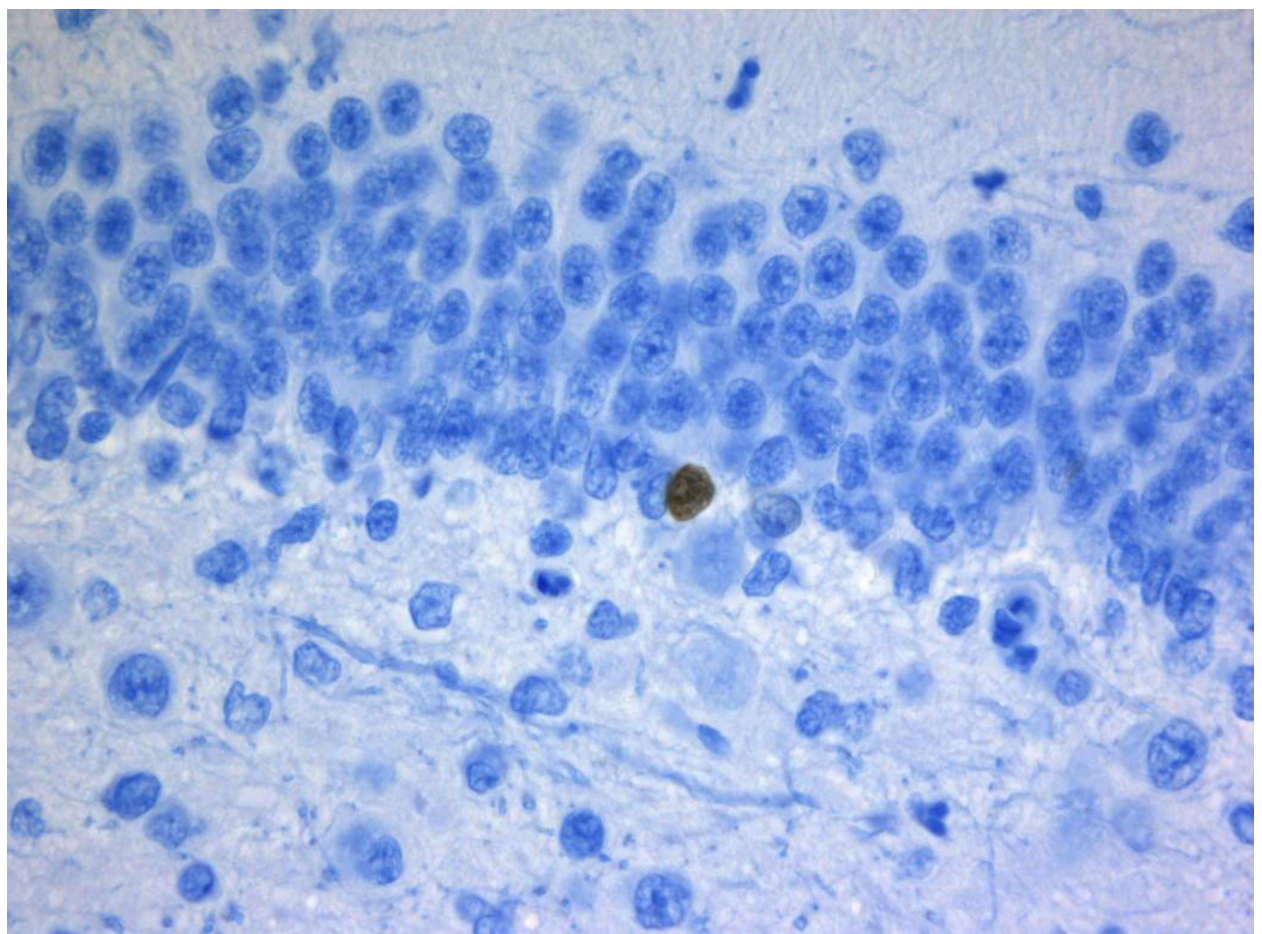

Abbildung 18: Ausschnittsvergrößerung BrdU-Färbung (Abbildung 16) eines infizierten Tieres. (60-fache Vergrößerung). 


\section{LITERATURVERZEICHNIS}

Aberg MA, Aberg ND, Hedbacker H, Oscarsson J, Eriksson PS (2000): Peripheral infusion of IGF-1 selectively induces neurogenesis in the adult rat hippocampus. J Neurosci 20, 2896-2903

Adams RD, Kubic CS, Bonner FJ (1948): The clinical and pathological aspects of influenzal meningitis. Arch Pediatr $\underline{65}, 354-76,408-41$

Altmann J (1963): Autoradiographic investigation of cell proliferation in the brains of rats and cats. Anat Rec $\underline{145}, 573-91$

Altmann J, Das GD (1965): Autoradiographic and histlogical studies of postnatal neurogenesis:

IV. Cell proliferation and migration in the anterior forebrain with special reference to persisting neurogenesis in the olfactory bulb. J Comp Neurol $\underline{137}$, 433-458

Altman J, Bayer SA (1990): Mosaic organisation of the hippocampal neuroepithelium and the multiple germinal sources of dentate granule cells. J Comp Neurol 301, 325-42

Ambrogini P, Cuppini R, Cuppini C, Ciaroni S, Cecchini T, Ferri P, Sartini S, Del Grande P (2000): Spatial learning affects immature granule cell survival in adult rat dentate gyrus. Neurosci Lett $\underline{286}, 21-4$

Anderson V, Bond L, Catroppa C, Grimwood K, Keir E, Nolan T (1997): Childhood bacterial meningitis: Impact of age at illness and acute medical complications on long term outcome. J Int Neuropsychol Soc $\underline{74}, 147-58$

Ansari B, Coates PJ, Greenstein BD, Hall PA (1993): In situ end-labelling detects DNA strand breaks in apoptosis and other physiological and pathological states. J Pathol $\underline{170}, 1-8$

Arends MJ, Wyllie AH (1991): Apoptosis: Mechanisms and roles in pathology. Int Rev Exp Pathol $\underline{32}, 223-54$

Arvidsson A, Kokaia Z, Lindvall O (2001): N-methyl-D-aspartate receptor-mediated increase of neurogenesis in adult rat dentate gyrus following stroke. Eur J Neurosci $\underline{14}, 10-8$ 
Ashkenazi A, Dixit VM (1998): Death Receptors: Signaling and Modulations. Science 281, $1305-8$

Auer M, Pfister LA, Leppert D, Tauber MG, Leib SL (2000): Effects of clinically used antioxidants in experimental pneumococcal meningitis. J Infect Dis $\underline{182}, 347-50$

Azeh I, Mäder M, Smirnov A, Beuche W, Nau R, Weber F (1998): Experimental pneumococcal meningitis in rabbits: the increase of matrix metalloproteinase- 9 in cerebrospinal fluid correlates with leucocyte invasion. Neurosci Lett $\underline{256}, 127-30$

Bayer SA, Yackel JW, Puri PS (1982): Neurons in the rat dentate gyrus granular layer substantially increase during juvenile and adult life. Science $\underline{216}, 890-2$

Betarbet R, Zigova T, Bakay RA, Luskin MB (1996): Dopaminergic and GABAergic interneurons of the olfactory bulb are derived from the neuronatal subventricular zone. Int J Dev Neurosci $\underline{14}, 921-30$

Biebl M, Cooper CM, Winkler J, Kuhn HG (2000): Analysis of neurogenesis and programmed cell death reveals a self-renewing capacity in the adult rat brain. Neurosci Lett $291,17-20$

Block F, Nolden-Koch M (2000): Klinisch-neurologische Aspekte akut-entzündlicher Hirnerkrankungen. Der Radiologe 40, 989-97

Blumcke I, Schewe JC, Normann S, Brüstle O, Schramm J, Elger CE, Wiestler OD (2001): Increase of nestin-immunoreactive neural precursor cells in the dentate gyrus of pediatric patients with early-onset temporal lobe epilepsy. Hippocampus 11 , 311-21

Bohr V, Paulson OB, Rasmussen N (1984): Pneumococcal meningitis, late neurologic sequelae and features of prognostic impact. Arch Neurol 41, 1045-9

Braun JS, Novak R, Herzog KH, Bodner SM, Cleveland JL, Tuomanen E (1999): Neuroprotection by a caspase inhibitor in acute bacterial meningitis. Nat Med $\underline{5}, 298-302$ 
Bremner J, Vermetten E, Afzal N, Vythilingam M (2004): Deficits in verbal declarative memory function in women with childhood sexual abuse-related posttraumatic stress disorder. J Nerv Ment Dis $\underline{192}$, 643-9

Brezun JM, Daszuta A (1999): Depletion in serotonin decreases neurogenesis in the dentate gyrus and the subventricular zone of adult rats. Neuroscience $\underline{89}, 999-1002$

Brown TH, Zador A: Hippocampus. In: The synaptic organisation of the brain, Hrgs. Shepherd GM, 3. Auflage; Oxford University Press, Oxford 1990, 346-388

Buja LM, Eigenbrodt ML, Eigenbrodt EH (1993): Apoptosis and Necrosis: Basic types and mechanisms of cell death. Arch Pathol Lab Med 117, 1208-14

Burroughs M, Cabellos C, Prasad S, Tuomanen E (1992): Bacterial components and the pathophysiology of inury to the blood-brain barrier: does cell wall add to the effects of endotoxin in gramnegative meningitis? J Infect $\underline{165}$, S82-S85

Butovsky O, Ziv Y, Schwartz A, Landa G, Talpalar AE, Pluchino S, Martino G, Schwartz M (2006): Microglia activated by IL-4 or IFN-gamma differentially induce neurogenesis and oligodendrogenesis from adult stem/progenitor cells. Mol Cell Neurosci $\underline{31}$, 149-60

Cairns H, Russell DS (1946): Cerebral arteritis and phlebitis in pneumococcal meningitis. J Pathol Bacteriol 58, 649-65

Cameron HA, Gould E (1994): Adult neurogenesis is regulated by adrenal steroids in the dentate gyrus. Neuroscience $\underline{61}, 203-9$

Cameron HA, McKay RD (1999): Restoring production of hippocampal neuros in old age. Nat Neurosci $\underline{2}, 894-7$

Cameron HA, McKay RD (2001): Adult neurogenesis produces a large pool of new granule cells in the dentate gyrus. J Comp Neurol $\underline{435}$, 406-17

Cameron HA, Woolley CS, McEwen BS, Gould E (1993): Differentation of newly born neurons and glia in the dentate gyrus of the adult rat. Neuroscience $\underline{56}, 337-44$ 
Cameron H, McEwen BS, Gould E (1995): Regulation of adult neurogenesis by excitatory input and NMDA receptor activation in the dentate gyrus. J Neurosci 15, 4687-92

Cameron HA, Tanapat P, Gould E (1998): Adrenal steroid and N-methyl-D-aspartate receptor activation regulate neurogenesis in the dentate gyrus of adult rats through a common pathway. Neuroscience $\underline{82}, 349-54$

Cartwright K, Reilley S, White D, Stuart J (1992): Early treatment with parenteral penicillin in meningococcal disease. Br Med J $\underline{305}, 143-7$

Castelo-Branco G, Wagner J, Rodriguez FJ, Kele J, Sousa K, Rawal N, Pasolli HA, Fuchs E, Kitajewski J, Arenas E (2003): Differential regulation of midbrain dopaminergic neuron development by Wnt-1, Wnt-3a and Wnt-5a. Proc Natl Acad Sci U S A $\underline{100}$, 12747-52

Cawston TE (1996): Metalloproteinase inhibitors and the prevention of connective tissue breakdown. Pharmacol Ther $\underline{70}, 163-82$

Chen G, Rajkowska G, Du F, Seraji-Bozorgzad N, Manji HK (2000): Enhancement of hippocampal neurogenesis by lithium. J Neurochem $\underline{75}, 1729-34$

Christen S, Schaper M, Lykkesfeldt J, Siegenthaler C, Bifrare YD, Banic S, Leib SL, Tauber MG (2001): Oxidative stress in brain during experimental bacterial meningitis: differential effects of alpha-phenyl-tert-butyl-nitrone and N-acetylcysteine treatment. Free Radic Biol Med 31, 754-62

Ciani L, Salinas PC (2005): WNTs in the vertebrate nervous system: from patterning to neuronal connectivity. Nat Rev Neuosci $\underline{6}, 351-62$

Clarke AR, Purdie CA, Harrison DJ, Morris RG, Bird CC, Hooper ML, Wyllie AH (1993): Thymocyte apoptosis induced by p53-dependent and independent pathways. Nature $\underline{362}, 849-51$

Cohen JJ (1993): Apoptosis. Immunol Today 14, 126-30

Cundell RC, Gerard NP, Gerard C, Idanpaan-Heikkila I, Tuomanen E (1995): Streptococcus pneumoniae anchor to activated human cells by the receptor for platelet-activating factor. Nature $\underline{377}, 435-8$ 
Czèh B, Michaelis T, Watanabe T, Frahm J, de Biurrun G, van Kampen M, Bartolomucci A, Fuchs E (2001): Stress-induced changes in cerebral metabolites, hippocampal volume and cell proliferation are prevented by antidepressant treatment with tianeptine. Proc Natl Acad Sci U S A 98, $12796-801$

Dacey RG, Sande MA (1974): Effect of probenecid on cerebrospinal fluid concentrations of penicillin and cephalosporin derivatives. Antimicrob Agents Chemother $\underline{6}$, 437-41

Dash PK, Mach SA, Moore AN (2001): Enhanced neurogenesis in the rodent hippocampus following traumatic brain injury. J Neurosci Res $\underline{63}$, 313-9

De Gans J, van de Beek D; European Dexamethasone in Adulthood Bacterial Meningitis Study Investigators (2002): Dexamethasone in adults with bacterial meningitis. N Engl J Med $\underline{347}$, $1549-56$

Deutsche Gesellschaft für Pädiatrische Infektiologie (DGPI) 2003: Meningitis; in: DGPI Handbuch Infektionen bei Kindern und Jugendlichen; Hrsg. Deutsche Gesellschaft für Pädiatrische Infektiologie; Futuramed Verlag, München 2003, 882-9

Diener HC, Putzki N, Berlit P, Hacke W, Hufnagel A, Hufschmidt A, Mattle H, Meier U, Oertel HW, Reichmann H: Leitlinien für Diagnostik und Therapie in der Neurologie; Hrsg. Kommission "Leitlinien der Deutschen Gesellschaft für Neurologie", 3. Auflage; Georg Thieme Verlag, Stuttgart 2005

Dodge PR (1994): Neurological sequelae of acute bacterial meningitis. Pediatric annals $\underline{23}$, 101-6

Dodge PR, Davis H, Feigin RD, Holmes SJ, Kaplan SL, Jubelirer DP, Stechenberg BW, Hirsh SK (1984): Prospective evaluation of hearing impairment as a sequela of acute bacterial meningitis. N Engl J Med $\underline{311}, 869-74$

Duke RC, Cohen JJ (1986): IL-2 addiction: withdrawal of growth factor activates a suicide programm in dependent T cells. Lymphokine Res $\underline{5}, 289-99$ 
Ekdahl CT, Mophael P, Elmer E, Lindvall O (2001): Capsae inhibitors increase short-term survival of progenitor-cell progeny in the adult rat dentate gyrus following status epilepticus. Eur $\mathbf{J}$ Neurosci $\underline{14}, 937-45$

Eriksson PS, Perfilieva E, Björk-Eriksson T, Alborn M, Nordborg C, Peterson DA, Gage FH (1998): Neurogenesis in the adult human hippocampus. Nat Med $\underline{4}, 1313-7$

Evan GI, Wyllie AH, Gilbert CS, Littlewood T, Land H, Brooks M, Waters CM, Penn LZ, Hancock CL (1992): Induction of apoptosis in fibroblasts by c-Myc protein. Cell $\underline{69}, 119-28$

Fadok VA, de Cathelineau A, Daleke DL, Henson PM, Bratton DL (2001): Loss of phospholipid asymmetry and surface exposure of phosphatidylserine is required for phagocytosis of apoptotic cells by macrophages and fibroblasts. J Biol Chem $\underline{276}, 1071-7$

Farber (1982): Biology of disease: membrane injury and calcium homeostasis in the pathogenesis of coagulative necrosis. Lab Invest $\underline{47}, 114-23$

Felling RJ, Levison SW (2003): Enhanced neurogenesis following stroke. J Neurosci Res $\underline{73}$, 277-83

Fesus L, Thomazy V, Falus A (1987): Induction and activation of tissue transglutaminase during programmed cell death. FEBS Lett $\underline{224}, 104-8$

Fradkin LG, Garriga G, Salinas PC, Thomas JB, Yu X, Zou Y (2005): Wnt signalling in neural circuit development. J Neurosci $\underline{25}$, 10376-8

Gerber J, Tauber SC, Armbrecht I, Schmidt H, Brück W, Nau R (2009): Increased neuronal proliferation in human bacterial meningitis. Neurology $\underline{73}, 1026-32$

Gerschenson LE, Rotello RJ (1992): Apoptosis: a different type of cell death. FASEB J $\underline{6}, 2450-5$

Girgis NL, Kilpatrick ME, Farid Z, Sippel JE (1991): A review of the treatment of bacterial meningitis. Trans R Soc Trop Med Hyg $\underline{85}, 1-3$

Gobé GC, Axelsen RA, Harmon BV, Allan DJ (1988): Cell death by apoptosis following Xirradiation of the foetal and neonatal rat kidney. Int J Radiat Biol 54, 567-76 
Goitein KJ, Shapiro M (1992): Intracranial pressure and cerebral perfusion pressure in experimental Streptococcus pneumoniae meningitis. Res Exp Med 192, 41-7

Gold R, Schmied M, Rothe G, Zischler H, Breitschopf H, Wekerle H, Lassmann H (1993): Detection of DNA fragmentation in apoptosis: application of in situ nick translation to cell culture systems and tissue sections. J Histochem Cytochem 41, 1023-30

Gold R, Schmied M, Giegerich G, Breitschopf H, Hartung HP, Toyka KV, Lassmann H (1994): Differentiation between cellular apoptosis an necrosis by the combined use of In situ Tailing and nick translation techniques. Laboratory Investigations $\underline{71}, 219-25$

Goldman JE (1995): Lineage, migration and fate determination of postnatal subventricular zone cells in the mammalian CNS. J Neurooncol $24,61-4$

Gould E, Tanapat P (1997): Lesion-induced proliferation of neuronal progenitors in the dentate gyrus of the adult rat. Neuroscience $\underline{80}, 427-36$

Gould E, Tanapat P, McEwen BS, Flügge G, Fuchs E (1998): Proliferation of granule cell precursors in the dentate gyrus of adult monkeys is diminished by stress. Proc Natl Acad Sci U S A $\underline{95}$, $3168-71$

Grimwood K, Anderson P, Anderson V, Tan L, Nolan T (2000): Twelve year outcomes following bacterial meningitis: further evidence for persisting effects. Arch Dis Child $\underline{83}, 111-6$

Gray WP, Sundstrom LE (1998): Kainic acid increases the proliferation of granule cell progenitors in the dentate gyrus of the adult rat. Brain Res $\underline{790}, 52-9$

Gueneau G, Privat A, Drouet J, Court L (1982): Subgranular zone of the dentate gyrus of young rabbits as a secondary matrix. A high-resolution autoradiographic study. Dev Neurosci $\underline{5}$, 345-58

Guerra-Romeo L, Tureen JH, Täuber MG (1992): Pathogenesis of central nervous system injury in bacterial meningitis. Antibiot Chemother $\underline{45}, 18-29$ 
Guerra-Romeo L, Tureen JH, Fournier MA, Makrides V, Täuber MG (1993): Amino acids in cerebrospinal and brain interstitial fluid in experimental pneumococcal meningitis. Pediatr Res $\underline{33}$, 510-3

Hailer NP, Grampp A, Nitsch R (1999): Proliferation of microglia and astrocytes in the dentate gyrus following entorhinal cortex lesion: a quantitative bromodeoxyuridine-labelling study. Eur J Neurosci $11,3359-64$

Henry RC, Taylor PH (1978): Cerebrospinal fluid otorrhea and otorhinorrhea following closed head injury. J Larngol Otol 92, 743-56

Hicks RR, Smith DH, Lowenstein DH, Saint Marie R, McIntosh GH (1993): Mild experimental brain injury in the rat induces cognitive deficits associated with regional neuronal loss in the hippocampus. J Neurotrauma $\underline{10}, 405-14$

Hillis LD, Braunwald E (1977): Myocardial ischemia. N Engl J Med 296, 971-8, 1034-41, 1093-6

Horner HC, Packan DR, Sapolsky RM (1990): Glucocorticoids inhibit glucose transport in cultures hippocampal neurons and glia. Neuroendocrinology $\underline{52}, 57-64$

Igarashi M, Gilmartin RC, Gerald B, Wilburn F, Jabbour JT (1984): Cerebral arteritis and bacterial meningitis. Arch Neurol 41, 531-5

Isamukhamedov I, Padeiskaia EN, Pershin GN (1964): Pneumococcal meningitis in the rabbit as a chemotherapeutic model. Farmakol Toksikol 27, 594-600

Iwai T, Hara A, Niwa M, Nozaki M, Uematsu T, Sakai N, Yamada H (1995): Temporal profile of nuclear DNA fragmentation in situ in gerbil hippocampus following transient forebrain ischemia. Brain Res $\underline{671}, 305-8$

Iwai M, Sato K, Omori N, Nagano I, Manabe Y, Shoji M, Abe K (2002): Three steps of neural stem cells development in gerbil dentate gyrus after transient ischemia. J Cereb Blood Flow Metab $\underline{22}, 411-9$ 
Jin K, Mao XO, Sun Y, Xie L, Greenberg DA (2002): Stem cell factor stimulates neurogenesis in vitro and in vivo. J Clin Invest $\underline{110}, 311-9$

Kabani A, Jadavji T (1992): Sequelae of acute bacterial meningitis in children. Antibiot Chemother $\underline{45}, 209-17$

Kaplan MS, McNelly NA, Hinds JW (1985): Population dynamics of adult-formed granule neurons of the rat olfactory bulb. J Comp Neurol $\underline{239}, 117-25$

Karandaris D, Shulman M (1976): Recent survey of infectious meningitis in adults: Review of laboratory findings in bacterial, tuberculous and aseptic meningitis. South Med J $\underline{69}$, 449-57

Keenan PA, Jacobson MW, Soleymani RM, Newcomer JW (1995): Commonly used therapeutic doses of glucocorticoids impair explicit memory. Ann N Y Acad Sci 761, 400-2

Kempermann G (2002): Why New Neurons? Possible functions for adult hippocampal neurogenesis. J Neurosci $\underline{22}, 635-8$

Kempermann G: Aktivitätsabhängige Regulation von Neurogenese im erwachsenen Hippokampus. Med. Habil. -Schrift Berlin 2002

Kempermann G, Kuhn HG, Gage FH (1997): More hippocampal neurons in adult mice living in an enriched environment. Nature $\underline{386}, 493-5$

Kempermann G, Kuhn HG, Gage FH (1998): Experience-induced neurogenesis in the senescent dentate gyrus. J Neurosci 18 , 3206-12

Kennedy W, Hoyt M, McCracken GH Jr. (1991): The role of corticosteroid therapy in children with pneumococcal meningitis. Am J Dis Child $\underline{145}, 1374-8$

Kerr JF, Searle J (1972): A mode of cell loss in malignant neoplasms. J Pathol 107, 41-4

Kerr JF, Searle J (1973): Deletion of cells by apoptosis during castration-induced involution of the rat prostate. Virchows Arch B Cell Pathol $\underline{13}, 87-102$ 
Kerr JF, Wyllie AH, Currie AR (1972): Apoptosis: a basic biological phenomenon with wideranging implications in tissue kinetics. Br J Cancer $\underline{26}$, 239-57

Kirsche W (1967): Über postembryonale Matrixzonen im Gehirn verschiedener Vertebraten und deren Beziehung zu Hirnbauplanlehre. Z mikrosk-anat Forsch 77, 313-406

Kirschenbaum B, Nedergaard M, Preuss A, Barami K, Fraser RAR and Golman SA (1994): In vitro neuronal production and differentation by precursor cells derived from adult human forebrain. Cereb Cortex $\underline{6}, 576-89$

Kolb B, Pedersen B, Ballermann M, Gibb R, Whishaw IQ (1999): Embryonic and postnatal injections of bromodeoxyuridine produce age-dependent morphological and behavorial abnormalities. J Neurosci $\underline{19}, 2337-46$

Kornack DR, Rakic P (1999): Continuation of neurogenesis in the hippocampus of the macaque monkey. Proc Natl Acad Sci U S A $\underline{96}, 5768-73$

Kornelisse R, de Groot R, Neijens H (1995): Bacterial meningitis: mechanisms of disease and therapy. Eur J Pediatr 154, 85-96

Kostyukova NN, Volkova MO, Ivanova VV, Kvetnaya AS (1995): A study of pathogenic factors of Streptococcus pneumoniae strains causing meningitis. FEMS Immunol Med Microbiol $\underline{10}$, $133-7$

Kristiansen BE, Ask E, Jenkins A, Fermer C, Radstrom P, Skold O (1991): Rapid diagnosis of meningococcal meningitis by polymerase chain reaction. Lancet $\underline{337}, 1568-9$

Kuhn HG, Dickinson-Anson H, Gage FH (1996): Neurogenesis in the dentate gyrus of the adult rat: age-related decrease of neuronal progenitor proliferation. J Neurosci $\underline{16}, 2027-33$

Kuhn HG, Winkler J, Kempermann G, Thal LJ, Gage FH (1997): Epidermal growth factor and fibroblast growth factor-2 have different effects on neuronal progenitors in the adult rat brain. $\mathrm{J}$ Neurosci $\underline{17}, 5820-9$

Kuhn HG, Palmer TD, Fuchs E (2001): Adult neurogenesis: a compensatory mechanism for neuronal damage. Eur Arch Psychiatry Clin Neurosci 251, 152-8 
Kure S, Tominaga T, Yoshimoto T, Tada K, Narisawa K (1991): Glutamate triggers internucleosomal DNA cleavage in neuronal cells. Biochem Biophys Res Commun $\underline{179}, 39-45$

Landfield PW, Waymire JC, Lynch G (1978): Hippocampal aging and adrenocorticoids: quantitative correlations. Science 202, 1098-102

Lassmann H, Bancher C, Breitschopf H, Wegiel J, Bobinski M, Jellinger K, Wisniewski HM (1995): Cell death in Alzheimer's disease evaluated by DNA fragmentation in situ. Acta Neuropathol $\underline{89}, 35-41$

Lau YL, Kenna AP (1986): Post-traumatic meningitis in children. Injury 17, 407-11

Lauder JM (1990): Ontogeny of the serotonergic system in the rat: serotonin as a developmental sign. Ann NY Acad Sci $\underline{600}, 297-314$

Lavdas AA, Blue ME, Lincoln J, Parnavelas JG (1997): Serotonin promotes the differentiation of glutamate neurons in organotypic slice cultures of the developing cerebral cortex. J Neurosci $\underline{17}$, $7872-80$

Lawrence M, Springer A (1991): Leukocytes roll on a selectin at physiologic flow rates: distinction from and prerequisite for adherence through integrins. Cell $\underline{65}, 859-73$

Lebel MH (1992): Dexamethason therapy of bacterial meningitis. Antibiot Chemother $\underline{45}, 169-83$

Lebel MH, Freij BJ, Syrogiannopoulos GA, Chrane DF, Hoyt MS, Stewart SM, Kennard BD, Olsen KD, McCracken GH (1988): Dexamethasone therapy for bacterial meningtis. Results of two double-blind, placebo controlled trials. N Engl J Med 319, 964-71

Leib SL, Kim YS, Ferriero DM, Täuber MG (1996a): Neuroprotective effect of excitatory amino acid antagonist kynurenic acid experimental bacterial meningitis. J Infect Dis $\underline{173}, 166-71$

Leib SL, KimYS, Chow LL, Sheldon RA, Täuber MG (1996b): Reactive oxygen intermediates contribute to necrotic and apoptotic neuronal injury in an infant rat model of bacterial meningitis due to group B streptococci. J Clin Invest $\underline{98}, 2632-9$ 
Leib SL, Leppert D, Clements J, Täuber MG (2000): Matrix metalloproteinases contribute to brain damage in experimental pneumococcal meningitis. Infect Immun $\underline{68}, 615-20$

Lemaire V, Aurousseau C, Le Moal M, Abrous DN (1999): Behavourial trait of reactivity to novelty is related to hippocampal neuogenesis. Eur J Neurosci 11, 4006-14

Leonhardt H, Tillmann B, Töndury G, Zilles K: Graue und weisse Substanz des Hirnmantels. In: Anatomie des Menschen Band III: Nervensystem und Sinnesorgane; Georg Thieme Verlag, Stuttgart 1987, 260-318

Lie DC, Colamarino SA, Song HJ, Désiré L, Mira H, Consiglio A, Lein ES, Jessberger S, Lansford H, Dearie AR, Gage FH (2005): Wnt signalling regulates adult hippocampal neurogenesis. Nature $\underline{437}, 1370-5$

Liebetanz D, Gerber J, Schiffner C, Schütze S, Klinker F, Jarry H, Nau R, Tauber SC (2012): Preinfection physical exercise decreases mortality and stimulates neurogenesis in bacterial meningitis. J Neuroinflammation $\underline{9}, 168-77$

Lipton SA, Rosenberg PA (1994): Excitatory amino acids as a final common pathway for neurologic disorders. N Engl J Med $\underline{330}, 613-22$

Liu J, Solway K, Messing RO, Sharp FR (1998): Increased neurogenesis in the dentate gyrus after transient global ischemia in gerbils. J Neurosci $\underline{18}, 7768-78$

Lo SK, Lee S, Ramos RA, Lobb R, Rosa M, Chi-Rosso G, Wright SD (1991): Endothelialleukocyte adhesion molecule 1 stimulates the adhesive activity of leukocyte integrin CR 3 (CD 11b/CD 18, Mac-1, alpha m beta 2) on human neutrophils. J Exp Med 173, 1493-500

Loeffler JM, Ringer R, Hablutzel M, Täuber MG, Leib SL (2001): The free radical scavenger alpha-phenyl-tert-butyl nitrone aggravates hippocampal apoptosis and learning deficits in experimental pneumococcal meningitis. J Infect Dis $\underline{183}, 247-52$

Louis C, Alvarez-Buylla A (1994): Long-distance neuronal migration in the adult mammalian brain. Science $\underline{264}, 1145-8$ 
Luskin MB (1993): Restricted proliferation and migration of postnatally generated neurons derived from the forebrain subventricular zone. Neuron $\underline{11}, 173-89$

Malberg JE, Eisch AJ, Nestler EJ, Duman RS (2000): Chronic antidepressant treatment increases neurogenesis in adult rat hippocampus. J Neurosci $\underline{20}$, 9104-10

Magariños AM, McEwen BS, Flügge G, Fuchs E (1996): Chronic psychosocial stress causes apical dendritic atrophy of hippocampal CA3 pyramidal neurons in subordinate tree shrews. J Neurosci $\underline{16}, 3534-40$

Martin DP, Schmidt RE, DiStefano PS, Lowry OH, Carter JG, Johnson EM Jr (1988): Inhibitors of protein synthesis and RNA synthesis prevent neuronal death caused by nerv growth factor deprivation. J Cell Biol $\underline{106}, 829-44$

Martin LJ, Al-Abdulla NA, Brambrink AM, Kirsch JR, Sieber FE, Portera-Cailliau C (1998): Neurodegeneration in excitotoxicity, global cerebral ischemia, and target deprivation: A perspective on the contributions of apoptosis and necrosis. Brain Res Bull 46, 281-309

Mattiesen WR, Tauber SC, Gerber J, Bunkowski S, Brück W, Nau R (2009): Increased neurogenesis after hypoxic-ischemic encephalopathy in humans is age related. Acta Neuropathol 117 , $525-34$

McLean JH, Shipley MT (1988): Postmitotic, postmigrational expression of tyrosine hydroxylase in olfactory bulb of dopaminergic neurons. J Neurosci $\underline{8}, 3658-69$

Meli DN, Christen S, Leib SL, Täuber MG (2002): Current concepts in the pathogenesis of meningits caused by Streptococcus pneumoniae. Curr Opin Infect Dis $\underline{15}$, 253-7

Menet V, Gimenez y Ribotta M, Chauvet N, Drian MJ, Lannoy J, Colucci-Guyon E, Privat A (2001): Inactivation of the glial fibrillary acidic protein gene, but not that of vimentin, improves neuronal survival and neurite growth by modifying adhesion molecule expression. J Neurosci $\underline{21}$, $6147-58$

Merkelbach S, Sittinger H, Schweizer I, Müller M (2000): Cognitive outcome after bacterial meningitis. Acta Neurol Scand $\underline{102}, 118-23$ 
Mezey E, Chandross KJ, Harta G, Maki RA, McKercher SR (2000): Turning blood into brain: cells bearing neuronal antigens generated in vivo from bone marrow. Science 290, 1779-82

Michaelis M, Blenk KH, Jänig W, Vogel C (1995): Development of spontaneous activity and mechanosensitivity in axotomized afferent nerve fibers during the first hours after nerve transection in rats. J Neurophysiol $\underline{74}, 1020-7$

Mignatti P, Rifkin DB (1996): Plasminogen activators and matrix metalloproteinases in angiogenesis. Enzyme Protein $\underline{49}, 117-37$

Miller MW, Nowakowski RS (1988): Use of bromodeoxyuridine-immunohistochemistry to examine the proliferation, migration and time of origin of cells in the central nervous system. Brain $\operatorname{Res} \underline{457}, 44-52$

Minturn JE, Geschwind DH, Fryer HJ, Hockfield S (1995): Early postmitotic neurons transiently express TOAD-64, a neural specific protein. J Comp Neurol 355, 369-79

Monje ML, Toda H, Palmer TD (2003): Inflammatory blockade restores adult hippocampal neurogenesis. Science $\underline{302}, 1760-5$

Morris DC, Zhang ZG, Wang Y, Zhang RL, Greg S, Liu XS, Chopp M (2007): Wnt expression in the adult rat subventricular zone after stroke. Neurosci Lett $\underline{418}, 170-4$

Nakagawa E, Aimi Y, Yasuhara O, Tooyama I, Shimada M, McGeer PL, Kimura H (2000): Enhancement of progenitor cell division in the dentate gyrus triggered by initial limbic seizures in rat models of epilepsy. Epilepsia $\underline{41}, 10-18$

Nakagawa S, Kim J, Lee R, Malberg JE, Chen J, Steffen C, Zhang Y, Nestler EJ, Duman, RS (2002): Regulation of neurogenesis in adult mouse hippocampus by cAMP and the cAMP response element-binding protein. J Neurosci $\underline{22}$, 3673-82

Nau R, Soto A, Brück W (1999): Apoptosis of neurons in the dentate gyrus in humans suffering from bacterial meningitis. J Neuropathol Exp Neurol $\underline{58}$, 265-74

Nau R, Haase S, Bunkowski S, Brück W (2002): Neuronal apoptosis in the dentate gyrus in humans with subarachnoidal hemorrhage and cerebral hypoxia. Brain Pathol $\underline{12}$, 329-36 
Neu HC (1992): Microbiology of bacterial meningitis pathogens. Antibiot Chemother $\underline{45}$, 52-67

Niemöller M, Täuber MG (1989): Brain edema and increased intracranial pressure in the pathophysiology of bacterial meningitis. Eur J Clin Microbiol Infect Dis $\underline{8}, 109-17$

Odio CM, Faingezicht I, Paris M, Nassar M, Baltodano A, Rogers J, Sáez-Llorens X, Olsen KD, McCracken GH Jr. (1991): The beneficial effects of early dexamethasone administration in infants and children with bacterial meningitis. N Engl J Med $\underline{324}, 1525-31$

Oppenheim RW (1991): Cell death during development of the nervous system. Annu Rev Neurosci $\underline{14}, 453-501$

O'Shea JD, Hay MF, Cran DG (1978): Ultrastructural changes in the theca interna during follicular atresia in sheep. J Reprod Fertil $\underline{54}, 183-7$

Padosch SA, Vogel P, Böttiger BW (2001): Neuronale Apoptose nach zerebraler Ischämie. Grundlagen, Pathophysiologie und Interventionsmöglichkeiten. Der Anästhesist 50, 905-20

Palmer TD, Ray J, Gage FH (1995): FGF-2-responsive neuronal progenitors reside in proliferative and quiescent regions of the adult rodent brain. Mol Cell Neurosci $\underline{6}, 474-86$

Palmer TD, Takahashi J, Gage FH (1997): The adult rat hippocampus contains primordial neuronal stem cells. Mol Cell Neurosci $\underline{8}, 389-404$

Palmer TD, Willhoite AR, Gage FH (2000): Vascular niche for adult hippocampal neurogenesis. J Comp Neurol 425, 479-94

Parent JM, Tada E, Fike JR, Lowenstein DH (1999): Inhibition of dentate granule cell neurogenesis with brain irradiation does not prevent seizure-induced mossy fiber synaptic reorganisation in the rat. J Neurosci $\underline{19}, 4508-19$

Paton JA, Nottebohm FN (1984): Neurons generated in the adult brain are recruited into functional circuits. Science $\underline{225}, 1046-8$ 
Paul R, Lorenzel S, Koedel U, Sporer B, Vogel U, Frosch M, Pfister HW (1998): Matrix metalloproteinases contribute to the blood-brain disruption during bacterial meningitis. Ann Neurol $\underline{44}$, 592-600

Penick E, Powell B, Nickel E, Bingham S, Riesenmy K, Read M, Campbell J (1994): Comorbidity of lifetime psychiatric disorder among male alcoholic patients. Alcohol Clin Exp Res $\underline{18}, 1289-93$

Perry JE, Cluff LE (1963): Manifestations of fatal pneumococcal infection in rabbits. J Lab Clin Med 62, 549-58

Peterson DA (2002): Stem cells in brain plasticity and repair. Curr Opin Pharmacol 2, 34-42

Pfausler B, Spiss H, Beer R, Kampl A, Engelhardt K, Schober M, Schmutzhard E (2003): Treatment of staphylococcal ventriculitis associated with external cerebrospinal fluid drains: a prospective randomized trial of intravenous compared with intraventricular vancomycin therapy. J Neuro$\operatorname{surg} \underline{98}, 1040-4$

Pfister HW, Koedel U, Haberl RL, Dirnagl U, Feiden W, Kuckdesche LG, Einhaupl KM (1990): Microvascular changes during the early phase of experimental bacterial meningitis. J Cereb Blood Flow Metab $\underline{10}, 914-22$

Pfister HW, Fontana A, Täuber M, Tomasz A, Scheld W (1994): Mechanisms of brain injury in bacterial meningitis. Workshop summary. Clin Infect Dis $\underline{19}$, 463-79

Picard-Riera N, Decker L, Delarasse C, Goude K, Nait-Oumesmar,B, Liblau,R, Pham-Dinh D, Baron-Van Evercooren A (2002): Experimental autoimmune encephalomyelitis mobilizes neural progenitors from the subventricular zone to undergo oligodendrogenesis in adult mice. Proc Natl Acad Sci U S A 99, 13211-6

Pineda V, Fontanals D, Larramona H, Domingo M, Anton J, Segura F (2002): Epidemiology of invasive Streptococcus pneumoniae infections in children in an area of Barcelona, Spain. Acta Paediatr $\underline{\text { 91, }}$ 1251-6

Plaut AG (1983): The IgA1 proteases of pathogenic bacteria. Annu Rev Microbiol 푸, 603-22 
Potts MB, Rola R, Claus CP, Ferriero DM, Fike JR, Noble-Haeusslein LJ (2009): Gluthathione peroxidase overexpression does not rescue impaired neurogenesis in the injured immature brain. $\mathbf{J}$ Neurosci Res $\underline{87}, 1848-57$

Quagliarello VJ, Scheld WM (1992): Bacterial meningitis: pathogenesis, pathophysiology and progress. N Engl J Med $\underline{327}, 864-72$

Quinn CC, Gray GE, Hockfield S (1999): A family of proteins implicated in axon guidance and outgrowth. J Neurobiol $\underline{41}, 158-64$

Reinert RR, Al-Lahham A, Lemperle M, Tenholte C, Briefs S, Haupt S, Gerards HH, Lutticken R (2003): Emergence of macrolide and penicillin resistance among invasive pneumococcal isolates in Germany. J Antimicrob Chemother $\underline{49}$, 61-8

Reznikov K (1975): Local proliferation of cells of the granular layer of the dentate gyrus of the mouse hippocampus during postnatal ontogenesis and following brain injury. Ontogenez $\underline{6}, 242-$ 50

Ring A, Novak R, Schmitz FJ, Heinz HP (1996): Klassische und aktuelle Aspekte zur Meningitis purulenta. Nervenarzt $\underline{67}, 630-8$

Ring A, Weiser JN, Tuomanen E (1998): Pneumococcal trafficking across the blood-brain barrier. Molecular analysis of a novel bidirectional pathway. J Clin Invest 102, 347-60

Rorke LB, Pitts FW (1963): Purulent meningitis. The pathologic basis of clinical manifestations. Clin Pediatr $\underline{2}, 64-71$

Rosenberg GA, Navratil M, Barone F, Feuerstein G (1996): Proteolytic cascade enzyme increase in focal cerebral ischemia in rat. J Cereb Blood Flow Metab 16, 360-6

Rosenow C, Ryan P, Weiser JN, Jonson S, Fontan P, Ortquist A, Masure HR (1997): Contribution of novel choline-binding proteins to adherence, colonisation and immunogenicity of Streptococcus pneumoniae. Mol Microbiol 25, 819-29

Rotello RJ, Hocker MB, Gerschenson LE (1989): Biochemical evidence for programmed cell death in rabbit uterine epithelium. Am J Pathol 134, 491-5 
Rupprecht T, Pfister HW (2005): Clinical experience with linezolid for the treatment of central nervous system infections. Eur J Neurol $\underline{12}, 536-42$

Sapolsky RM, Pulsinelli WA (1985): Glucocorticoids potentiate ischemic injury to neurons: therapeutic implications. Science $\underline{229}, 1397-400$

Schaad UB, Kaplan SL, McCracken GH Jr (1995): Steroid therapy for bacterial meningitis. Clin Infect Dis $\underline{20}, 685-90$

Scheld WM, Brodeur JP (1983): Effect of methylprednisolon on entry of ampicillin and gentamicin into cerebrospinal fluid in experimental pneumococcal and Escherichia coli meningitis. Antimicrob Agents Chemother $\underline{23}, 108-12$

Scheld WM, Dacey RG, Winn HR (1980): Cerebrospinal outflow resistance in rabbits with experimental meningitis. Alterations with penicillin and methylprednisolon. J Clin Invest $\underline{66}, 243-53$

Schlech WF 3rd (1992): The epidemiology of bacterial meningitis. Antibiot Chemother 45, 5-17

Schmidt H, Nau R (2004): Therapie der bakteriellen Meningitis. Akt Neurol 31, 231-40

Schmidt H, Heimann B, Djukic M, Mazurek C, Fels C, Wallesch CW, Nau R (2006): Neuropsychological sequelae of bacterial and viral meningitis. Brain $\underline{129}, 333-45$

Schmitz C, Axmacher B, Zunker U, Korr H (1999): Age-related changes of DNA repair and mitochondrial DNA synthesis in the mouse brain. Acta Neuropathol 97, 71-81

Schoenwolf GG, Smith JL (1990): Mechanisms of neurulation: traditional viewpoints and recent advances. Development $\underline{109}, 243-70$

Schreiber SS, Sakhi S, Dugic-Djordjevic MM, Nicols NR (1994): Tumor suppressor p53 induction and DNA damage in granule cells after adrenalectomy. Exp Neurol 130, 368-76 
Schuchat A, Robinison K, Wenger JD, Harrison LH, Farley M, Reingold AL, Lefkowitz L, Perkins BA (1997): Bacterial meningitis in the United States in 1995. Active Surveillance Team. N Engl J Med 337, 970-6

Scott L, Pomeroy MD, Holmes SJ, Dodge PR, Feigin RD (1990): Seizures and other neurologic sequelae of bacterial meningitis in children. N Engl J Med $\underline{323}, 1651-7$

Scoville WB, Milner B (1957): Loss of recent memory after bilateral hippocampal lesion. J Neurol Neurosurg Psychiatry $\underline{20}, 11-21$

Searle J, Lawson TA, Abbott PJ, Harmon B, Kerr JF (1975): An electron-microscope study of the mode of cell death induced by cancer-chemotherapeutic agents in populations of proliferating normal and neoplastic cells. J Pathol 116, 129-38

Searle J, Kerr JF, Bishop CJ (1982): Necrosis and apoptosis: distinct modes of cell death with fundamentally different significance. Pathol Annu 17, 229-59

Selden JR, Dolbeare F, Clair JH, Nichols WW, Miller JE, Kleemeyer KM, Hyland RJ, DeLucca JG (1993): Statistical confirmation that immunofluorescent detection of DNA repair in human fibroblasts by measurement of bromodeoxyuridine incorporation is stoichiometric and sensitive. Cytometry $\underline{14}, 154-67$

Sherry DF, Jacobs LF, Gaulin SJ (1992): Spatial memory and adaptive specialization of the hippocampus. Trends Neurosci $\underline{15}, 298-303$

Shihabuddin LS, Ray J, Gage FH (1997): FGF-2 is sufficient to isolate progenitors found in the adult mammalian spinal cord. Exp Neurol 148, 577-86

Shors TJ, Miesegaes G, Beylin A, Zhao M, Rydel T, Gould E (2001): Neurogenesis in the adult is involved in the formation of trace memories. Nature 410, 372-6

Spellerberg B, Tuomanen E (1994): The pathophysiology of pneumococcal meningitis. Annals of Medicine 26, 411-8

Springer TA (1990): Adhesion receptors of the immun system. Nature $\underline{346}, 425-34$ 
Strang JR, Pugh EJ (1992): Meningococcal infections: reducing the case fatality rate by giving penicillin before admission to hospital. Br Med J $\underline{305}$, 141-3

Swartz MN (1984): Bacterial meningitis: more involved than just the meninges. N Engl J Med $\underline{311}, 912-4$

Takagi Y, Nozaki K, Takahashi J, Yodoi J, Ishikawa M, Hashimoto N (1999): Proliferation of neuronal precursor cells in the dentate gyrus is accelerated after transient forebrain ischemia in mice. Brain Res $\underline{831}, 283-7$

Tanapat P, Gould E (1997): EGF stimulates proliferation of granule cell precursors in the dentate gyrus of the adult rat. Soc Neurosci Abstr $\underline{23}, 317$

Tanapat P, Hastings NB, Reeves AJ, Gould E (1999): Estrogen stimulates a transient increase in the number of new neurons in the dentate gyrus of the adult female rat. J Neurosci $19,5792-801$

Tang T, Frenette PS, Hynes RO, Wagner DD, Mayadas TN (1996): Cytokine-induced meningitis is dramatically attenuated in mice deficient in endothelial selectins. J Clin Invest $\underline{97}$, 2485-90

Täuber MG, Moser B (1999): Cytokines and chemokines in meningeal inflammation: biology and clinical implications. Clin Infect Dis $\underline{28}, 1-11$

Täuber MG, Khayam-Bashi H, Sande MA (1985): Effects of ampicillin and corticosteroids on brain water content, CSF pressure and CSF lactate in experimental pneumococcal meningitis. J Infect Dis $\underline{151}, 528-34$

Täuber MG, Ferriero D, Kennedy SL, Sheldon RA, Guerra RL (1993): Brain levels of neuropeptide $\mathrm{Y}$ in experimental pneumococcal meningitis. Mol Chem Neuropathol $\underline{18}, 15-26$

Tauber SC, Stadelmann C, Spreer A, Brück W, Nau R, Gerber J (2005): Increased expression of BDNF and proliferation of dentate granule cells after bacterial meningitis. J Neuropathol Exp Neurol $\underline{64}, 806-15$

Tauber SC, Bunkowski S, Ebert S, Schulz D, Kellert B, Nau R, Gerber J (2009): Enriched environment fails to increase meningitis-induced neurogenesis and spatial memory in a mouse model of pneumococcal meningitis. J Neurosci Res $\underline{87}, 1877-83$ 
Tauber SC, Bunkowski S, Brück W, Nau R (2011): Septic metastatic encephalitis: Co-existence of brain damage and repair. Neuropathol Appl Neurobiol $\underline{37}, 768-76$

Taylor HG, Michaels RH, Mazur PM, Bauer R, Linden CB (1984): Intelectual, neuropsychological and achievement outcomes in children six to eight years after recovery from Haemophilus influenza meningitis. Pediatrics $\underline{74}, 198-205$

Tenney JH (1986): Bacterial infections of the central nervous system in neurosurgery. Neurol Clin $\underline{4}, 91-114$

Toledo EM, Colombres M, Inestrosa NC (2008): Wnt signalling in neuroprotection and stem zell differentiation. Prog Neurobiol $\underline{86}, 281-96$

Tsai YH, Williams EB, Hirth RS, Price KE (1975): Pneumococcal meningitis - therapeutic studies in mice. Chemotherapy $21,342-57$

Tumani H, Smirnov A, Barchfeld S, Olgemoller U, Meier K, Lange P, Bruck W, Nau R (2000): Inhibition of glutamin synthetase in rabbit pneumococcal meningitis is associated with neuronal apoptosis in the dentate gyrus. Glia $\underline{30}, 8-11$

Tunkel AR, Wispelwey B, Scheld WM (1990): Bacterial meningitis: recent advances in pathophysiology and treatment. Ann Intern Med 112, 610-23

Tunkel AR, Hartman BJ, Kaplan SL, Kaufman BA, Roos RL, Scheld WM, Whitley RJ (2004): Practice guidelines for the management of bacterial meningitis. Clin Infect Dis $\underline{39}, 1267-84$

Tuomanen E (1994): Modulation of inflammation in bacterial meningitis. Isr J Med Sci $\underline{30}, 339$ 41

Tuomanen E, Liu H, Hengstler B, Zak O, Tomasz A (1985): The induction of meningeal inflammation by components of the pneumococcal cell wall. J Infect Dis $\underline{151}, 859-68$

Tuomanen E, Saukkonen K, Sande S, Cioffe C, Wright SD (1989): Reduction of inflammation, tissue damage and mortality in bacterial meningitis in rabbits treated with monoclonal antibodies against adhesion-promoting receptors of leukocytes. J Exp Med 170, 959-69 
Tuomanen E, Austrian R, Masure H (1995): Pathogenesis of pneumococcal infection. N Engl J Med $\underline{332}, 1280-4$

Tureen J, Dworkin R, Kennedy S, Täuber M, Sande M (1990): Loss of cerebrovascular autoregulation in experimental meningitis in rabbits. J Clin Invest $\underline{85}, 577-81$

Twamley E, Hami S, Stein M (2004): Neuropsychological function in college students with and without posttraumatic stress disorder. Psychiatry Res $\underline{126}, 265-74$

Tzanakaki G, Blackwell CC, Kremastinou J, Kallergi C, Kouppari G, Weir DM (1992): Antibiotic sensitivities of Neisseria meningitidis isolatetd from patients and carriers in Greece. Epidemiol Infect $\underline{108}, 449-55$

Tzeng SF, Wu JP (1999): Responses of microglia and neuronal progenitors to mechanical brain injury. Neuroreport $\underline{10}, 2287-92$

Van de Beek D, Schmand B, de Gans J, Weisfelt M, Vaessen H, Dankert J, Vermeulen M (2002): Cognitive impairment of adults with good recovery after bacterial meningitis. J Infect Dis $\underline{186}$, $1047-52$

Van de Beek D, Farrar JJ, de Gans J, Mai NT, Molyneux EM, Peltola H, Peto TE, Roine I, Scarborough M, Schultsz C (2010): Adjunctive dexamethasone in bacterial meningitis: a metaanalysis of individual patient data. Lancet Neurol $\underline{9}, 229-31$

Van Praag H, Kempermann G, Gage FH (1999a): Running increases cell proliferation and neurogenesis in the adult mouse dentae gyrus. Nat Neurosci $\underline{2}$, 266-70

Van Praag H, Christie BR, Sejnowski TJ, Gage FH (1999b): enhances neurogenesis, learning and long-term potentiation in mice. Proc Natl Acad Sci U S A $\underline{96}$, 13427-31

Van Praag H, Schinder AF, Christie BR, Toni N, Palmer TD, Gage FH (2002): Functional neurogenesis in the adult hippocampus. Nature $\underline{415}, 1030-4$

Vaux DL, Haecker G, Strasser A (1994): Viral, worm and radical implications for apoptosis. Cell $\underline{76}, 777-9$ 
Viale P, Pagani L, Cristini F, Stefini R, Bergomi R, Colombini P, Carosi G (2002): Linezolid for the treatment of central nervous system infections in neurosurgical patients. Scand J Infect Dis $\underline{34}$, $456-9$

Wagner JP, Black IB, DiCicco-Bloom E (1999): Stimulation of neonatal and adult rat brain neurogenesis by subcutaneous injection of basic fibroblast growth factor. J Neurosci $\underline{19}$, 6006-16

Waters CM (1996): Mechanisms of neuronal cell death - an overview. Mol Chem Neuropathol $\underline{28}, 145-51$

Weisfelt M, de Gans J, van der Poll T, van de Beek D (2006): Pneumococcal meningitis in adults: new approaches to management and prevention. Lancet Neurol $\underline{5}, 332-42$

Wellmer A, Noeske C, Gerber J, Munzel U, Nau R (2000): Spatial memory and learning deficits after experimental pneumococcal meningitis in mice. Neurosci Lett $\underline{296}, 137-40$

Welsch U: Histologie: Farbatlas der Zytologie, Histologie und Mikroskopischen Anatomie des Menschen/Sobotta, 5. Auflage; Urban und Schwarzenberg Verlag, München 1997, S. 234

Wenger JD, Hightower AW, Facklam RR, Gaventa S, Broome CV (1990): Bacterial meningitis in the United States, 1986: report of a multistate surveillance study. The Bacterial Meningitis Study Group. J Infect Dis 162, 1316-23

Williams GT, Smith CA, Spooncer E, Dexter TM, Taylor DR (1990): Haemopoietic colony stimulating factors promote cell survival by suppressing apoptosis. Nature $\underline{343}, 76-9$

Woodbury D, Schwarz EJ, Prockop DJ, Black IB (2000): Adult rat and human bone marrow stromal cells differentiate into neurons. J Neurosci Res $\underline{61}, 364-370$

Wyllie AH (1995): The genetic regulation of apoptosis. Curr Opin Genet Dev $\underline{5}, 97-104$

Wyllie AH, Morris RG (1982): Hormone-induced cell death. Purification ad properties of thymocytes undergoing apoptosis after glucocorticoid treatment. Am J Pathol 109, 78-87

Zhang JR, Tuomanen E (1999): Molecular and cellular mechanisms for microbial entry into the CNS. J Neurovirol $\underline{5}, 591-603$ 
Zupanc G (2001): A comparative approach towards the understanding of adult neurogenesis. Brain Behav Evol $\underline{58}, 246-9$

Zysk G, Brück W, Gerber J, Brück Y, Prange HW, Nau R (1996): Anti-inflammatory treatment influences neuronal apoptotic cell death in the dentate gyrus in experimental pneumococcal meningitis. J Neuropathol Exp Neurol 55, 722-8

Zysk G, Schneider-Wald BK, Hwang JH, Bejo L, Kim KS, Mitchell TJ, Hakenbeck R, Heinz HP (2001): Pneumolysin is the main inducer of cytotoxicity to brain microvascular endothelial cells caused by Streptococcus pneumoniae. Infect Immun $\underline{69}, 845-52$ 


\section{Danksagung}

Mein besonderer Dank gilt meinem Betreuer Prof. Dr. med. Joachim Gerber für die hervorragende Unterstützung meiner Arbeit.

Herrn Prof. Dr. med. Roland Nau danke ich herzlichst für die Überlassung des Themas, die Möglichkeit zum selbständigen Arbeiten und die stetige Hilfsbereitschaft.

Herrn Prof. Dr. med. Martin George Täuber von der Universität Bern, Schweiz, danke ich für die freundliche Bereitstellung des Pneumokokkenstammes.

Frau S. Bunkowski danke ich für die Einführung in die Laborarbeit und die Immunhistochemie sowie für ihre ständige Hilfsbereitschaft und Unterstützung im Labor.

Meiner Familie danke ich für die Ausdauer und Geduld, die aufmunternden Worte, die hilfreiche Kritik und Korrekturen. 